Illinois State University

ISU ReD: Research and eData

Theses and Dissertations

$3-1-2021$

\title{
Emotionally Intelligent Leadership: An Application To Student Affairs
}

Alexander David Snowden

Illinois State University, alex.snowden@gmail.com

Follow this and additional works at: https://ir.library.illinoisstate.edu/etd

Part of the Higher Education Administration Commons

\section{Recommended Citation}

Snowden, Alexander David, "Emotionally Intelligent Leadership: An Application To Student Affairs" (2021). Theses and Dissertations. 1413.

https://ir.library.illinoisstate.edu/etd/1413

This Dissertation is brought to you for free and open access by ISU ReD: Research and eData. It has been accepted for inclusion in Theses and Dissertations by an authorized administrator of ISU ReD: Research and eData. For more information, please contact ISUReD@ilstu.edu. 
EMOTIONALLY INTELLIGENT LEADERSHIP: AN APPLICATION TO STUDENT

AFFAIRS

\section{ALEXANDER DAVID SNOWDEN}

161 pages

The purpose of this study is to show the prevalence of emotionally intelligent leadership (EIL) that exists among student affairs professionals. The study evaluates the scores among student affairs professionals on the Emotionally Intelligent Leadership for Employees: Inventory (EILE-I) by utilizing information such as educational background, level of experience, gender, and racial identity.

The survey instrument, the Emotionally Intelligent Leadership for Employees Inventory, was designed and administered to 1068 student affairs professionals. Statistical tests from the responses included descriptive statistics, exploratory factor analysis, reliability analysis, and analysis of variance. Results showed that student affairs professionals scored an average of “Somewhat High” or higher in emotionally intelligent leadership among all three consciousnesses, which include self, other, and context. Furthermore, statistical significance was found in the areas of years of service and racial identity. Additionally, an interaction effect was found between Latinx men and Latinx women. A number of recommendations for future studies and applications are also shared.

KEYWORDS: Emotionally Intelligent Leadership, Emotional Intelligence, Leadership, Student Affairs, Higher Education 
AFFAIRS

ALEXANDER DAVID SNOWDEN

A Dissertation Submitted in Partial

Fulfillment of the Requirements

for the Degree of

DOCTOR OF PHILOSOPHY

Department of Educational Administration and Foundations

ILLINOIS STATE UNIVERSITY

2021 
Copyright 2021 Alexander David Snowden 
EMOTIONALLY INTELLIGENT LEADERSHIP: AN APPLICATION TO STUDENT

AFFAIRS

ALEXANDER DAVID SNOWDEN

COMMITTEE MEMBERS:

Phyllis McCluskey-Titus, Chair

John Rugutt

Guy Banicki

Grahaeme Hesp 


\section{ACKNOWLEDGMENTS}

I wish to begin by dedicating this dissertation to my grandfather, Mason Snowden, who was a consistent source of support and motivation throughout my doctoral journey. I also wish to express my gratitude and love to my wife and partner, Nancy, who spent countless nights helping me ideate my topic and making me think strategically about my approach. To my son, Mason, whose arrival gave me the motivation needed to finish this comprehensive journey, and also a special thank you to my family_my parents, George and Marcia, and my sisters, Amanda and Allison, who provided unwavering love and support throughout this process.

I also want to share my sincere appreciation to Larry Long, a statistical wizard that without hesitation, helped me run data sets, check for errors, and ensured the accuracy of my research data. Additionally, to my fraternity brother and colleague, Dr. Scott Allen, one of the original theorists of emotionally intelligent leadership: Thank you for your conversations, thoughts, and permissions throughout this process. To my colleagues at Illinois State University and throughout the world: When I needed you, you were all there for me from talking through items to participating in my study. The end is here thanks to you.

I have to also share my sincere gratitude and appreciation for my chair, Dr. Phyllis McCluskey-Titus. Your support for me throughout my education and career has not gone unnoticed. You were there every step of the way to celebrate my wins and encourage me through the struggles. I also wish to thank my committee, Dr. John Rugutt, Dr. Guy Banicki, and Dr. Grahaeme Hesp. Your wisdom and time are priceless.

A.D.S. 


\section{CONTENTS}

ACKNOWLEDGMENTS

CONTENTS

TABLES

FIGURES

viii

CHAPTER I: INTRODUCTION 1

$\begin{array}{lr}\text { Background } & 1\end{array}$

$\begin{array}{ll}\text { Statement of Problem } & 7\end{array}$

$\begin{array}{lr}\text { Theoretical Framework } & 8\end{array}$

$\begin{array}{lc}\text { Emotionally Intelligent Leadership } & 8\end{array}$

Emotionally Intelligent Leadership for Employee Inventory 9

$\begin{array}{ll}\text { Purpose of Study } & 10\end{array}$

$\begin{array}{ll}\text { Research Questions } & 10\end{array}$

Method of the Study 12

$\begin{array}{ll}\text { Definition of Terms } & 12\end{array}$

$\begin{array}{ll}\text { Significance of Study } & 13\end{array}$

$\begin{array}{ll}\text { Limitations } & 15\end{array}$

$\begin{array}{lr}\text { Assumptions } & 16\end{array}$

$\begin{array}{ll}\text { Overview of the Chapters } & 17\end{array}$

CHAPTER II: REVIEW OF THE LITERATURE 19

$\begin{array}{lr}\text { Introduction } & 19\end{array}$

$\begin{array}{ll}\text { Emotional Intelligence } & 20\end{array}$

$\begin{array}{lr}\text { Leadership } & 27\end{array}$ 
Emotionally Intelligent Leadership $\quad 30$

$\begin{array}{ll}\text { Consciousness of Self } & 31\end{array}$

Emotional Self-Perception 33

$\begin{array}{ll}\text { Emotional Self-Control } & 34\end{array}$

$\begin{array}{ll}\text { Authenticity } & 34\end{array}$

$\begin{array}{ll}\text { Healthy Self-Esteem } & 35\end{array}$

$\begin{array}{ll}\text { Flexibility } & 35\end{array}$

$\begin{array}{ll}\text { Optimism } & 36\end{array}$

$\begin{array}{ll}\text { Initiative } & 36\end{array}$

$\begin{array}{ll}\text { Achievement } & 37\end{array}$

$\begin{array}{ll}\text { Consciousness of Others } & 37\end{array}$

$\begin{array}{ll}\text { Displaying Empathy } & 39\end{array}$

$\begin{array}{ll}\text { Inspiring Others } & 40\end{array}$

$\begin{array}{ll}\text { Coaching Others } & 40\end{array}$

$\begin{array}{ll}\text { Capitalizing on Difference } & 41\end{array}$

$\begin{array}{ll}\text { Developing Relationships } & 42\end{array}$

$\begin{array}{ll}\text { Building Teams } & 42\end{array}$

Demonstrating Citizenship 43

$\begin{array}{ll}\text { Managing Conflict } & 43\end{array}$

$\begin{array}{ll}\text { Facilitating Change } & 44\end{array}$

$\begin{array}{ll}\text { Consciousness of Context } & 45\end{array}$

Analyzing the Group $\quad 46$

$\begin{array}{ll}\text { Assessing the Environment } & 47\end{array}$ 
Student Affairs

Chapter Summary

CHAPTER III: METHODOLOGY 55

$\begin{array}{ll}\text { Introduction } & 55\end{array}$

Research Questions $\quad 56$

Research Design $\quad 56$

$\begin{array}{ll}\text { Study Participants } & 58\end{array}$

$\begin{array}{ll}\text { Instrumentation and Measures } & 58\end{array}$

Validity and Reliability 63

$\begin{array}{ll}\text { Distribution Procedures } & 64\end{array}$

Data Collection Timeline $\quad 65$

Data Analysis Procedures $\quad 65$

$\begin{array}{ll}\text { Descriptive Statistics } & 65\end{array}$

Exploratory Factor Analysis $\quad 66$

$\begin{array}{ll}\text { Reliability Analysis } & 67\end{array}$

Analysis of Variance $\quad 67$

$\begin{array}{ll}\text { Chapter Summary } & 67\end{array}$

CHAPTER IV: SUMMARY OF RESULTS 68

$\begin{array}{ll}\text { Introduction } & 68\end{array}$

Summary of Participant Survey Sample $\quad 69$

$\begin{array}{ll}\text { Solicitation of Participants } & 69\end{array}$

$\begin{array}{ll}\text { Participant Sample } & 71\end{array}$

Summary of Descriptive Statistics for EILE-I Instrument Items 72 
Summary of Results of Factor Analysis

Summary of Reliability Analysis $\quad 85$

Results of the Analysis for Research Questions $\quad 88$

$\begin{array}{ll}\text { Research Question } 1 & 89\end{array}$

Research Question $2 \quad 92$

$\begin{array}{ll}\text { Research Question } 3 & 94\end{array}$

$\begin{array}{ll}\text { Research Question } 4 & 99\end{array}$

$\begin{array}{ll}\text { Chapter Summary } & 104\end{array}$

$\begin{array}{ll}\text { CHAPTER V: DISCUSSION } & 105\end{array}$

$\begin{array}{ll}\text { Introduction } & 106\end{array}$

$\begin{array}{ll}\text { Summary of Findings } & 107\end{array}$

Discussion of Findings in Relationship to Research Questions 108

$\begin{array}{ll}\text { Research Question } 1 & 109\end{array}$

Research Question $2 \quad 112$

$\begin{array}{ll}\text { Research Question } 3 & 114\end{array}$

$\begin{array}{ll}\text { Research Question } 4 & 116\end{array}$

$\begin{array}{ll}\text { Future Recommendations and Implications for Practice } & 120\end{array}$

$\begin{array}{ll}\text { Development of Student Affairs Core Competencies } & 120\end{array}$

$\begin{array}{ll}\text { Professional Development in Cultural Education } & 123\end{array}$

$\begin{array}{ll}\text { Mentorship } & 127\end{array}$

$\begin{array}{ll}\text { Development of the Instrument } & 129\end{array}$

$\begin{array}{ll}\text { Chapter Summary } & 131\end{array}$

$\begin{array}{ll}\text { REFERENCES } & 134\end{array}$ 
APPENDIX A: EMOTIONALLY INTELLIGENT LEADERSHIP FOR EMPLOYEES:

INVENTORY

APPENDIX B: EMOTIONALLY INTELLIGENT LEADERSHIP FOR EMPLOYEES:

INVENTORY NEW CAPACITY SCORING

151

APPENDIX C: COVER LETTER FOR EMAIL

154

APPENDIX D: COVER LETTER FOR SOCIAL MEDIA POST

158

APPENDIX E: INFORMED CONSENT

159

APPENDIX F: EMOTIONALLY INTELLIGENT LEADERSHIP SCORING FOR

EILS:I 2.0

161 


\section{TABLES}

Table

Page

1. Capacities by Consciousness $\quad 59$

2. Consciousness Score Chart 61

3. Summary of Descriptive Statistics for EILE-I Instrument Items 73

4. Rotated Factor Matrix for Capacities $\quad 81$

5. Summary of Cronbach’s Alpha Reliability Coefficient $(\mathrm{N}=863)$

6. Descriptive Statistics for Total Consciousness Score 90

7. Consciousness Score Chart 90

8. Significance with Consciousness of Self and Years in the Profession 96

9. Significance with Consciousness of Others and Years in the Profession 98

10. 2x4 Factorial ANOVA of Gender and Race 102

11. Factorial Analysis of Variance of Differences in Gender and Race 103 


\section{FIGURES}

Figure

Page

1. Graph of Estimated Marginal Means of Consciousness of Context

104 


\section{CHAPTER I: INTRODUCTION \\ Background}

Since the inception of emotional intelligence in 1987 by Keith Beasley, a number of studies on the topic have been conducted (Ciarrochi et al., 2007; Conte, 2005; Goleman, 1995; Shankman, Allen, \& Haber-Curran, 2015). These studies have focused on a variety of areas, such as emotional intelligence as all-encompassing (Ciarrochiet al., 2007), emotional intelligence as a framework (Goleman, 2001), and emotional intelligence in organizational behavior (Conte, 2007). Fewer studies have focused on areas of student affairs and emotionally intelligent leadership (EIL). EIL is an area that is recently coming to light, and is theorized by the researcher to be utilized among student affairs professionals. The problem that exists is that this subsection of emotional intelligence research has only been conducted with students so far, and not with student affairs professionals. This leads the researcher to believe that the understanding of EIL in relation to student affairs professionals has the potential to make stronger professionals. More research is needed in EIL to understand its prevalence among student affairs professionals. It is also important to research the use of EIL within student affairs professionals from different professional preparation programs and levels of experience to evaluate if the scores universally remain the same or if scores differ based on various backgrounds. This in turn will show EIL's prevalence within student affairs professionals, where training and development about EIL could be occurring, and the career level of a student affairs professional where EIL is most prevalent.

What is emotional intelligence, or EQ? The genesis of the EQ concept, originally known as emotional quotient, is defined as "the vital parameter against which to judge a person" (Beasley, 1987, p. 25). This short article and foundational definition did not gain much traction 
into the development of EQ today as it is referenced very little in other EQ literature. Through evaluation of the research, the earliest foundation of EQ was attributed to Mayer and Salovey (1990), who rebranded the concept of emotional quotient as emotional intelligence (EQ) because their research showed that EQ was more than just a parameter of judgment-it was also a way to interpret received information. Mayer and Salovey (1990) redefined the term emotional intelligence as "the subset of social intelligence that involves the ability to monitor one’s own and others' feelings and emotions, to discriminate among them and to use the information to guide one's thinking and actions” (p. 5). It would be this definition that would set the foundation for internalization of one's emotions and feelings toward self and others in understanding their interactions. This definition, at the time, was a conceptual thought that would lead researchers to develop a number of instruments for further study, such as the Bar-On Emotional Quotient Inventory (EQ-I), Multifactor Emotional Intelligence Scale (MEIS), and the Mayer-Salovey-Caruso Emotional Intelligence Test (MSCEIT) (Bar-On, 1997; Mayeret al., 1997; Mayer et al., 2002). This shift in the measurement of emotional intelligence from theory to application would lead to the development of research into key concepts, definitions, and instruments that would be applied in various forms (Goleman, 1995; Caruso et al., 2016; Ciarrochi \& Mayer, 2007).

The most prominent and potentially controversial development in the research of EQ emerged from Daniel Goleman. Goleman (1995) added a new dimension to Mayer and Salovey’s definition by explaining emotional intelligence as "having abilities such as being able to motivate oneself and persist in the face of frustrations; to control impulse and delay gratification; to regulate one's moods and keep distress from swamping the ability to think; to empathize and to hope" (p. 34). This adaptation added a layer of how the information is "given 
and received" to the Mayer and Salovey (1990) definition. Goleman pointed out in his definition that it is not just what emotion is being expressed, but also in how emotion is interpreted by others.

Goleman's book, Emotional Intelligence, would be considered foundational, as evident by the high number of citations. Goleman made assertions about how emotional intelligence could be applied to business and industry, which led a number of individuals to speak out against him because his claims were not rooted in research. Waterhouse (2006), a critic of Goleman, stated that Goleman lacked credibility because until 1995, "the datasets are privately owned... [by] business consulting firms” (p. 218). If datasets were privately owned, then how could Goleman's research be credible? Wong (2015) supported Waterhouse when she shared that the controversy around Goleman was that "up to 1995, no management studies had been reported that provided direct evidence about the relationship between people's emotional intelligence and their job performance and career success” (p. 12). This controversy would yield a shift from Goleman being declared the main expert on emotional intelligence and a number of other researchers emerging with various theories and research on emotional intelligence.

One such definition of emotional intelligence that emerged was from Caruso et al. (2016), who defined the concept as "abilities to accurately perceive emotions, to understand their causes and trajectories, to utilize them to help you think, and to effectively manage them" (Foreword). Ciarrochi and Mayer (2007), who viewed EQ competencies as constructs, outlined emotional intelligence as “defined personality traits, abilities, and motives” (p. 30). As more and more definitions came into existence, Goleman (2005) also redefined EQ as “abilities to recognize and regulate emotions in ourselves and in others” (p. 14). 
These three definitions had a number of similarities and minor differences, which would show how EQ was beginning to form as a field of study. All three definitions showed EQ as being rooted in emotions, as well as how those emotions are interpreted and responded to (Caruso et al., 2016; Ciarrochi \& Mayer, 2007; Goleman, 2005). What makes the definitions unique is that the aforementioned researchers were still trying to understand how these interpretations and responses were valid for the research. These same researchers also showed that there is still a need to explore the understanding of why EQ is important in today's society. This conclusion is drawn because all the definitions lack application, which will be vital as the concept continues to be refined and developed.

As the number of definitions of EQ increased, so did the number of instruments available to measure it. It is important to note that these theoretical discussions explain what EQ is, but they did not fully demonstrate how EQ could be studied or applied. Conte (2005) showed that the development of multiple definitions and instruments will prove to be crucial as researcher's journey to discover new results and instruments related to this topic. Conte, in hopes of providing validity on the topic, completed an in-depth study into a number of instruments in existence around EQ. Conte explained that emotional intelligence lacked substance due to the "vague theoretical development for many of the measures and because the content across EQ measures varies widely” (Conte, 2005, p. 437). Conte found that although scoring concerns were present since each measure was based on a different definition, validity existed and emotional intelligence was a concept that could be measured and studied in individuals. This study of the instruments, as well as Conte's findings, showed that common adoption of definitions or approaches was needed as the study into EQ continued. 
Reliability of the concept of EQ would be shown by another set of researchers. Mathews et al. (2002), found the reliability in EQ that is necessary to promote and continue the research into the concept through evaluation of research on the topic. Mathews et al. (2002) claimed that "few fields of psychological investigation appear to have touched so many disparate areas of human endeavor, since its inception, as emotional intelligence” (p. 4). They drew this claim by studying psychology and "attributing [EQ] to its somewhat optimistic view of human condition [and] the potential of emotional intelligence to improve our ability to understand and assist people” (Hanson, 2002, p. 458). One argument to support this statement in the professional world is that it is believed that "emotional intelligence can be trained and improved in various social contexts” (Mathews et al., 2002, p. 5). This conclusion is drawn from researchers' evaluations of EQ application into clinical psychology with therapeutic techniques, and occupational psychology that offers stress management techniques.

Although these techniques are utilized within EQ research, Mathews et al. (2002) argued that all EQ research has to be rooted in "three pillars: reliable and valid measurement, processbased theory, and practical application” for validity to exist (p. 28). The argument the researchers made based on these pillars is that a "systematic differentiation of these constructs may replace conceptual cacophony with a more harmonious structuring of ideas in the field” (Mathews et al., 2002, p. 233). Cherniss et al. (2006) summed up this validity by stating that the "early stages of theory development, having several versions of emotional intelligence theory is a sign of vitality in the field, not a weakness” (p. 239). This vitality and desire to understand EQ draws new approaches to EQ through a topical lens.

Topic-based research within emotional intelligence is based on either a certain field of study or a specified area. One such topic area is leadership, which has a number of definitions 
and interpretations. Pendelton and Furnham (2012) defined leadership as "creating conditions for people to thrive as individuals, collectives, and the achievement of certain goals” (p. 2). Rost (1993) viewed leadership as “an influential relationship among leaders and followers who intend real changes that reflect their mutual purposes” (p. 102). Another interpretation of a leader is simply an individual who can convince at least one other individual to follow them. No matter how leadership is defined, it is a topic area where emotional intelligence can thrive because a key component of EQ is understanding the emotions of others, as well as how to respond. The base of this research, rooted in emotionally intelligent leadership, leads to the work of Shankman, Allen, and Haber-Curran (2015). These researchers define emotionally intelligent leadership as "promoting an intentional focus on three facets: consciousness of self, consciousness of others, and consciousness of context” (Shankman, Allen, \& Haber-Curran, 2015, p. 9). After Shankman, Allen, \& Haber-Curran (2015) shared results from their study on EIL among college students, I believe their findings showed the potential for application among student affairs professionals, which is tested in this dissertation.

One such area of application of emotionally intelligent leadership study is student affairs professionals, who to date have not been widely studied through an emotional intelligence lens. Student affairs work, according to the American College Personnel Association, consists of "any advising, counseling, management, or administrative function at a college or university that exists outside the classroom” (Love, 2003, para. 5). If utilizing the Emotionally Intelligent Leadership for Students: Inventory (EILS-I 2.0) can show leadership in students, then it can also potentially be utilized for the study of those individuals who contribute to the direct development of students in the field of student affairs. 


\section{Statement of Problem}

There has been little research conducted about student affairs professionals and emotional intelligence. Furthermore, there has been even less research on emotionally intelligent leadership (EIL) principles used among student affairs professionals. This was shown through extensive evaluation of research in the field, which highlighted the finding that no studies existed at the time of this dissertation on the topic of EIL and student affairs. Therefore, the problem that exists is that the prevalence of EIL use has not been studied among student affairs professionals. This leads the researcher to believe that understanding the prevalence of EIL among student affairs professionals can provide the opportunity to develop stronger, more emotionally intelligent professionals. Understanding a person’s own EIL will bring selfawareness into the practice of student affairs, which can lead to a number of positive outcomes. These outcomes could include a stronger application of EIL within student affairs work, potential development of a standardized competency in EIL, and overall better development of the profession.

By focusing on EIL instead of solely on leadership or emotional intelligence, the data will give a new and refreshing evaluation within this field. However, due to the inability to find any research on EIL and student affairs professionals, more research is necessary in EIL to understand what EIL practices currently exist among student affairs professionals. It is also important to research the use of EIL within student affairs professionals from different graduate programs, experience levels, and other background parameters to better understand if the use of emotionally intelligent leadership is significantly different based on these factors, and to what degree. This in turn will show its prevalence within student affairs practitioners and set the groundwork for future research on EIL within the profession. 


\section{Theoretical Framework}

The theoretical framework for this dissertation is emotionally intelligent leadership (EIL) and the three consciousnesses within the theory. The theoretical framework for EIL and the instrument that is utilized in measuring student affairs professionals' EIL scores is briefly introduced here and explained in greater depth in a subsequent chapter.

\section{Emotionally Intelligent Leadership}

Emotionally intelligent leadership is the foundational theory for this study. The term “emotionally intelligent leadership,” or EIL, was defined by Shankman Allen, and HaberCurran in 2015 as a way to "promote an intentional focus on three facets: consciousness of self, consciousness of others, and consciousness of context” (p. 1). To further understand EIL, it is important to also define the three consciousnesses. Consciousness of self is defined as "awareness of your abilities, emotions, and perceptions. Consciousness of self is about prioritizing the inner work of reflection, introspection and appreciation of one's self-awareness" (Shankman Allen, \& Haber-Curran, 2015, p. 10). The second consciousness, consciousness of others, focuses on others' interpretations; within this consciousness, if an individual is attentive to “people’s abilities, emotions, and perceptions, [they] can better inspire, connect with, work with, and influence others” (Shankman et al., 2015, p. 111). Finally, consciousness of context is explained in this way: "Demonstrating [EQ] involves awareness of the setting and situation... [which] is about paying attention to how environmental factors and internal group dynamics affect the process of emotional intelligence” (Shankman et al., 2015, p. 10). It is important to note that within these three consciousnesses, based on the current research, 19 distinct capacities exist. These 19 capacities define a person's emotionally intelligent leadership. Shankman, Allen, and Miguel (2015) showed in their work that all individuals have some 
degree of emotionally intelligent leadership. This prevalence of EIL is based on one's experiences and ability to interpret the three consciousnesses utilizing the 19 capacities. If all individuals have some level of emotionally intelligent leadership, and it can be developed, then it is therefore important for student affairs professionals to have an understanding of their own EIL and how it can be applied to their work.

\section{Emotionally Intelligent Leadership for Employee Inventory}

The Emotionally Intelligent Leadership for Students: Inventory (EILS-I 2.0) was developed by Shankman, Allen, and Miguel (2015) as a way for researchers to study individuals' EIL. This instrument to date has only been utilized with students with a degree of success. This study adapts and tests the EILS-I 2.0 instrument and applies it to understand the prevalence of emotionally intelligent leadership within student affairs professionals. This adapted instrument will be noted as Emotionally Intelligent Leadership for Employees: Inventory (EILE-I).

If the instrument is successful in measuring and providing evidence of the prevalence of EIL scores among student affairs professionals, then the sample of student affairs professionals who participate can be further evaluated based on their scores around the three consciousnesses and the 19 capacities that make up emotionally intelligent leadership. This evaluation, which is done within this dissertation, includes statistical tests utilizing background information to study

EIL among student affairs professionals. The tests and results can be found in Chapter 4. These outcomes explain what student affairs professionals scored on the EILE-I and interpret how those scores differ based on their educational background, years of service, gender, and racial identity. These results answer the research questions about EIL, which include the understanding of EIL's prevalence within student affairs professionals, difference in scores 
when applied to different background information, and potential application for future studies. These results and findings are presented in Chapters 3 and 4 of this dissertation. This theoretical framework forms the basis of the study.

\section{Purpose of Study}

The purpose of this study is to show the prevalence of emotionally intelligent leadership (EIL) that exists among student affairs professionals. Furthermore, the study evaluates the scores among student affairs professionals on the EILE-I by utilizing information such as educational background, level of experience, gender, and racial identity. These various elements of the study serve as an exploration of EIL among student affairs professionals that is believed to: lead to future application among student affairs programs, represent a way to assess job performance, enhance professional development, and possibly add a competency within the profession. The recommendations that have come from the study are found in Chapter 5.

The study of EIL among student affairs professionals utilizes the EILE-I instrument, which is adapted from the EILS-I 2.0, introduced by Shankman, Allen and Miguel (2015). This instrument determines how student affairs professionals score themselves in relation to EIL. This study then applies the EIL scores to various identifiers, such as level of experience, educational background, racial identity, and gender. Upon completion of the data analysis found in Chapter 4, the study discusses the importance and implications of developing the emotionally intelligent leadership of student affairs professionals.

\section{Research Questions}

Because this is an exploratory study, it focuses on understanding the prevalence of emotionally intelligent leadership among student affairs professionals in order to evaluate how it is evident, and how it can lead to future studies and practices that will make stronger 
professionals in the field of student affairs. The conceptual design applies the EILE-I instrument to measure student affairs professionals' responses to a series of questions. The research question format is used in lieu of hypothesis statements because the design efforts within the study are at the exploratory stage, and because a pilot was not conducted with student affairs professionals prior to its distribution (Claudet, 1999). Therefore, the use of research questions to guide the study allows for a certain amount of data analysis flexibility, as relationships among the data variables are examined to answer the research questions. A pilot study also was not conducted due to previous research showing validity and reliability of the original EILS-I 2.0, and the EILE-I adaptation is believed not to affect a significant change (Miguel \& Allen, 2016). Further, student affairs professionals who took the EILE-I would produce scores that became the primary form of analyses for this study. Based on the review of the literature and the adaptation of the EILS-I 2.0 to be applied to student affairs professionals, the following research questions were generated:

1. How do student affairs professionals score on the EILE-I inventory in terms of emotionally intelligent leadership?

2. Do emotionally intelligent leadership scores differ by student affairs professionals based on their student affairs graduate program?

3. Do the scores of emotionally intelligent leadership differ based on the number of years a student affairs professional has been in the field?

4. Is there a relationship between emotionally intelligent leadership and background characteristics, such as self-identified gender and race among student affairs professionals? 


\section{Method of Study}

The researcher conducted a quantitative study, utilizing an instrument that was revised. Survey questions were developed and adapted based upon the Emotionally Intelligent Leadership for Students: Inventory (Shankman, Allen, \& Miguel, 2015). The study instrument is based on the original inventory, which was developed using a sample of 443 college students. This original sample found prevalence of EIL scores among students and therefore it is believed that, with adaptation, it will also find prevalence of the use of EIL among student affairs professionals (Miguel \& Allen, 2016). The new instrument, the Emotionally Intelligent Leadership for Employees: Inventory, was administered to a sample of 1,068 student affairs professionals using various strategies that are explained in the methodology chapter of this dissertation. All individuals who took the survey did so voluntarily and have declared themselves to be student affairs professionals within the United States, and were 18 years of age or older. Participants were sent the survey via email or through other communication methods that outlined the purpose of the study, their role in the research, the confidentiality of responses, and directions for completing the online instrument.

The data analysis is conducted utilizing descriptive statistics, exploratory factor analysis, reliability analysis, analysis of variance, and factorial ANOVA. This method of analysis is explained further in Chapter 3.

\section{Definition of Terms}

The following terms are used throughout this dissertation:

Student affairs professionals: A professional staff member who works at a college or university in student services, such as, but not limited to, advising, enrollment, student life, and career 
services. The instrument is limited to those who are self-identified student affairs professionals within the United States and are 18 years of age or older.

Emotionally Intelligent Leadership for Employees: Inventory (EILE-I): The Emotionally Intelligent Leadership for Employees: Inventory (EILE-I) is the new instrument adapted from the Emotionally Intelligent Leadership for Students: Inventory (EILS-I 2.0) and utilized to measure this construct within the field of student affairs (Shankman, Allen, \& Migue, 2015, p. 7).

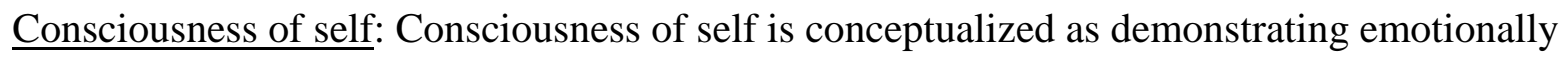
intelligent leadership and involves awareness of one’s abilities, emotions, and perceptions. Consciousness of self is about prioritizing the inner work of reflection and introspection, and appreciating that self-awareness is a continual and ongoing process (Shankman, Allen, \& Miguel, 2015, p. 10).

Consciousness of others: Consciousness of others is conceptualized as demonstrating emotionally intelligent leadership, and involves awareness of the abilities, emotions, and perceptions of others. Consciousness of others is about initially working with and influencing individuals and groups to bring about positive change (Shankman, Allen, \& Miguel, 2015, p. 7). Consciousness of context: Consciousness of context is conceptualized as demonstrating emotionally intelligent leadership that involves awareness of the setting and situation. Consciousness of context is about paying attention to how environmental factors and internal group dynamics affect the process of leadership (Shankman, Allen, \& Miguel, 2015, p. 7).

\section{Significance of the Study}

This study provides emotionally intelligent leadership (EIL) scores among student affairs professionals. Further, this study looks at various background variables for 
understanding score differentials, consistency, and other possible factors that would account for the differences in student affairs professionals' EIL scores. Initial research into EIL and student affairs professionals found no studies that have been done that have connected this leadership style to this specific group of people. Therefore, this study provides insight and future application on the importance of use and understanding of EIL among student affairs professionals. The analysis of the data collected from the instrument will determine how student affairs professionals score within EIL. The study will also show the differences in scores of student affairs professionals in relation to their years of service in the field, as well as educational background, gender, racial identity, and a relationship within a number of other variables based on the findings.

This in turn will have a number of practical applications, more so than just demonstrating that EIL exists among student affairs professionals. These applications, which are shared in Chapter 5, are around the topics of core competency, mentorships, and cultural awareness. The data explain how student affairs professionals utilize EIL based on their years of experience and to what degree. This shows how EIL, when applied to a number of background factors, can enhance the profession. It is first imperative to explain why this research is important.

A number of studies exist that examine emotional intelligence from the perspective of the work student affairs professionals do with students (Jaeger \& Eagan, 2007; Parker \& Stone, 2020; Wu \& Stemmler, 2008). Further research also found a number of studies on leadership within student affairs (Kuk \& Banning, 2016; Porterfield \& Whitt, 2016; Ruthkosky, 2013). However, no research was found at the time of this dissertation that has been done on EIL among student affairs professionals. 
By focusing on EIL instead of solely on leadership or emotional intelligence, the data give a new and refreshing evaluation of student affairs professionals and how EIL is utilized in their work. This opens up a number of possible new areas for study, evaluation, and application that can in turn create stronger employees, a better work environment, and ongoing development that will have a direct impact on the field.

It is also important to discuss that adapting an instrument that previously has only been completed and administered successfully to college students shows that the proper instrument for evaluation of EIL already exists, and can be applied to student affairs professionals. This instrument can also be applied to a multitude of background variables to study various aspects of student affairs professionals' understanding and use of emotionally intelligent leadership, thus giving stronger insight into the field and this theory.

In summary, studying emotionally intelligent leadership within student affairs professionals utilizing the EILE-I instrument accomplishes a number of objectives: (1) showing current levels of EIL among student affairs professionals, (2) providing a better understanding of levels of EIL in correlation to education and background variables, (3) recommending future applications into the development, education, and training of the Student Affairs workforce, and (4) supplying an adapted instrument that can be applied to multiple background variables for a strong study focused on the correlation of the theory to the profession.

\section{Limitations}

The study has some limitations. The first is that the data collected in this study are selfreported and all of the information will be derived from the recollections of student affairs professionals, and their thoughts and perceptions. It is therefore important to consider that 
people's perceptions are influenced by what is going on in their lives at that moment in time, and are also influenced by what they remember about specific experiences after that fact.

The second limitation is that the sample might not be representative of the total population of student affairs professionals within each area of the profession. An example of this is that the researcher solicited student affairs professionals as a whole, not based on their more specific area of work such as resident life, academic advising, etc. Student affairs professionals who participated in the inventory were solicited through multiple measures; therefore, all areas that may be considered a part of student affairs are not guaranteed to be represented.

The third limitation of the study is that there is no evident research that the EILE-I tool has been utilized on student affairs professionals prior to this study. Because of this, there will be no direct comparable data in existence to show a prior outcome of the study and its results. However, the instrument has been applied, under its previous adaptation, to students and was found to be a valid and reliable instrument (Miguel \& Allen, 2016). Therefore, since the new instrument was not changed much from the original instruments, it is being assumed that previous studies under other adaptations sufficed for the instrument to be considered valid and reliable.

\section{Assumptions}

It is vital to state the assumptions regarding this study. First, survey respondents declared themselves to be student affairs professionals who work at a higher education institution within the United States, and are 18 years of age or older. Since this survey was focused on the student affairs profession, and those who took the survey received it because they were classified in this field and met these qualifications, then the data being analyzed 
would reflect this population. This is important because we are looking at one population, and not the workforce in general. This allows the data to be analyzed for varying levels of background data in one career field to show how EIL scores differ or are consistent within the student affairs profession.

The second assumption is that participants completed the inventory only once. The inventory was locked to one response per IP address. Although possible to retake with other IP addresses, it is assumed all participants only took the survey once and that the data are accurate for one inventory per participant.

Finally, it is assumed that those participating in the inventory have a basic understanding of emotional intelligence. This is verified by providing a definition within the instrument and securing the participant's acknowledgement of understanding emotional intelligence prior to the start of the survey. This acknowledgement of emotional intelligence creates a baseline understanding of one of the key concepts by participants as they complete the EILE-I survey. The definition being utilized for acknowledging emotional intelligence is "the subset of social intelligence that involves the ability to monitor one's own and others' feelings and emotions, to discriminate among them and to use the information to guide one's thinking and actions” (Mayer \& Salovey, 1990, p. 5).

\section{Overview of the Chapters}

This dissertation seeks to add to the literature the significance of studying EIL scores among student affairs professionals. Further, the study will evaluate EIL scores among student affairs professionals by utilizing the EILE-I instrument with various background variables to see if differences or similarities emerge from scores. This study then utilizes the data by adding to 
the research on EIL among student affairs professionals, which yields a number of recommendations for future application and study.

The data collected are analyzed utilizing descriptive statistics, factor analysis, reliability analysis, analysis of variance, and factorial ANOVA to answer the research questions previously stated.

This dissertation is organized into five chapters. Chapter 1 provides an overview of the problem, research questions to be addressed, and the rationale for the study. Chapter 2 consists of a historical review of the literature on emotional intelligence, leadership, emotionally intelligent leadership, and student affairs. Chapter 3 provides the research plan and methodology for the study, along with the processes put in place by the researcher for the study. Chapter 4 provides background and statistical results for the study and relates the results to the research questions. Chapter 5 provides the researcher's conclusions related to the findings, along with how these findings affect the current body of literature related to emotionally intelligent leadership and student affairs professionals. Chapter 5 also includes recommendations for future research and application in relation to emotionally intelligent leadership within student affairs. 


\section{CHAPTER II: REVIEW OF THE LITERATURE}

\section{Introduction}

The purpose of this study is to determine emotionally intelligent leadership scores among student affairs professionals by applying an adapted Emotionally Intelligent Leadership for Students: Inventory (adapted to Emotionally Intelligent Leadership for Employees: Inventory). This chapter contains a review of the literature regarding emotionally intelligent leadership and shows how little research exists on this topic within student affairs. The dissertation study provides an understanding of the prevalence of emotionally intelligent leadership scores of student affairs professionals by taking into account information provided within this literature review and a series of statistical tests. The dissertation study contributes to the development of a better understanding of the EIL scores among student affairs professionals by utilizing the EILE-I and background demographic information. These demographic areas include years of service, professional preparation program, gender, and racial identity. Understanding one’s emotionally intelligent leadership score will benefit student affairs professionals, both in their work and their work with students. Prior to implementing the dissertation study, it is important to first introduce a literature review to look at the research and history of the topics of emotional intelligence, leadership, emotionally intelligent leadership, and the student affairs profession. These are the topics that are the most relevant to this dissertation study, and are important to understand prior to the study being conducted. This literature review will specifically show how these areas have evolved and are synthesized together for use in this study.

The chapter begins by defining and synthesizing the concept of emotional intelligence (EQ), which makes up one part of the emotionally intelligent leadership (EIL) theory. The 
chapter continues with a disentanglement of leadership, which is the second part of the theory, and is necessary for the evolution of EIL. The chapter follows with a breakdown of emotionally intelligent leadership, which includes an understanding of the overall concept and the consciousnesses that make up EIL. This breakdown will also share the original 19 capacities interwoven with the three consciousnesses of EIL to demonstrate how EQ and leadership are currently applied and analyzed within the theory. This review of the literature will also include an explanation of the student affairs profession, as this is the profession where EIL will be studied. These explorations into emotionally intelligent leadership, from its roots of emotional intelligence and leadership, will develop a picture of how the theory of EIL can be applied to the field of student affairs, and sets the foundation for this dissertation study.

\section{Emotional Intelligence}

The research into emotional intelligence has a short but rich history, as it has developed over time. The first documented reference to the concept of emotional intelligence can be found in a Mensa publication from the late 1980s. The genesis of the concept, originally known as emotional quotient, is attributed to Keith Beasley. Beasley (1987) defined emotional quotient as "the vital parameter against which to judge a person" (p. 25). The article, which was only a page long, did not share much of the research, but seemed to be more of an opinion piece about a concept that Beasley was working on. This simplistic statement appeared not to gain much traction for researchers and would remain relatively untouched for four years until a new set of researchers would begin to look into Beasley's concept.

In 1990, Mayer and Salovey rebranded the concept of emotional quotient as "emotional intelligence" and expanded on what was originally introduced by Beasley in 1987. Mayer and Salovey (1990) redefined the term "emotional intelligence" as "the subset of social intelligence 
that involves the ability to monitor one's own and others' feelings and emotions, to discriminate among them and to use the information to guide one’s thinking and actions” (p. 5). This concept gave meaning to EQ as a focus on the internalization of one's emotions and feelings toward self and others in understanding their interactions. The new outlook on EQ broke down Beasley's (1987) original definition by showing how the concept was more than just how we interpret others' emotions—it was how the interpreters' emotions are observed as well. Emotional intelligence required the elements of how we interpret our own emotions, as well as how we interpret others' emotions, in order to be a functioning theory. This brought substance to the original concept by Beasley (1987) and expanded the opportunity to further research emotional intelligence. This article by Mayer and Salovey (1990), and in turn, the concept, can be viewed as a landmark piece on emotional intelligence. It was published in the journal Imagination, Cognition, and Personality and paved the way for Goleman to popularize the concept in 1995.

The research by Goleman (1995) added a new dimension to Mayer and Salovey's definition by explaining emotional intelligence as "having abilities such as being able to motivate oneself and persist in the face of frustrations; to control impulse and delay gratification; to regulate one's moods and keep distress from swamping the ability to think; to empathize and to hope” (p. 34). This deeper explanation into emotional intelligence gave a breakdown of EQ, and in turn, areas of study such as emotions within oneself and emotions within others. It also enhanced the concept of EQ through the interpretation of emotions. This, coupled with Goleman's introduction of the concept in his 1995 published book, Emotional Intelligence, which focused on explaining this definition, would give rise to its popularity.

When Mayer and Salovey (1990) published the research that introduced the EQ concept, little research was developed as a follow-up. This had not changed prior to the published work 
of Goleman. This lack of research was supported by Wong (2015), who stated, "Up to 1995 no management studies have been reported that provided direct evidence about the relationship between people’s emotional intelligence and their job performance and career success” (p. 12). This lack of research leading up to Goleman's first publication of his work could be why there were so many critics of Goleman that center on his absence of evidence. Waterhouse (2006) supported Wong by not giving credibility to Goleman because until 1995, "the datasets are privately owned... [by] business consulting firms” (p. 218). If these were privately owned, then how could Goleman have been able to collect enough research to support his definition of emotional intelligence?

The criticism against Goleman from these two researchers led to concerns about the validity of the EQ theory. Goleman, who is considered the first “expert” on emotional intelligence, did not actually show strong evidence to back his theory, which is why his critics believed he was more concerned with writing the book on emotional intelligence than he was with validating it. Wong and Waterhouse were just two of many authors with this belief, which puts Goleman in a position to expand the research and prove his theory or stand down as an expert on the topic.

Based on this criticism, it is a wonder that Goleman's research could create such a movement to understand emotional intelligence when so many found it unreliable. Hein (2006) set out to explain this phenomenon, and in his evaluation of Goleman, he acknowledged that he believed Goleman raised "awareness of emotions and their importance around the world” (para. 3) through his book. This view from Hein leads to the conclusion that Goleman focused on demonstrating the need to research the topic, as opposed to being the researcher of the topic without the evidence to back up his claims. 
Although criticism of Goleman existed, there were other researchers, such as Conte (2005), who sought to confirm the validity of emotional intelligence by extending the research. To do this, Conte (2005) conducted controlled research on several participants and utilized various emotional intelligence measures that were in practice between 2000 and 2004. These measures included the Bar-On Emotional Quotient Inventory (EQ-I), the Multifactor Emotional Intelligence Scale (MEIS), and the Mayer-Salovey-Caruso Emotional Intelligence Test (MSCEIT) (Bar-On, 1997; Mayer et al., 1997; Mayer et al., 2002). By using these, Conte (2005) found that "validity evidence for EQ measures had lagged behind reliability evidence” (p. 437). Conte (2005) explained further that emotional intelligence lacked substance due to the "vague theoretical development for many of the measures and because the content across EQ measures varies widely” (p. 437). In other words, EQ had mechanisms of study, but these measures did not prove emotional intelligence's overall existence. At first glance, Conte (2005) was agreeing with skeptics that EQ was a failed concept that could not be studied. However, upon further examination of his findings, the solution of breaking down the components of emotional intelligence would lead researchers to be able to measure emotional intelligence in ways they had not before. Conte (2005) found that although scoring concerns are present since each measure is based on a different definition, validity existed and emotional intelligence was a concept that could be measured and studied in individuals. This groundbreaking finding also served as a guide to Mathews et al. (2002), a group of researchers who further studied and found validity in emotional intelligence.

Mathews et al. (2002) stated that "few fields of psychological investigation appear to have touched so many disparate areas of human endeavor, since its inception, as has emotional intelligence” (p. 4). One argument to support this statement in the professional world is that it is 
believed "emotional intelligence can be trained and improved in various social contexts" (Mathews et al., 2002, p. 5). Within their research, Mathews et al. (2002) validated this statement through four key aspects that comprise EQ: constructs, measures within the constructs, key processes, and trainability. Mathews et al. (2002) stated that a "systematic differentiation of these constructs may replace conceptual cacophony with a more harmonious structuring of ideas in the field” (p. 233).

The year prior to the revelation on constructs from Mathews et al., Goleman reemerged with a new outlook on emotional intelligence that would revitalize research into the area through not only constructs, but also the foundation of future studies into emotional intelligence. Goleman (2001) changed his definition of emotional intelligence to an individual's "abilities to recognize and regulate emotions in ourselves and in others" (p. 14). Although this was Goleman's new basis for emotional intelligence, it was not the groundbreaking research in his work. This came from his development of the first emotional intelligence framework. Goleman (2001) explained that "emotional intelligence derives its theory rooted in four clusters or domains” (p. 14). These four domains include self-awareness, self-management, social awareness, and relationship management. Within each of these domains was a number of elements that could be studied as constructs within the theoretical framework of EQ. It is from Goleman's framework and the constructs he developed that emotional intelligence was catapulted into the field of study it is today.

With Goleman’s new research (2001) and Mathew et al. (2002) focused on validating EQ through constructs, application for EQ began to move into the forefront of study. Bradberry (2015) stated that emotional intelligence "taps into the fundamental element of human behavior... [but] you can't simply predict emotional intelligence based on how smart someone 
is” (para. 5). Research shows that emotional intelligence is a theory based on the interpretation of emotions; therefore, intelligence alone is not a leading factor in the measurement of an individual's emotional intelligence. If emotional intelligence is based on elements of human behavior and interaction, then further application of the concept could be applied broadly.

These various applications could work in business, education, psychology, and everyday interactions, which may be a reason that EQ is so widely studied. Cherniss et al. (2006) stated that the "early stages of theory development, having several versions of emotional intelligence theory is a sign of vitality in the field, not a weakness” (p. 239). The researchers further explained that "it’s important to keep in mind that there are several different models of [emotional intelligence] that now are being studied, and each have been measured in different ways” (Cherniss et al., 2006, p. 240).

Much like the evolution of emotional intelligence as a theoretical concept, the definition of EQ has also been evolving as the research progresses with a large number of contributions from various fields of study. Chapin (2015) found that there are "multiple conceptualizations of emotional intelligence, however, most models of emotional intelligence can be divided into two broad categories: ability models and traits and mixed models” (p. 26). Breaking the definitions into two distinct models allows for a better understanding of the EQ concept. First, there are some similarities within the two models described by Chapin (2015). Chapin’s (2015) research explained that ability models focus on how one would utilize their emotions based on what they understand of themselves. This means that ability is taught through experiences, which trains an individual to learn to use a particular emotion as they need it in various situations. Trait and mixed models, according to Chapin (2015), have the same understanding of the concept of ability models, but require individuals to have the emotion (trait) or develop the trait before one 
truly understands emotions, whether intentionally and unintentionally. These differences, although subtle, have emerged from my research to be some of the defining arguments for the various definitions. The differing models demonstrate a clear need for further research with the goal of intertwining the models in order to enhance and clarify a single definition for conceptualizing emotional intelligence.

Emotional intelligence has had an interesting trajectory since the emotional quotient was first discussed by Beasley (1987). Arguments that are both pro and con regarding the existence of emotional intelligence have pushed a number of developments and paths through which EQ has been defined, measured, and tested. Although a standardized definition cannot be found when comparing a number of definitions presented by researchers, such as Goleman (2002), Cherniss et al. (2006), Mayer \& Salovey (1990), and Mathews et al. (2002), there are two key factors that show to be consistent among most of the research into emotional intelligence. The first key factor is that EQ has a focus on how one manages, interprets, and responds in relation to their own emotions. The second commonality is that EQ focuses on how emotions are projected from others and how we internalize what is expressed by others in order to understand what they are projecting. These two key elements make up emotional intelligence, and the basis of the study into the concept and theory.

This section focused on providing a brief understanding of emotional intelligence, and included the brief and rocky history of emotional intelligence's conceptual development. The section also shared how the definitions, concepts, and measurements have changed over time. These definitions, concepts, and measurements include the search to measure the topic, finding validity, criticism of the theory, and consistent understandings. These elements of emotional intelligence are just one part of emotionally intelligent leadership. It is necessary to also 
understand leadership prior to unraveling EIL because the two theories are vital for understanding the concept of emotionally intelligent leadership. The next section will briefly review leadership, which will build an understanding of the topic that will eventually be woven into emotionally intelligent leadership.

\section{Leadership}

Leadership is a broad topic that has a number of definitions, theories, and frameworks based on how it is researched and applied. The topic of leadership includes a complex set of interactions between an individual and a group. Pendelton and Furnham (2012) explained that historically, leadership is "studied through the lens of different approaches or disciplines" (p. 6). This in many cases guides the definition of, research about, and approach to the topic. A second definition found on leadership concluded that leadership occurs in three ways: “(1) making [individuals] more aware of the importance of task outcomes, (2) inducing them to transcend their own self-interest for the sake of the organization or team, and (3) activating their higher order needs. (Rosari, 2019, p. 18).” Because leadership is a broad term and is associated with a number of definitions, as was shown above, researchers are required to choose a definition and approach when utilizing the topic.

The first question to answer is, how would leadership be defined? Pendelton and Furnham (2012) defined leadership as “creating conditions for people to thrive as individuals, collectives, and the achievement of certain goals” (p. 2). Rost (1993) viewed leadership as "an influential relationship among leaders and followers who intend real changes that reflect their mutual purposes” (p. 102). Another interpretation of leadership is simply an individual who can convince at least one other individual to follow them. Each of these definitions has elements of emotional intelligence. Therefore, it can be concluded that no matter how leadership is defined, 
it is a topic area in which emotional intelligence can thrive. This is because two key components alluded to within each definition of EQ are understanding the emotions of others, and how to respond. This understanding of how you will approach a situation in terms of your emotions, and how individuals may respond with their own emotions, is the core of emotional intelligence. It is important to remember that emotionally intelligent leadership is a form of leadership that, according to Shankman, Allen, \& Haber-Curran (2015), contains the promotion of an "intentional focus on three facets: consciousness of self, consciousness of others, and consciousness of context” (p. 9). All three consciousnesses are considered and evaluated when reviewing EIL and its application for an individual.

Prior to choosing an approach on the topic of leadership, it is important to acknowledge the three categories of research that consistently emerge, which are: how leaders emerge, who they are, and what they do (Pendleton \& Furnham, 2011). Each of the categories contains a set of approaches to studying leadership. Since this study of emotionally intelligent leadership focuses on how an individual score on an inventory based on 19 capacities, it is therefore prudent not to focus on how leaders emerge. This is important to leadership, but this study does not measure how a person got to this score; rather, it focuses on what the person scores. The category of who leaders are is also not evaluated within this study. This is because this approach to leadership study focuses on trying to understand the personality, or evolution of a leader. Emotionally intelligent leadership is based on the premise that all individuals contain levels of EIL, and therefore all individuals are emotionally intelligent leaders to some degree. Therefore, EIL does not focus on who is a leader, but rather on what they do.

This study of EIL is a review of all individuals' current understandings of their own emotionally intelligent leadership. Therefore, the leadership category approach to the inventory 
will focus on leadership actions as the basis of the study. Four approaches exist within this category: cognitive, ideological, social, and work. Studying leadership within EIL utilizes the cognitive approach. The cognitive approach evaluates leadership by addressing thinking, and therefore "looks closely at perception, information processing, understanding, knowledge, and, sometimes, creativity” (Pendleton \& Furnham, 2011, p. 8). Emotional intelligence has been defined one way as the "abilities to accurately perceive emotions, to understand their causes and trajectories, to utilize them to help you think, and to effectively manage them" (Caruso et al., 2016, Foreword). When reviewing the definition of EQ and applying the cognitive approach, EIL can be evaluated.

Wofford (1994) explained the cognitive approach as beginning with attention to received information. Through this approach, "the leader [receives] feedback on the results of his previous behavior and gets data from his environment. These inputs flow into the cognitive system through automatic or controlled processes” (Wofford, 1994, p. 5). These processes allow an individual to acquire items simultaneously, and through their subconscious. It is important to distinguish between an automatic process and controlled process. An automatic process involves taking data that is known or familiar (Wofford, 1994). A controlled process means that a person takes "one item at a time and deals with that item on a conscious level" (Lord \& Mahr, 1991; Wofford, 1994). Once this portion of the process is complete, the inputs are internally coded within short-term memory before being moved to long-term memory. An individual's internal thought processes then categorize the inputs for a return to response. An example of how a leader utilizes cognitive processes in the workforce is based on three areas; "1) the feedback leaders get about subordinates’ performances; 2) information leaders receive about the characteristics of subordinates; and 3) information about the nature of the task and 
environmental conditions” (Mitchell et al., 1981; Wofford, 1994). Evaluation of the cognitive process toward emotionally intelligent leadership reveals the same elements of consciousness of self, consciousness of others, and consciousness of context all internalized together. This is necessary for going through the same process that is used to evaluate leadership., and is why this approach to the study of leadership aligns the most with the study of emotionally intelligent leadership.

Since the current study of emotionally intelligent leadership does not focus on understanding why or how someone leads, but rather, is based on what EIL capacities an individual contains, it is not necessary to review overall theories of leadership. It is necessary, however, to focus on the study of how emotional intelligence and leadership come together in order for an individual to internalize the capacities of EIL in relation to their consciousnesses of applying emotionally intelligent leadership. This interweaving of concepts develops the theory of emotionally intelligent leadership and the potential applications for the future development of leaders. This study and evaluation of leadership and emotional intelligence comes together in the theory of emotionally intelligent leadership.

\section{Emotionally Intelligent Leadership}

Emotionally intelligent leadership, or EIL, is a synthesis of "two major bodies of research and theory: emotional intelligence (EQ) and leadership” (Shankman, Allen, \& HaberCurran, , 2015, p. 9). Both of the aforementioned topics have been studied separately since their inception until recently, where they were combined into one theory of thought, which is known as emotionally intelligent leadership (EIL). This theory of EIL was defined by Shankman, Allen, and Haber-Curran, (2015) as “promoting an intentional focus on three facets: consciousness of self, consciousness of others, and consciousness of context” (p. 9). This view 
of EIL shifts the current study of the topic from its traditional focus on the theories separately and to the combination of emotional intelligence and leadership.

It is important to note that emotionally intelligent leadership has been studied by few researchers; the topic is a new area of emotional intelligence that emerged in publications as recently as 2015 (Shankman, Allen, \& Haber-Curran., 2015). Emotionally intelligent leadership lacks widespread research, based on this researcher's own findings, and what was found in the existing research of Shankman, Allen, and Haber-Curran (2015) has not been explored previously. Emotionally intelligent leadership has also only been applied to student leaders in one study, making the exploration into student affairs professionals a new frontier for the concept.

Prior to a review of the previously conducted study and instrument, it is necessary to understand the elements and concepts that make up emotionally intelligent leadership. When examining the elements of emotionally intelligent leadership, three key components arise within the research: consciousness of self, consciousness of others, and consciousness of context. These three concepts, introduced by Shankman, Allen, and Haber-Curran (2015), are important because they illustrate EIL within individuals as containing an understanding of self, understanding of others, and the ability to determine how an emotion is interpreted. Within all of these concepts exist 19 capacities that develop and articulate an individual's EIL within these three consciousnesses. To further explore EIL, these three concepts are broken down and explained, as well as the capacities within each consciousness.

\section{Consciousness of Self}

The first of the three concepts to understand is consciousness of self. The researchers defined consciousness of self as "awareness of your abilities, emotions, and perceptions. 
Consciousness of self is about prioritizing the inner work of reflection, introspection and appreciation of one’s self-awareness” (Shankman, Allen, \& Haber-Curran, 2015, p. 10). The definition focuses on how an individual interprets their own emotions in a given situation. This interpretation includes understanding a person's own emotions and what their utilization of emotion can do for a given situation from an internal or external understanding.

Another way to view consciousness of self is self-awareness. To demonstrate EIL means "being aware of yourself in a number of ways (such as) being in tune with your values, strengths, limitations, and worldview (and therefore) focus your energy on a crucial element of effective leadership: self-awareness” (Shankman, Allen, \& Haber-Curran, 2015, p. 21). Webber and Forster (2017) explained self-awareness as leading oneself by “attending to one’s thoughts, feelings, and behavior... [which] awareness enables people to understand their responsibilities and actions within the leadership relationship” (p. 45). An individual must have self-awareness and understand that self-awareness if they are to develop their internal emotionally intelligent leadership.

Fundamentally, the steps to building self-awareness are prioritizing self-awareness, seeking feedback, and reflecting, according to Shankman, Allen, \& Haber-Curran (2015). Although the researchers proposed these steps to help an individual build up their selfawareness, an individual's consciousness of self is enacted and built within eight capacities. These eight capacities include emotional self-perception, emotional self-control, authenticity, healthy self-esteem, flexibility, optimism, initiative, and achievement. Of the eight, "two of the capacities (emotional self-perception and emotional self-control) are closely linked with emotional intelligence while the other six blend emotional intelligence and leadership” (Shankman, Allen, \& Haber-Curran, 2015, p. 26). 


\section{Emotional Self-Perception}

Self-perception has two postulates. The first is that "individuals learn about their own attitudes, emotions, and other internal states from observation of their own behavior and the circumstances in which their behavior occurs” (Greenbert \& Murphy, 2015, para. 2). The second is “the extent that individuals' internal cues regarding their internal states are weak or ambiguous, they must infer those internal states in the same way an observer would” (Greenbert \& Murphy, 2015, para. 2) With this definition of self-perception, the researchers expressed the capacity of emotional self-perception as “describing, naming, and understanding your emotions” (Shankman, Allen, \& Haber-Curran, 2015, p. 31). Within consciousness of self, emotional self-perception occurs when an individual knows themselves well enough "to identify [one's] emotional responses as well as being conscious of how you react emotionally to situations, people, and social dynamics” (Shankman, Allen, \& Haber-Curran, 2015, p. 31). This means that an individual who is in tune with their self-perception has the ability to be aware of and interpret feelings in real time. It doesn't necessarily mean a person can control their emotions or change them, but that they have a higher chance of doing so because they have an understanding of their emotions. This capacity is within consciousness of self because it has a direct focus on one’s internal understanding of themselves.

\section{Emotional Self-Control}

The second capacity within consciousness of self is emotional self-control. Self-control is defined as being able to "represent an individual's capacity to override impulses, break habits, and avoid temptations” (Hagger et al., 2019, p.765). From the perspective of the capacity of emotional self-control, it is defined as “intentionally managing your emotions and understanding how and when to demonstrate them appropriately” (Shankman, Allen, \& Haber- 
Curran, 2015, p. 41). In emotionally intelligent leadership, this is practiced through navigating stress, managing issues, and regulating responses. An individual who is strong in this capacity would be aware of how they will react, respond in a way they choose, and interpret in real time information to manage a future response. It is important to point out that this capacity is not about disregarding emotion, but about intentionally managing emotions. This is a part of consciousness of self because it focuses on the individual and how they are responding to situations and controlling emotions accordingly in a way they desire to respond.

\section{Authenticity}

The third capacity, and the first to blend EQ and leadership, is authenticity. Authenticity is defined as how "one acts in accord with the true self, expressing oneself in ways that are consistent with inner thoughts and feelings” (Harter, 2002, p. 382). As a capacity, the researchers took this definition and combined it with leadership to define authenticity as “developing credibility, being transparent, and aligning words with actions” (Shankman, Allen, \& Haber-Curran, 2015, p. 51). Authenticity is an internal review of oneself to help a person understand what they value and align their actions with those values. Although not directly related to emotions, how one portrays those values through emotion is how this connects to EIL. Another way to view this concept is through authentic leadership. Authentic leadership emphasizes developing authentic relationships with others, which is more interpersonal in nature and recognizes that all leadership is relational at its core (Avolio \& Gardner, 2005; Shankman, Allen, \& Haber-Curran, 2015). As a capacity of consciousness of self, authenticity requires one to be in tune with themselves and to project themselves honestly using emotions to outwardly communicate with others. 


\section{Healthy Self-Esteem}

Osborne (2019) asserted that "self-esteem equals success divided by pretensions” (para. 2). In other words, self-esteem equates to understanding how an individual comes to feel about and perceive themselves. The capacity of healthy self-esteem is viewed through emotionally intelligent leadership as "balancing confidence in your abilities with humility” (Shankman, Allen, \& Haber-Curran, 2015, p. 61). The researchers further explained that this means "knowing yourself well enough to stand up for what you believe in while understanding you may not know it all and need to create space for the thoughts, opinions, and values of others” (Shankman, Allen, \& Haber-Curran, 2015, p. 61). For the capacity of healthy self-esteem, a balance of self, self-efficacy, and resilience is necessary. The first element—self — relates to understanding your capabilities and believing in what you can do. Self-efficacy is defined as “people’s beliefs about their capabilities to exercise control over their own level of functioning and over events that affect their lives” (Bandura, 1993, p. 118). An individual must be able to have self-efficacy to have a healthy and positive self-esteem. Finally, resilience is necessary to look past barriers and not to give up on working toward achieving a goal and building selfesteem. These elements, which are built around the consciousness of self and are based on a person's belief in their own abilities, is why this capacity is important in EIL.

\section{Flexibility}

The fifth capacity of consciousness of self is flexibility. Flexibility within EIL is defined as “adapting your approach and style based on changing circumstances” (Shankman, Allen, \& Haber-Curran, 2015, p. 71). An individual who is in tune with their emotionally intelligent leadership has the ability to interpret what is needed, and is able to change and adapt as necessary to a given situation or emotion. This can include the modification of ideas, 
approaches, and behaviors. Modification can often be difficult, but in EIL, situations and emotions involved with a situation can change; within EIL, this will require a person to be able to adapt and change based on these shifts.

\section{Optimism}

Much like the previous capacities not directly related to emotion, optimism is a key capacity of emotionally intelligent leadership. Optimism refers to a "generalized sense of confidence about the future, characterized by their broad expectancy that outcomes are likely to be positive” (Boniwell, 2012, p.19). As a capacity of emotionally intelligent leadership, optimism is "having a positive outlook...[and] setting a positive tone for the future" (Shankman, Allen, \& Haber-Curran. 2015, p. 79). In EIL, it is important for an individual to be optimistic and hopeful for what the future can hold. This is because emotionally, optimism yields positivity and helps an individual evaluate approaches to situations, emotions, and future outlooks. It also can be viewed as a link between EQ and leadership. Optimism, as a state of mind, is positive and in most cases yields positive emotions. This in turn can help an individual approach a situation, evaluate their own emotions, and lead based on a positive outlook. In contrast to optimism, pessimism would hurt that outlook, result in negative emotions, and can, overall, negatively impact a leader's approach to a given situation. Optimism is a key component of consciousness of self and within EIL.

\section{Initiative}

The seventh capacity of consciousness of self is initiative. The capacity of initiative is defined as "being a self-starter and being motivated to take the first step" (Shankman, Allen, \& Haber-Curran, 2015, p. 91). In leadership, initiative is required to make a change and move forward those who follow the leader. An individual must have initiative in emotionally 
intelligent leadership if they want to take the lead in a given area. Those who regress from taking initiative and instead postpone action do so for the reasons of apathy, fear of failure, unpopular opinion, and inability to manage conflict. Each of these failures is linked to emotions and an individual's ability to overcome and produce results. Therefore, how one views themselves and their confidence to act is vital to the consciousness of self and, in turn, EIL.

\section{Achievement}

The final capacity of consciousness of self is achievement. Achievement was defined by Hill \& O’Dell (2015) as “the tendency to strive for success or to attain a desirable goal” (para. 2). In its simplest definition, achievement is a means for striving for excellence (Shankman, Allen, \& Haber-Curran., 2015). Individuals who score high in the achievement capacity "get satisfaction for succeeding at tasks...[and/or] have self-imposed standards of excellence” (Bass, 2008, p. 179). Since only individuals can set what they perceive to be an achievement, it must be a consciousness of self to reach success. This is an important capacity in leadership because leaders set goals and work to reach them. Achievement is the goal to reach and the desire of oneself to guide or lead others to reach it, and is the last of the eight capacities that individuals contain within the portion of EIL that includes consciousness of self. The next area to evaluate is the consciousness of others.

\section{Consciousness of Others}

The need to know the emotions of those a person interacts with defines the second facet of emotionally intelligent leadership, as set forward by Shankman, Allen, and Haber-Curran (2015): the consciousness of others. Shankman, Allen, and Haber-Curran (2015) defined consciousness of others as follows: "Demonstrating emotionally intelligent leadership involves awareness of the abilities, emotions, and perceptions of others... about intentionally working 
with and influencing individuals [and] groups” (p.10). This definition encompasses the desire and need to be able to interpret others' emotional intelligence to truly be proficient in EIL. If an individual engages with consciousness of others, that means they are attuned to "people's abilities, emotions, and perceptions, [and they] can better inspire, connect with, work with, and influence others” (Shankman, Allen, \& Haber-Curran, 2015, p. 111). This further explains how consciousness of others is important not only in interpreting emotions, but also in how leadership and EQ are symbiotic.

A person's emotional intelligence means that they understand their internal emotions and interpret others' emotions. This makes the consciousness of others vital to EQ and the EIL theoretical framework. The importance of being conscious of others is that in EIL, much like EQ, the theories are not one-dimensional through an internal lens; rather, they are multidimensional based on interactions with others. Interpreting someone else's emotions through an interaction can affect a person's own emotions, as well as how the other individual will respond. This is not dependent on where a person is situated in a group because the need to interpret others' emotions is vital to human interactions. The question that arises is: How does one build a consciousness of others and measure this facet of emotionally intelligent leadership? Within the consciousness of others, there are nine capacities identified: displaying empathy, inspiring others, coaching others, capitalizing on difference, developing relationships, building teams, demonstrating citizenship, managing conflict, and facilitating change. The nine capacities relate, evaluate, measure, and demonstrate leadership, emotional intelligence, or a hybrid of the two. Every person possesses a level of each of these capacities, and how that person rates within each will help build a picture of where they are within EIL. 


\section{Displaying Empathy}

The first capacity within the consciousness of others is displaying empathy. As was explained in emotional intelligence, empathy is a key component of EQ. Displaying empathy is explained as "placing a high value on emotions and being emotionally in tune with others" (Buckingham \& Clifton, 2001; Lawrence et al., 2004; Shankman, Allen, \& Haber-Curran, 2015). Empathy requires an individual to understand their internal feelings, and be able to acknowledge and identify how others are feeling. In essence, an individual is going through the same emotions as the other person. It is important not to confuse empathy with sympathy, which is “putting yourself in another person's place but retaining your own perspective and still using your own standard of judgement” (Komives et al., 2007, p. 171). Sympathy is understanding an emotion but not feeling, or being perceived as feeling, the same as the other individual.

Displaying empathy from a social perspective is considered to be a process involving key behaviors. McCauley and Van Velsor (2003) explained the key behaviors of social perspectives as:

- Being able to listen to and absorb information skillfully

- Recognizing that other people's views of the situations may be different from yours

- Understanding that other people’s assumptions may be and should be different from yours, and

- Understanding and accepting the limitations of your own point of view. (p. 369) 
These key behaviors are necessary to understand, interpret, and display, since empathy is part of EIL and the consciousness of others. This capacity of displaying empathy is the first one necessary for the consciousness of others because with EQ, one of the pinnacle feelings that requires learning is empathy.

\section{Inspiring Others}

The second capacity within the consciousness of others is inspiring others. Inspiring others is explained as energizing individuals and groups (Shankman, Allen, \& Haber-Curran, 2015). Inspiration occurs "when people are excited about a better future...[and] emotionally intelligent leaders foster feelings of enthusiasm and commitment to organizational mission, vision, and goals” (Shankman, Allen, \& Haber-Curran, 2015, p. 129). Inspiring individuals are able to understand what others need, and respond in a way that encourages people to believe in them and potentially follow them. To do this, EIL states that individuals must understand others' emotions to be able to interpret those emotions and respond in a potentially inspiring way. Bass (2008) cautioned that someone who inspires an individual does not necessarily inspire all individuals. This does not lessen the capacity of a person to inspire others; rather, it highlights the perspective that people are inspired differently and someone utilizing EIL will evaluate, weigh, and decide how to respond to potential inspiration. The capacity of inspiring others within the consciousness of others is one approach and way to develop in EIL.

\section{Coaching Others}

Coaching others is the third capacity within the consciousness of others, and is a capacity focused on enhancing others' skills and abilities (Shankman, Allen, \& Haber-Curran, 2015). The researchers explained the concept of coaching others as "helping others enhance their skills, talents, and abilities” (Shankman, Allen, \& Haber-Curran, 2015, p. 139). This 
capacity focuses more towards leadership than EQ as part of the EIL theory. Since an individual cannot always be the leader in every situation, it becomes necessary to understand others as a way to help them develop. To coach others, Avolio (2005) explained that an individual must be in tune with their "style, character, and how they relate to others over extended periods of time" (p. 212). McCauley and Van Velsor (2003) expanded this and explained that coaching occurs in three parts: assessing, challenging, and supporting. In both explanations of coaching, the relational aspect of this definition and how people coach others is how emotional intelligence and leadership infuse within this capacity. This makes coaching others a necessary capacity within the consciousness of others and the EIL model.

\section{Capitalizing on Difference}

Capitalizing on difference is the next capacity within the consciousness of others. Shankman, Allen, and Haber-Curran (2015) explained capitalizing on difference as “recognizing that our unique identities, perspectives, and experiences are assets, not barriers” (p. 149). In this capacity, an individual embraces differences by receiving them, internalizing them, and then responding accordingly. Since consciousness of others is about response and interaction, it is therefore an important capacity within this concept of leadership. In groups, it can be beneficial to understand differences and learn how to work together to accomplish goals. Differences can include elements of our social identities, which in most cases are set at birth and reflect our social group status, including include gender identity, race, ethnicity, sexual orientation, age, ability, and socioeconomic status (Jones \& McEwen, 2000; Shankman, Allen, \& Haber-Curran, 2015; Shriberg \& Shriberg, 2011; Terrell \& Lindsay, 2009). In emotionally intelligent leadership, these differences help define our interactions and build our groups. 


\section{Developing Relationships}

The fifth capacity of consciousness of others is developing relationships. To develop a relationship is to create meaningful connections. Within emotionally intelligent leadership, developing relationships is crucial in order to encourage opportunities for relationships to grow and develop (Shankman, Allen, \& Haber-Curran, 2015). This fits with leadership, since “every element of leadership implies interpersonal relationships” (Couto \& Eken, 2002, p. 201). This statement can be taken a step further with the understanding that positive relationships in groups and organizations lead to increased performance, group member commitment, positive feelings, and experience within the group (Lencioni, 2002; Shankman, Allen, \& Haber-Curran, 2015). This shows that all interactions are some form of relationship. By focusing on developing relationships, an individual utilizes EIL to build community, as well as potential leadership opportunities.

\section{Building Teams}

Much like the previous capacity, the next capacity is based on community. This capacity is called "building teams," which means working with others to accomplish a shared purpose. Shankman, Allen, and Haber-Curran (2015) explained building teams as "effective communication, creating a shared purpose, and clarifying roles to get results” (p. 169). Building teams is specifically utilized, as opposed to building groups, because teams require interdependence, whereby members work collaboratively, hold each other accountable, and are committed to a common purpose (Northhouse, 2012; Shankman, Allen, \& Haber-Curran, 2015). In leadership, there must be at least two individuals, and in this capacity an individual will utilize emotional intelligence to build consensus and an organization plan for working toward a common goal. Teamwork has played into a number of theories, such as Tuckman's (1965) 
group development theory and Lencioni’s (2002) five dysfunctions of a team. As a topic that has been studied a number of times, it is important to realize that a team is necessary for effective leadership. To build a team, one must interpret and respond to build a consensus and common goal among the individuals. This is why, within the consciousness of others, building teams is important to the emotionally intelligent leadership model.

\section{Demonstrating Citizenship}

Demonstrating citizenship is the seventh capacity within the consciousness of others. Demonstrating citizenship is about "being engaged and following through on your commitments... [which in] emotionally intelligent leaders [means meeting] their ethical and moral obligations for the benefit of others and the larger purpose” (Shankman, Allen, \& HaberCurran, 2015, p. 179). This capacity is built much upon the other capacities in the sense that it contributes toward what makes the others effective. Demonstrating citizenship is about fulfilling the obligations that one commits to in a group. It is important to note that this capacity definition is that all members of a group are citizens within that group, and thus have a commitment to better the whole. A good citizen will also be an individual who is both active and contributing. The capacity of demonstrating citizenship is built more on leadership than emotional intelligence; however, EQ is utilized in how we interpret and respond to the obligations as a citizen. This is why the capacity of demonstrating citizenship is vital to the EIL model.

\section{Managing Conflict}

The next capacity of consciousness of others is managing conflict. Conflict will exist in every group and it is important to be able to identify and resolve conflicts as effectively as possible. This capacity is defined as "working through differences to facilitate the group 
process” (Shankman, Allen, \& Haber-Curran, 2015, p. 187). When conflict arises, it always contains some degree of emotions. Emotional intelligence teaches that it is important for a person to be able to interpret their emotions and those of others in deciding how to approach a given situation. In leadership, conflict can, at times, decide the fate or credibility of a leader. This capacity is important to understand because it can make or break a group if not approached appropriately. Couto and Eken (2002) explained that "however much leaders enjoy or dislike conflict, they recognize its inevitability and its primary role in clarifying values” (p. 209). The capacity to manage conflict is vital for EQ and leadership development, and therefore is a pillar of consciousness of others within the EIL model.

\section{Facilitating Change}

The final capacity within the consciousness of others is facilitating change. This capacity focuses on working toward a new direction within a group or between two individuals. Facilitating change is explained as "advancing ideas and initiatives through innovation and creativity... [and within EIL] seeking to improve on the status quo and mobilize others towards a better future” (Shankman, Allen, \& Haber-Curran, 2015, p. 197). A question to ask within this capacity is, what is change? The answer is that "leadership is about change: seeking to improve others, our organizations, our communities, and the world in which we live” (Shankman, Allen, \& Haber-Curran, 2015, p. 197). Change can take on a number of forms, but it includes situations where leaders evaluate approaches and solutions as a way to move the group in a particular direction. Therefore, leaders are always looking at change in order to solve problems. In emotional intelligence, facilitating change can mean understanding what an individual needs, as well as what that person's followers need, interpreting that need, and then working on a solution to make the change. Based on this logic, it can be deduced that change is a major 
component of emotional intelligence and leadership, and therefore belongs in the EIL model. The capacity is within the consciousness of others because change is focused on the group and the need to understand others in order to make a change.

As with emotional intelligence, the need for an individual to understand their own internal emotions, as well as the emotions of others, is necessary. This section explored which capacities unite emotional intelligence and leadership from the "consciousness of others" portion of the EIL theory. Like consciousness of self, it is necessary to have both for emotional intelligence. The next area to explore in EIL is consciousness of context, which elevates EIL into a new area of study within emotional intelligence and leadership.

\section{Consciousness of Context}

The final consciousness within emotionally intelligent leadership that is explored by Shankman, Allen, and Haber-Curran (2015) is the consciousness of context. Shankman, Allen, and Haber-Curran (2015) explained that "demonstrating [EQ] involves awareness of the setting and situation... [which] is about paying attention to how environmental factors and internal group dynamics affect the process of emotional intelligence” (p. 10)—in other words, consciousness of context. Essentially, emotional intelligence exists heavily in the context and environment in which it is used. Context is created in the "environment in which leaders and followers work and comprise both the setting and the situation” (Fiedler, 1972; Shankman, Allen, \& Haber-Curran, 2015).

When breaking down the elements that create context, the two distinct areas for review are the setting and the situation. The setting refers to the environment and structure of the group or organization (Shankman, Allen, \& Haber-Curran, 2015). Situation, when viewed through the lens of EIL, is considered more dynamic. Situation is viewed as the "many different forces of a 
time and place, including but not limited to individual personalities, politics, power relationships, social trends, and tensions or challenges that emerge in a setting” (Shankman, Allen, \& Haber-Curran, 2015, p. 209). This additional view of context is what makes the emotionally intelligent leadership theory more grounded and shifts the approach to emotional intelligence.

The previous understanding of emotional intelligence simply focused on how people understand their own emotions, and how they understand others' emotions through interactions. Even though these two are vital for EQ to exist, the main focus of emotional intelligence, according to Shankman, Allen, and Haber-Curran (2015), is that even if a person does understand emotions from themselves and others, emotion is multifaceted and the context in which it is used is necessary to fully interpret any emotion. If one is to truly be emotionally intelligent, then they must also understand the setting and situation to develop the context for EIL. It is important to also explain that like the previous two consciousnesses, there are two capacities found within the consciousness of context: analyzing the group, and analyzing the environment.

\section{Analyzing the Group}

The first capacity of consciousness of context is analyzing the group. Shankman, Allen, and Haber-Curran (2015) shared that "analyzing the group is about recognizing values, rules, rituals, and internal politics” within the group (p. 217). In simpler form, an individual is observing group dynamics and understanding how to diagnose, interpret, and address those dynamics. Every group and organization is unique in their values, operations, rituals, and power dynamics. This is because a group’s culture is made up of symbolic elements, role elements, interactive elements, and context elements (Driskell \& Brenton, 2005). To become a part of a 
group or as they create a new group, individuals must analyze the group and understand the elements in order to be integrated into it successfully. This understanding of a group's culture through these elements is vital because even if a person is in tune with their own consciousness of self and others, without understanding the context, they cannot apply emotionally intelligent leadership. Therefore, this capacity of analyzing the group focuses on an individual's skills and knowledge in their ability to interpret group dynamics. All groups change and operate differently and as an individual in the group or as a person who is joining the group, one must be able to learn all aspects of the group to apply their own consciousness of self and others.

\section{Assessing the Environment}

The second and final capacity of consciousness of context is assessing the environment. Assessing the environment is viewed as "recognizing the social, cultural, economic, and political forces that influence leadership” (Shankman, Allen, \& Haber-Curran, 2015, p. 227). The capacity of assessing the environment can be simplified as interpreting the external forces and trends. Although similar to analyzing the group, this capacity focuses on how external elements can affect a group, which a leader needs to account for when leading. This is opposed to analyzing the group capacity, which focuses on the internal workings of a group.

Understanding the environmental factors of the group can be viewed as "systems of thinking or having systems perspective, that is, taking into account the larger environment for which the organization exists” to allow for the group to be successful and continue to operate (Heifetz, 1994; Shankman, Allen, \& Haber-Curran, 2015, 2015; Wheatley, 2005). This environmental scanning helps with consciousness of context by allowing a leader to understand these external factors and put the situations and environments into context to help the leader respond appropriately. 
The concept of emotionally intelligent leadership is a newer way of looking at emotional intelligence and leadership. The synthesis of "two major bodies of research and theory: emotional intelligence (EQ) and leadership” help give this theory a foundation and application for use in the workforce (Shankman, Allen, \& Haber-Curran, 2015, 2015, p. 9). The section showed how EIL is made up of three distinct consciousnesses: self, others, and context. Within each of these consciousnesses there are capacities, 19 in total, that contain elements of emotional intelligence and leadership. Each capacity, to some degree, is within all individuals and makes EIL possible. The potential understanding of EIL within student affairs professionals through the combination of EQ and leadership is what this dissertation is about. To apply EIL, a review of student affairs professionals is necessary since this will be the focus of the study, and is where emotionally intelligent leadership will be applied.

\section{Student Affairs}

Since this is a study examining student affairs professionals and their prevalence of emotionally intelligent leadership scores, it is important to provide information related to who student affairs professionals are and what they do. Student affairs, according to the American College Personnel Association (ACPA), consists of "any advising, counseling, management, or administrative function at a college or university that exists outside the classroom” (Love, 2003, para. 5). The Student Affairs Administrators in Higher Education (NASPA) association, which is the largest professional association for student affairs professionals, defines student affairs as "the delivery of services enhancing educational experiences of college students" (NASPA, 2010, p. 2). Another view of the term "student affairs" refers to the "university offices that supplement the academic mission of the university by providing out of the classroom programs and services to students” (Newman, 2009, p. 49). These various definitions of student affairs 
can be summed up as professional support of the college that does not fall under academic affairs.

Student affairs is made up of various professional offices such as advising, student life, career services, and residential life. The placement of these offices within the university organizational structure varies from college to college. Because of these variations in models, type of institution, and services offered, the student affairs philosophy within each college can also differ. Although student affairs roles are different and vary widely across institutional types in terms of the divisional structure and components of the offices, which show different applications of philosophy, a consensus can still be formed on how and where professionals generally place themselves within the higher education landscape. This consensus is best summarized as five key characteristics that include “(a) theory-based practice, (b) adherence to ethical standards, (c) professional involvement, (d) advocacy for students, and (e) contributions to the educational process” (Creamer et al., 2001, p. 32). This generalization of student affairs professionals' work shows that no matter the function on campus, these professionals are a key component in today's higher education landscape.

Long (2012) brought forth the argument that these professionals are important to today’s college, and stated that "student affairs professionals could not have a significant impact on students' intellectual, psychological, or emotional growth without first understanding the motivations, abilities, and environments which drive, create and define students” (p. 5). People who work in the student affairs profession can argue that they impacted students as a whole because they began utilizing student development theories and learning theories to implement their work with students on college campuses and meet student needs. Student development can be defined as "being used to describe the student affairs educational philosophy of educating the 
whole student, including the intellectual, social, emotional, moral, and vocational development of college students” (Moore \& Upcraft, 1990, p. 6). Enough student development theories exist that they can be categorized; they are rooted in psychosocial development, development of social identities, cognitive and structural development, typologies and student learning, organizational approaches, campus environments, student success, emerging theoretical perspectives, and theoretical critiques (Schuh et al., 2010). This approach to theory, first introduced in the foundational document of the profession, the Student Personnel Point of View (ACPA, 1937), shows that student affairs has consistently utilized student development theory as the foundation of student development and the profession as a whole (Brown \& Barr, 1990; Miller \& Winston, 1991; Moore \& Upcraft, 1990).

Student affairs professionals not only utilize student development theories, but also "work in collaboration with faculty, participate actively in the learning process, and create curricular experiences that spur student development inside the classroom as well as outside” (Long, 2012, p. 5). This understanding of the student affairs profession's impact on colleges and students leads to the question of how this field got started.

Over time, since the inception and establishment of student affairs in the Student Personnel Point of View (ACPA, 1937), student affairs as a field "strives continuously to create learning outcomes that represent seamless opportunities for student learning” (Creamer, Winston, \& Miller, 2001, p. 4). Other documents that advocated for and developed the profession around the development of the whole student include The Student Learning Imperative (ACPA, 1994) and Learning Reconsidered (NASPA \& ACPA, 2004). These three documents serve as the foundation for, and guiding principles of, the whole profession. These documents also contributed to the evolution of student affairs by showing how, over time, the 
profession has shifted and grown. This is done through theory application, the division's roles on a campus, and adaptation to the ever-changing needs of students. It is also important to acknowledge that these documents do not limit a professional to a certain area or office within the college; rather, they establish generalized acknowledgement of the roles and impact of student affairs professionals on the college campus.

Student affairs professionals, according to Reynolds (2010), can be counselors who are professionally licensed, as well as non-licensed staff members who believe they have a purpose of helping others (p. 429). Within this role, "student affairs professionals possess and utilize helping skills to assist students dealing with behavioral, developmental, and emotional issues” (Reynolds, 2010, p. 431). Like the perception of being counselors, student affairs staff also view themselves as administrators on a college campus. This can include the performance of administrative tasks such as budgeting, contract writing, and staff oversight. A number of resources, handbooks, and practices share that these administrative tasks—among others, such as programming — are what is needed in order for student affairs professionals to provide student success outside the classroom (Schuh et al., 2010; Rogers, 1990; Rentz \& Zhang, 2011).

Student affairs administrators can arguably be considered most adaptive professionals on a college campus because they are not predefined to one specific office or role. Creamer et al. (2001) stated that "student affairs administrators must perform as educators, leaders, and managers ... (and) integrate these roles fully to meet the needs of students” (p. 5). This means that student affairs professionals are in a number of various roles and tasks based on campus needs, not simply the duties involved with one position. These various roles create the underlying foundation for the work of student affairs professionals. Although student affairs professionals must integrate a number of key roles, the population of students who attend 
college is ever changing. This has led student affairs professionals to invest in staff resources, make commitments to diversity, develop conflict resolution skills, understand assessment, develop relationships, and get involved in professional organizations (Barr, 1993).

If the field is constantly changing to meet the needs of students, and the research shows that the field can be fluid, then how do student affairs professionals operate effectively? Student affairs professionals wear a multitude of hats that help them be effective because they are able to utilize student development methods, practices, theories, and activities that educate and develop the whole student and apply all of those in different ways based on the needs of the college. This is done by recognizing a standardization of professional competencies for student affairs educators.

In 2010, ACPA and NASPA worked together to develop a set of core competencies expected of all members of the profession. In August 2015, after a review from the joint committee and feedback from membership, ten competencies were created to set the standards for the student affairs profession (NASPA, 2015). These ten competencies are:

1. Personal and Ethical Foundations

2. Values, Philosophy, and History

3. Assessment, Evaluation, and Research

4. Law, Policy, and Governance

5. Organizational and Human Resources

6. Leadership

7. Social Justice and Inclusion

8. Student Learning and Development

9. Technology 


\section{Advising and Supporting}

The joint committee explained that these competencies "lay out essential knowledge, skills, and dispositions expected of all Student Affairs educators” (ACPA \& NASPA, 2015, p. 7). The joint committee also alluded to the universal application of these competencies, as they can be applied to most areas that make up student affairs on the college campus. Since the standardization of the student affairs professional competency, the field has looked for ways to root its work, activities, and goals within these ten areas.

As an established profession, student affairs professionals are now shown to demonstrate adherence to certain standards through the Council for the Advancement of Standards in Higher Education (CAS, 2020), guidelines (ACPA, 1994; ACPA \& NASPA, 2004), and a holistic student approach philosophy (NASPA \& ACPA, 1994). The student affairs profession also consists of staff who consider themselves to be counselors, administrators, educators, and programmers. As the profession grows to meet the needs of students and the college campus, so does the necessity to continue to develop these professionals. Without continuous development, the field will become stagnant and cease to meet the needs for which student affairs was created. This fear of stagnation leads the researcher to look at emotionally intelligent leadership among student affairs professionals as a possible strategy for helping the profession evolve.

\section{Chapter Summary}

The literature review outlined in this chapter is designed to provide a foundation of information related to emotional intelligence, leadership, emotionally intelligent leadership, and the student affairs profession. This review of the current research recommends that further research is necessary to assess emotionally intelligent leadership scores as they are applied to student affairs professionals. 
At the time of this dissertation, no research was found that examines emotionally intelligent leadership on a specialized population outside of student leaders. Previously conducted research into EIL and student leaders by Shankman, Allen, and Haber-Curran (2015) reveals the existence of a viable instrument for testing and recording emotionally intelligent leadership scores. Because emotional intelligence continues to be a field of growth, the topic areas within EQ are constantly being studied and developed. This is the case for emotionally intelligent leadership and why its application to student affairs professionals is relevant.

These explorations into emotionally intelligent leadership, from its roots of emotional intelligence and leadership, developed a picture of how EIL is believed to be prevalent in the field of student affairs. The next chapter focuses on the methodology that was used in conducting the dissertation study of the prevalence of EIL scores within student affairs professionals. 


\section{CHAPTER III: METHODOLOGY}

\section{Introduction}

Chapter 3 focuses on the methodology for data collection and analysis to develop an understanding of the prevalence of EIL among student affairs professionals. Furthermore, this methodology guides the exploration of the research questions outlined in Chapter 1 for the purpose of evaluating EIL among student affairs professionals with different background characteristics. The study measures the prevalence of EIL scores through quantitative methods that evaluate, test, and interpret data collected from a sample of student affairs professionals who took the Emotionally Intelligent Leadership for Employees: Inventory (EILE-I) and responded to a series of background questions.

The adaptation of the EILE-I from the Emotionally Intelligent Leadership Student Inventory (EILS-I 2.0) is the first step in collecting data that measures student affairs professionals' scores within the concept of emotionally intelligent leadership. The instrument, coupled with background questions, creates quantitative data that is then analyzed utilizing quantitative methodology.

The instrument accomplishes the collection of data by asking participants 57 questions that are connected to the 19 capacities of emotionally intelligent leadership and three questions pertaining to their backgrounds. The 19 capacities are divided into the three facets of emotionally intelligent leadership—namely, consciousness of self, consciousness of others, and consciousness of context.

This chapter describes the methods used for collecting and analyzing the data. Specifically, this chapter describes the research design, selection of participants, instrument 
used for data collection, validity and reliability of the instrument and data, data collection timeline, and data analysis procedures of the overall dissertation study.

\section{Research Questions}

The research questions that apply to this dissertation study on EIL among student affairs professionals are:

1. How do student affairs professionals score on the EILE-I inventory in terms of emotionally intelligent leadership?

2. Do emotionally intelligent leadership scores differ by student affairs professionals based on their student affairs graduate program?

3. Do the scores of emotionally intelligent leadership differ based on the number of years a student affairs professional has been in the field?

4. Is there a relationship between emotionally intelligent leadership and background characteristics, such as self-identified gender and race, among student affairs professionals?

\section{Research Design}

This exploratory research utilizes a survey research design to maximize the opportunity for a significant number of reliable respondents. Survey research design is appropriate for this research because the method of data collection utilizes a survey to collect data on a series of Likert-type questions for data analysis. The data is collected by intentional outreach through the two largest trade organizations within the student affairs profession, which are the American College Personnel Association (ACPA) and Student Affairs Administrators in Higher Education (NASPA). A number of other outreach approaches for acquiring participants were also utilized, which are explained within this chapter. The sample includes self-identified student affairs 
professionals who reside and work within the United States and are 18 years of age or older, and who provide responses through the Qualtrics survey software that collected the information.

The Emotionally Intelligent Leadership for Employees: Inventory (EILE-I) instrument is based on the Emotionally Intelligent Leadership Student Inventory (EILS-I 2.0), which was validated by Miguel and Allen (2016). Miguel and Allen (2016) conducted two cross-validation studies that found the EILS-I 2.0 to be valid. The first Study found a confirmatory factor analysis with MPlus 7.1 utilizing a maximum likelihood estimation. The same study also showed a confirmatory factor analysis on the 19 factors as acceptable based on the SRMR .05 score and TLI .93 fit indices scores. The second study was evaluated to cross-examine the first study. This second study found that based on scale reliabilities of the 19 capacities, all had an alpha above .74. A factor loading analysis was conducted, which yielded a statistical significance of .001 among seven of the EILS-I 2.0 capacities or factors. This is less than recommended for factor loading, but based on the data, it was necessary to have more subjects to further validate these items in correlation with the other factors that were found to be valid. For a complete breakdown of all tests within each study, see Miguel and Allen (2016). Since the adapted EILE-I instrument has only minor changes from the EILS-I 2.0, it is assumed that the new instrument has the same construct validity as the original instrument. The new instrument also has face validity based on its similarities to the previous EILS-I 2.0 instrument. Face validity is viewed as "experts examine the content of the instrument and indicate the degree to which the items measure the criteria or objectives" (Shuh, p. 123, 2009). This is important as emotionally intelligent leadership is a survey focused on someone's internal processing of response. 


\section{Study Participants}

The study had 1,068 participants who were acquired through two forms of identification. The first utilized the professional associations Student Affairs Administrators in Higher Education (NASPA) and American College Personnel Association (ACPA), which are the largest trade organizations for Student Affairs professionals. The second population for this study is self-identified student affairs professionals, who received the study through email, social media, or from colleagues who had previously received the survey. This mix of outreach methods allowed for the maximum number of participants to take part in the study. Utilizing these methods also ensured the widest range of participation based on solicitations through the Student Affairs Administrators in Higher Education (NASPA) website, the American College Personnel Association (ACPA) database, various institutions, and through sharing the instrument. Participation was not limited to any particular area of student affairs work, type of institution, identification outside of being a student affairs professional within the United States, or other specialized background information.

\section{Instrumentation and Measures}

This study involved participants answering questions on the EILE-I instrument. The purpose of this type of measurement is to ascertain information from a sample of student affairs professionals who are representative of the larger population of this field. The results from the scores of the survey are used to measure prevalence of EIL among student affairs professionals.

This type of methodology is chosen because this study is one of the earliest documented studies of student affairs professionals in relation to emotionally intelligent leadership, which was explained in Chapter 1. To determine prevalence of EIL use among student affairs professionals, there is a need for consistent measurement. Since data collection utilized 
databases and various sampling methods, a cross-section of student affairs professionals participated, which in turn reflected the larger population of student affairs professionals.

This type of research design utilizing the EILE-I is chosen because there is little information around student affairs professionals and the prevalence of their use of emotionally intelligent leadership. The intent was to sample a wide range of participants within the field of student affairs to show variance in selected background data markers around EIL.

The instrument utilized is originally the EILS-I 2.0, which was implemented on student leaders, and has been adapted as the EILE-I for this study of student affairs professionals. This instrument is in the form of a questionnaire with Likert-type items on a 7-point scale. The scale of measurement for the 57 questions are: Never (1), Almost Never (2), Rarely (3), Sometimes (4), Usually (5), Almost Always (6), Always (7). The instrument includes background information, along with 57 questions related to the 19 capacities found within the three facets of emotionally intelligent leadership. These capacities are grouped based on the EILS-I 2.0 developed by Shankman, Allen, and Miguel (2015); which can be seen in Table 1. A copy of the instrument can be found in Appendix A.

\section{Table 1}

\section{Capacities by Consciousness}

\begin{tabular}{|c|c|c|}
\hline Consciousness of Self & Consciousness of Others & Consciousness of Context \\
\hline Emotional Self-Perception & Inspiring Others & Analyzing the Group \\
\hline Emotional Self-Control & Coaching Others & Assessing the Environment \\
\hline
\end{tabular}

Table Continues 


\begin{tabular}{|c|c|c|}
\hline Consciousness of Self & Consciousness of Others & Consciousness of Context \\
\hline Authenticity & Capitalizing on Differences & \\
\hline Healthy Self-Esteem & Developing Relationships & \\
\hline Flexibility & Building Teams & \\
\hline Optimism & Demonstrating Citizenship & \\
\hline Initiative & Managing Conflict & \\
& & \\
\hline Achievement & Facilitating Change & \\
\hline Displaying Empathy & & \\
& & \\
\end{tabular}

Note: A table that shows grouping of emotionally intelligent capacities by their consciousnesses within emotionally intelligent leadership.

These 57 questions are then tested and grouped by the study's capacities, which are each answered by questions in the inventory. The process then takes the data collected from the capacity scores by totaling the answers to the Likert-type questions associated with each capacity. The outcome of this process is found in Appendix B. The total scores for each capacity were then tallied to obtain an overall score within each of the three facets of emotionally intelligent leadership: consciousness of self, consciousness of others, and consciousness of context. These scores then have associated thresholds of Low, Somewhat Low, Medium, Somewhat High, and High for the purpose of measuring responses for each 
consciousness. Because the capacities are not equally distributed between the three consciousnesses (as displayed in Table 1), these scores were tallied based on the number of identified questions that correlate with the capacities for developing the thresholds of low, somewhat low, medium, somewhat high, and high. Score thresholds that are associated with each of the three consciousnesses are outlined in the table below. The thresholds outlined within this process can be viewed in Table 2.

Table 2

Consciousness Score Chart

\begin{tabular}{|l|l|l|}
\hline Consciousness of Self Score & & \\
\cline { 2 - 3 } & Low & $0-7$ \\
\cline { 2 - 3 } & $\begin{array}{l}\text { Somewhat } \\
\text { Low }\end{array}$ & $38-75$ \\
\cline { 2 - 3 } & $\begin{array}{l}\text { Medium } \\
\text { Sow }\end{array}$ & 76-113 \\
\cline { 2 - 3 } & $\begin{array}{l}\text { Somewhat } \\
\text { High }\end{array}$ & $114-151$ \\
\cline { 2 - 3 } & High & $152-189$ \\
\hline
\end{tabular}

Table Continues 


\begin{tabular}{|l|l|l|}
\hline Consciousness of Context Score & & \\
\cline { 2 - 4 } & Low & $0-4$ \\
\cline { 2 - 4 } & $\begin{array}{l}\text { Somewhat } \\
\text { Low }\end{array}$ & $5-8$ \\
\cline { 2 - 4 } & Medium & $9-12$ \\
\cline { 2 - 3 } & $\begin{array}{l}\text { Somewhat } \\
\text { High }\end{array}$ & $13-17$ \\
\cline { 2 - 3 } & High & $18-21$ \\
\hline
\end{tabular}

Note: A table showing the score thresholds based on individual scores on the EILE-I.

The instrument also utilized background variables to analyze the data to see if the variance of EIL scores is significantly different among student affairs professionals. The background variables utilized are gender (Male; Female; Non-binary), self-identified race (White; LatinX; African American; Asian; Native American; Multi-Race, Race Not Listed), graduate-level student affairs program (Counseling; Administrative; Policy; Research; Theory to Practice; Non Student Affairs Master’s Program; No Master’s Degree Obtained), and years working in student affairs, post-Master’s ( $0-5$ years; $6-10$ years; $11-15$ years; $16+$ years). These variables are analyzed against the variables within the EILE-I inventory.

Finally, it is important to note that two other background questions were asked, but were not utilized in the data analysis for this study. Those two questions were used to acknowledge a participant's understanding of EQ definitions, and to verify that they are a student affairs professional working within a higher education institution. These questions are as follows: 
1. Please acknowledge if you understand this definition of emotional intelligence as the subset of social intelligence that involves the ability to monitor one’s own and others' feelings and emotions, to discriminate among them and to use the information to guide one’s thinking and actions. (Mayer \& Salovey, 1990) (Yes/No)

2. Do you identify as 18 or older and a student affairs professional currently working within a higher education institution? (Yes/No)

\section{Validity and Reliability}

The content validity of the instrument is established through reviews of literature related to previous studies on emotionally intelligent leadership and through previous evaluation of the EILS-I 2.0 instrument (Miguel \& Allen, 2016). Construct validity was found to be acceptable based on the SRMR .05 score and TLI .93 score in the first study completed by Miguel and Allen (2016). It is based on this study that the instrument is considered valid. The instrument is also being empirically examined through an exploratory factor analysis of the questions and their relation to the capacities - and in turn, their relation to the three facets of emotionally intelligent leadership.

The EILS-I 2.0 was studied by Miguel and Allen (2016) and was found to be reliable based on application of the scale reliability method to all 19 capacities scoring an alpha of .74 or above. The reliability characteristics of the 57-question survey on emotionally intelligent leadership within the EILE-I instrument utilized a Cronbach Alpha reliability procedure to examine the internal consistency of the capacities. Cronbach Alpha is used in calculating the reliability of items, which in this case are the questions within the instrument (Fraenkel et al., 2011). Reliability is examined and described in more detail within the data analysis section below. 


\section{Distribution Procedures}

As discussed earlier, this study utilized an ACPA request for participation and NASPA leadership to find qualified participants. This was accomplished through two different procedures for each organization. ACPA approved communication, found in Appendix C, that was submitted through their online request for dissertation support webpage. Other information that was provided for approval was verification of IRB approval and a series of vetting questions. After approval, ACPA distributed the survey among organization members that met the criteria for distribution. NASPA did not respond to requests for distribution to its membership. However, the researcher reached out via email to NASPA Knowledge Community Chairs and Regional Chairs that were listed on the NASPA website to request distribution of the survey. Communication utilized for this outreach can be found in Appendix B.

A number of other distribution strategies were also utilized by sharing the instrument through various institutional contacts, social media, and through participants who sent the instrument to others. This was done through multiple methods. Method one was simply asking colleagues to take the survey and then share the instrument with fellow colleagues. Method two utilized distribution of the instrument via social media outlets, which included Facebook, connected to the student affairs profession, as well as the researchers' own contacts to take the survey and to share it. The third distribution method was by asking those who completed the survey to share it with colleagues or to share colleagues’ email addresses with the researcher; the researcher then sent requests for those individuals to participate. This distribution yielded 1,068 participants; this number met the planned threshold requirement within the survey, which was set at 570 participants. 
The instrument included an agreement letter that explains IRB approval, the study's timeline, important definitions needed for participants to know prior to starting, the scope of the instrument, the confidentiality of the instrument, the instrument itself, and a request or function to forward the instrument anonymously to colleagues (Appendix D). Informed consent, which is also part of Qualtrics, was accepted prior to the start of the survey. An example of an Informed Consent statement can be found in Appendix E.

\section{Data Collection and Timeline}

The instrument, along with all pertinent information explained above, was distributed after receiving dissertation committee approval, IRB approval, and distribution approval by ACPA. The survey remained active for one month and yielded 1,068 participants through all distribution methods. Reminders were not necessary in order to reach a desired number of participants.

\section{Data Analysis Procedures}

Upon completion of the data collection procedures, the following analyses were completed: (a) descriptive statistical analysis of background variables and instrument items; (b) exploratory factor analysis of the survey components in relation to the capacities and facets of emotionally intelligent leadership; (c) internal consistency (Cronbach Alpha) reliability analyses of subscales and total scores of the instrument; (d) analysis of variance among the instruments' scores and collected background information; and (e) Factorial ANOVA analyses to examine the relationship between EIL use and the background characteristics of the respondents.

\section{Descriptive Statistics}

Descriptive statistics are used to represent the sample of respondents who completed the instrument. The descriptive statistics are also used to define the variables, as well as background 
information about the respondents. The statistics used were frequencies for the background questions and mean, mode, range of scores, and standard deviation for the EIL scores by background characteristics.

\section{Exploratory Factor Analysis}

Prior to conducting an exploratory factor analysis, a correlation matrix was run to evaluate the inter-item correlation of the 57 items. After completion, all of the items underwent an exploratory factor analysis that was conducted on the Likert-type items to assess the underlying constructs of the items.

Since the study is exploratory in nature, a number of considerations were made for the factor analyses of the questions and their measurement of the capacities. An exploratory factor analysis was conducted to see if three scales—representing the three facets of emotionally intelligent leadership, which are consciousness of self, consciousness of others, and consciousness of context—emerged. Content validity was established previously by Allen and Miguel (2016).

A set of general decisions were made when interpreting results of the factor analyses. In order for questions to be considered and categorized, the following criteria must have been met: First, the questions within the instrument must have a minimum of 10 respondents per question. Second, a magnitude of the loading on a factor had to be equal to or greater than .33. Third, each question that was related to the given capacity had to primarily load on a single factor. No questions were to be double loaded. The capacities were also run through the same procedures for results to be considered for analyses of scores within the three facets of EIL. 


\section{Reliability Analysis}

The Cronbach’s alpha reliability procedure was used to examine the internal consistency of the capacities. In this study, analysis was factored based on the scores for the questions and the capacities to understand the prevalence of scores among student affairs professionals in regard to their emotionally intelligent leadership.

\section{Analysis of Variance}

In order to make comparisons among the various background variables in relation to the instrument in data analysis, a variety of statistical comparisons were completed using t-test and ANOVA procedures. This is done with the background variables of individuals' selfidentifications of their gender, level of education, and years of experience. These background variables are used within the facets of emotionally intelligent leadership, which include consciousness of self, consciousness of others, and consciousness of context.

In order to assess how EIL scores differ by gender and race, a factorial ANOVA was conducted. The purpose of a factorial ANOVA was to highlight if differences in scores exist as a function of both gender and race.

\section{Chapter Summary}

This chapter provided an overview of the research methodology that includes research design, target population and sampling procedures, instrumentation and measures, data collection procedures, and a description of the various statistical procedures that were utilized to analyze the data. 


\section{CHAPTER IV: SUMMARY OF RESULTS}

\section{Introduction}

Chapter 4 describes the results of the study. Data were collected using the Emotionally Intelligent Leadership Employee Inventory (EILE-I) for understanding how prevalent the use of emotionally intelligent leadership (EIL) is among student affairs professionals. Previous studies in the field of student affairs have utilized emotional intelligence and leadership separately to understand student affairs professionals and their work. Prior to this study being conducted, no studies were found to have evaluated the prevalence of emotionally intelligent leadership scores among student affairs professionals. This makes this exploratory study unique, as well as identifying it as one of the pioneering studies into this topic within the profession. The study was developed to understand EIL among student affairs professionals because it is believed that EIL can be an area that can further develop stronger professionals and elevate the work done within this profession.

Specifically, this study focused on understanding the prevalence of emotionally intelligent leadership among student affairs professionals by evaluating overall scores and background characteristics through the utilization of the Emotionally Intelligent Leadership for Employees: Inventory (EILE-I). The adaptation of the EILE-I from the Emotionally Intelligent Leadership for Students: Inventory (EILS-I 2.0) is the first step in collecting data that measures Student Affairs professionals’ prevalence of use of the concepts of emotionally intelligent leadership. The instrument, coupled with background questions, created quantitative data that were then analyzed using quantitative methodology.

Furthermore, this summary of results presents the outcomes of running a series of tests, which were introduced in the methodology section, on student affairs professionals within the 
United States who are 18 years old or older. These statistical tests include descriptive statistics, exploratory factor analysis, reliability analysis one-way, and factorial ANOVA. These tests were run with a participation base of 1,068 Student Affairs professionals, 863 of which completed the EILE-I.

The results from these responses, which were analyzed through the statistical tests mentioned above, are presented within this chapter. The chapter is organized into the following sections: (a) Summary of Participant Survey Sample; (b) Descriptive Statistics for the Various Demographic Variables That Were Used as Independent and Dependent Variables; (c) Summary of Factor Analysis for the Various Capacities of the Study; (d) Summary of the Reliability Analysis of the Capacities and Consciousnesses; and (e) Analysis Pertinent to the Major Research Questions. The first section explains the data set of student affairs professionals utilized for this study. Each additional section will share the outcomes of the tests that were conducted on this sample and explained in the Methodology chapter.

\section{Summary of Participant Survey Sample}

Participants in this study were student affairs professionals who worked at an institution of higher education within the United States. All participants were 18 years of age or older. 1,068 student affairs professionals participated, 863 of whom completed the EILE-I. This section focuses on understanding the solicitation of participants, the participation sample, and how participants were categorized for the various tests.

\section{Solicitation of Participants}

To secure participants for the study, a number of recruitment methods were utilized. The first method utilized databases available through the American College Personnel Association (ACPA) and the Student Affairs Professionals in Higher Education (NASPA) organization. 
These two were selected because both organizations are the largest trade organizations for student affairs professionals. ACPA approved the solicitation of survey participation to all members who met the criteria of being student affairs professionals working at an institution of higher education within the United States (see Appendix C). ACPA did not release the number of individuals who received the instrument, but data from their website show a membership of 7,500. A majority of ACPA members are found within the United States and are considered student affairs professionals. NASPA did not respond to a request for solicitation, and therefore, the researcher reached out to all Knowledge Community and Regional Chairs to solicit participation through their established means of communication. Knowledge communities, according to NASPA, are "member-driven networks that empower [individuals] to explore key topics, professional functions, and personal identities alongside other student affairs educators” (NASPA, 2021). A region is how NASPA utilizes smaller communities within a geographic location, and there are seven that are identified within the association. This led to direct outreach to 44 knowledge communities and regions that were solicited with varying results and communication methods that included emails, newsletter articles on behalf of the researcher, and posts on social media accounts. No data were collected on how often or how many solicitations occurred after the initial outreach to the Regional Chairs and Knowledge Community leaders.

The second solicitation of participants came from self-identified student affairs professionals, who received the invitation to participate in the study through email or social media. The primary social media solicitation occurred through Facebook, in the form of direct messaging on the pages of student affairs groups, messaging through Facebook Messenger, or 
individual outreach from the researcher and/or colleagues within the field of student affairs (see Appendix D).

The third means of solicitation for participants occurred from individuals who completed the inventory and shared it with other colleagues directly. Participants were also solicited by individuals who took the instrument and disclosed email contact information for the researcher to directly reach out to other potential participants. These methods of solicitation yielded 1,068 participants over approximately one month (see Appendix C).

\section{Participant Sample}

Upon the closure of the instrument, 1,068 individuals who took the survey declared that they were eligible by being student affairs professionals working at institutions of higher education within the United States. All participants also declared that they were 18 years of age or older. Of the 1,068 participants, 205 did not complete any questions on the instrument and therefore were removed from the participant sample. The data utilized in this study were collected from the remaining 863 participants. Some questions were not answered or were skipped by a small number of participants in the survey response process. The researcher used a statistical method for replacing missing data to preserve the mean of responses; missing values were replaced with the mean for individual questions that participants did not respond to.

Utilizing various demographic data provided, the 863 participants can be further broken down into categories of gender, student affairs graduate program, years working in the profession, and racial identity. Based on the self-reported data, there were 259 men, 586 women, and 18 individuals who identified as non-binary. Participants also identified their graduate-level student affairs program as follows: 137 for counseling programs, 234 for administrative programs, 18 in policy programs, 155 in non-student affairs master’s programs, 
and 43 who did not have a master's degree. Although participants may have had terminal degrees, terminal degree data collection did not occur and was not a variable considered within this study. In a review of the demographic data in relation to years of service in the student affairs profession, it was revealed that there were 269 participants who had $0-5$ years of work experience, 204 who had 6-10 years, 179 who had 11-15 years, and 211 who had 16 or more years in the field.

Finally, participants identified themselves based on their racial identity categories. This yielded 644 participants who identified as White, 91 identified as Black or African American, 55 identified as Latinx, 7 identified as American Indian or Alaska Native, 10 identified as Asian, 46 identified as Mixed Race, and 9 who identified as another racial identity. Due to small numbers of participants who identified as American Indian or Alaska Native, Asian, Mixed Race and Race Not Listed, these results were combined into a category labeled "Another Racial Identity.” Overall, these results contribute new demographic data about racial categories, as 644 participants identified as White, 91 identified as Black or African American, 55 identified as Latinx, and 72 identified as Another Racial Identity.

\section{Summary of Descriptive Statistics for EILE-I Instrument Items}

Descriptive statistics were computed for the survey instrument used in the study. See Table 3, which includes the means and standard deviation for each item of the survey instrument. 


\section{Table 3}

Summary of Descriptive Statistics for EILE-I Instrument Items

\begin{tabular}{|c|c|c|}
\hline \multirow[t]{2}{*}{$\begin{array}{l}\text { Summary of Descriptive Statistics for Instrument Items } \\
\text { (n=863) } \\
\text { Range of Scores } \\
\text { 1-Never } \\
\text { 2-Almost Never } \\
\text { 3-Rarely } \\
\text { 4-Sometimes } \\
\text { 5-Usually } \\
\text { 6-Almost Always } \\
\text { 7-Always }\end{array}$} & & \\
\hline & Mean & SD \\
\hline Q1. I recognize how situations influence my emotions. & 5.66 & 0.80 \\
\hline Q2. I stay calm in challenging situations. & 5.57 & 0.76 \\
\hline Q3. I am honest about my intentions. & 6.13 & 0.80 \\
\hline Q4. I believe in my skills. & 5.42 & 0.93 \\
\hline Q5. I am open to change. & 5.51 & 0.86 \\
\hline Q6. I present a positive outlook. & 5.63 & 0.85 \\
\hline Q7. I act before someone tells me to. & 5.18 & 0.88 \\
\hline
\end{tabular}

Table Continues 


\begin{tabular}{|l|r|r|}
\hline & \multicolumn{1}{|l|}{ Mean } & \multicolumn{1}{l|}{ SD } \\
\hline Q8. I establish personal standards for myself. & 6.18 & 0.94 \\
\hline Q9. I place a high value on the feelings of others. & 5.80 & 1.00 \\
\hline Q10. I communicate an exciting vision. & 5.19 & 0.99 \\
\hline Q11. I help others realize their potential. & 5.63 & 0.88 \\
\hline Q12. I demonstrate an appreciation for cultural diversity. & 6.08 & 0.89 \\
\hline Q13. I build relationships with ease. & 5.62 & 0.96 \\
\hline Q14. I fulfill my responsibilities to others. & 6.25 & 0.68 \\
\hline Q15. I emphasize team goals. & 5.81 & 0.90 \\
\hline Q16. I address difficult situations effectively. & 5.34 & 0.82 \\
\hline Q17. I promote innovative thinking. & 5.55 & 0.98 \\
\hline Q18. I respond effectively to the group. & & 0.73 \\
\hline Q19. I intentionally alter my approach to leadership to meet the & & \\
\hline
\end{tabular}

Table Continues 


\begin{tabular}{|l|r|r|}
\hline & \multicolumn{1}{|c|}{ Mean } & \multicolumn{1}{l|}{ SD } \\
\hline Q20. I recognize how my emotions influence my actions. & 5.68 & 0.89 \\
\hline Q21. I remain calm in stressful situations. & 5.61 & 0.79 \\
\hline Q22. I present my motives in an honest manner. & 6.04 & 0.85 \\
\hline Q23. I demonstrate confidence. & 5.54 & 0.88 \\
\hline Q24. I adapt my behavior to changing situations. & 5.78 & 0.82 \\
\hline Q25. I foster a sense of hope. & 5.65 & 0.91 \\
\hline Q26. I take advantage of opportunities that come my way. & 5.58 & 0.93 \\
\hline Q27. I strive to improve based on my personal standard. & 6.07 & 0.89 \\
\hline Q28. I show concerns for the feelings of others. & 6.03 & 0.88 \\
\hline Q29. I inspire commitment to the group's vision. & 5.59 & 0.91 \\
\hline Q30. I help others enhance their abilities. & & \\
\hline
\end{tabular}

Table Continues 


\begin{tabular}{|l|r|r|}
\hline & \multicolumn{1}{|c|}{ Mean } & \multicolumn{1}{l|}{ SD } \\
\hline Q32. I create connections with others easily. & 5.66 & 0.95 \\
\hline Q33. I build strong teams. & 5.56 & 0.85 \\
\hline Q34. I follow through on my commitments to the group. & 6.24 & 0.72 \\
\hline Q35. I address conflict with individuals effectively. & 5.08 & 0.95 \\
\hline Q36. I seek to improve upon the status quo when future gains can be & 5.72 & 0.91 \\
\hline made. & 5.54 & 0.90 \\
\hline Q37. I follow the established rules of the group. & 5.73 & 0.86 \\
\hline Q38. I adapt my approach to leadership based on the situation. & 5.70 & 0.86 \\
\hline Q39. I recognize how my emotions affect me. & 5.79 & 0.73 \\
\hline Q40. I maintain composure. & & \\
\hline Q41. I act genuinely. & & \\
\hline & & \\
\hline
\end{tabular}

Table Continues 


\begin{tabular}{|l|r|r|}
\hline & \multicolumn{1}{|c|}{ Mean } & \multicolumn{1}{l|}{ SD } \\
\hline Q44. I communicate a positive outlook. & 5.73 & 0.85 \\
\hline Q45. I take advantage of new opportunities. & 5.61 & 0.91 \\
\hline Q46. I establish high personal standards for myself. & 6.25 & 0.87 \\
\hline Q47. I respond to the emotional needs of others. & 5.71 & 0.89 \\
\hline Q48. I inspire commitment to the group's mission. & 5.57 & 0.86 \\
\hline Q49. I create opportunities for others to learn. & 5.77 & 0.84 \\
\hline Q50. I appreciate individual differences. & 6.22 & 0.74 \\
\hline Q51. I build a strong network of relationships. & 5.74 & 0.90 \\
\hline Q52. I work well with others towards a shared goal. & 5.42 & 0.01 \\
\hline Q53. I recognize a need to give to the group. & 5.95 & 0.85 \\
\hline Q54. I manage conflict effectively. & 5.53 & 0.85 \\
\hline Q55. I consider ways to improve the group's performance through & & 0.87 \\
\hline
\end{tabular}

Note: A table that shows the mean and standard deviation for descriptive statistics related to the 57 questions in the EILE-I. 
Table 3 shows what the mean scores and standard deviation of 863 participants' responses were to the questions on the EILE-I survey. Although scores range from "Never” (1) to "Always” (7), the mean scores for all participants, for all questions, were 5.08 at the lowest and 6.30 at the highest. This means that in regards to emotionally intelligent leadership, the mean for student affairs professionals is between "Usually" (5) and "Almost Always" (6). It can then be concluded, based on this data, that student affairs professionals rate themselves to be high in EIL.

An evaluation of the top five scores and lowest five scores on the survey also leads to some conclusions. The five statements that generated the highest scores are: I act genuinely (Q41), I fulfill my responsibilities (Q14), I establish high standards for myself (Q46), I follow through on my commitments to the group (Q34), and I appreciate individual differences (Q50). The five lowest scores on the EILE-I survey came from the following statements: I address conflict with individuals effectively (Q35), I act before someone tells me to (Q7), I communicate an exciting vision (Q10), I manage conflict effectively (Q54), and I address difficult situations effectively (Q16). The responses generated from the statements previously mentioned show that student affairs professionals score highest within EIL on questions pertaining to self-evaluation. In regard to lowest scores, student affairs professionals score themselves weakest on questions related to conflict and pre-emptive response to situations. Although these statements generated the highest and lowest scores, student affairs professionals still averaged high scores on all questions within the EIL survey.

Table 3 also shares the standard deviation (SD) of the 863 responses for each question. Standard deviation measures the variation or spread of response scores among participants. The higher the standard deviation, the more variation in responses by participants compared to a 
lower standard deviation, meaning the more similar answers that were recorded by participants. The standard deviation for the responses of student affairs participants ranged from .68 to 1.01. This means that student affairs professionals who took the survey responded with answers that were more similar to each other than different. The conclusion can be drawn based on this that student affairs professionals are more similar in their EIL characteristics than different, as a collective.

\section{Summary of Results of Factor Analysis}

Prior to conducting analyses related to the primary research questions in this study, a series of factor analysis procedures were completed. Factor analysis is a quantitative measurement used to model the interrelationships among items. In the original study among college students, 19 capacities (or factors) were found among three consciousnesses that made up the foundation of emotionally intelligent leadership. In this study, factor analysis is being used to evaluate the same questions among student affairs professionals. This will evaluate if the same number of capacities exist within the group being studied, based on the responses to statements. It will also help draw the conclusion about whether statements from the instrument can be utilized in the same capacities as the EILS:I 2.0 or if they align differently. The results of these analyses, statements within the survey, and procedures for these variables are reported in the following sections.

A correlation matrix was first run on the 57 questions within the instrument. A correlation matrix is used to measure relationships between any paired survey questions. Correlations within a correlation matrix rate answers based on a scale of 0.0 to 1.0. Responses are considered to have a strong correlation if they score above .7, moderate if the score is between .5 and .7, and weak if the score is .4 or below. This helps to eliminate or keep questions 
that are considered relevant for the study. It also helps align the questions to the appropriate capacity and consciousness for further analysis. The purpose of running the correlation matrix for this study was to remove items that did not have at least one inter-correlation of .4, which removed questions Q7, Q31, and Q37.

The researcher then ran an exploratory factor analysis on the remaining 54 items. Using both Scree Plot and Eigen Value as diagnostics, a 12-factor solution seemed to be the best fit because it explains most closely the variance within the factors identified. The researcher then rotated the solution using varimax in order to evaluate the correlation of survey items within each of the 12 factors (capacities). The researcher then examined the loading outcome of this analysis and removed items that did not load at all, or cross loaded below .4. A question that did not load means it did not have a relationship to any of the other questions that remained in the analysis. A cross load means that the question is loaded to multiple factors, and a correlation to which factor the question is strongest with cannot be deduced. This means that the question itself is considered weak within all 12 factors (capacities) and therefore would not be a question to utilize in this study. Like the correlation matrix, answers are on a correlation scale of 0.0 to 1.0. Responses are considered to have a strong correlation if they score above .7, moderate if between .5 and .7 , and weak if .4 or below. If a question did cross load and it could be placed reasonably with a given factor, then the question's correlation with the higher score would place that question within that given factor. If this did not occur, then the question would be removed. Thus the questions that cross loaded at .4 or below and/or did not load with any factors were removed; this eliminated Q5, Q10, Q18, Q43, Q50, Q52, Q53, Q55, and Q56. Thus, 45 questions were left for the remainder of the research. The researcher then reran the factor analysis. The 12 factor solution still held and accounted for $69 \%$ of the variance, which means 
that the data collected can be explained with the 12 capacities. If more factors were considered, the amount of data that could be explained would be negligible. The researcher rotated the solution with varimax, which verifies both the loading of questions within the 12 factors, and that a correlation exists between the questions. The final factor loading that used the 45 remaining questions can be viewed in Table 4.

\section{Table 4}

Rotated Factor Matrix for Capacities

\begin{tabular}{|l|l|}
\hline Rotated Factor Matrix & Factor \\
\hline & \\
\hline Capacity 1: Development of Others & Factor 1 \\
\hline Q11. I help others realize their potential. & 0.677 \\
\hline Q12. I demonstrate an appreciation for cultural diversity. & 0.398 \\
\hline Q15. I emphasize team goals. & 0.453 \\
\hline Q17. I promote innovative thinking. & 0.429 \\
\hline Q29. I inspire commitment to the group’s vision. & 0.561 \\
\hline Q30. I help others enhance their abilities. & 0.717 \\
\hline
\end{tabular}

Table Continues 


\begin{tabular}{|l|l|}
\hline Capacity 1: Development of Others & Factor 1 \\
\hline Q33. I build strong teams. & 0.522 \\
\hline Q48. I inspire commitment to the group's mission. & 0.548 \\
\hline Q49. I create opportunities for others to learn. & 0.645 \\
\hline Q57. I learn about what it takes to succeed in different settings. & 0.332 \\
\hline Capacity 2: Self-Oriented & Factor 2 \\
\hline Q4. I believe in my skills. & 0.469 \\
\hline Q16. I address difficult situations effectively. & 0.557 \\
\hline Q23. I demonstrate confidence. & 0.475 \\
\hline Q35. I address conflict with individuals effectively. & 0.687 \\
\hline Q42. I remain confident when facing challenges. & 0.519 \\
\hline Q54. I manage conflict effectively. & 0.68 \\
\hline Capacity 3: Developing Relationships & 0.587 \\
\hline Q13. I build relationships with ease. & 0.804 \\
\hline Q32. I create connections with others easily. & \\
\hline Q51. I build a strong network of relationships. & \\
\hline
\end{tabular}

Table Continues 


\begin{tabular}{|l|l|}
\hline Capacity 4: Optimism & Factor 4 \\
\hline Q6. I present a positive outlook. & 0.68 \\
\hline Q25. I foster a sense of hope. & 0.612 \\
\hline Q44. I communicate a positive outlook. & 0.734 \\
\hline Capacity 5: Initiative & Factor 5 \\
\hline Q2. I stay calm in challenging situations. & 0.739 \\
\hline Q21. I remain calm in stressful situations. & 0.776 \\
\hline Q40. I maintain composure. & 0.608 \\
\hline Capacity 6: Displaying Empathy & Factor $\mathbf{6}$ \\
\hline Q9. I place a high value on the feelings of others. & 0.695 \\
\hline Q28. I show concerns for the feelings of others. & 0.728 \\
\hline Q47. I respond to the emotional needs of others. & 0.618 \\
\hline Capacity 7: Emotional Self-Perception & 0.567 \\
\hline Q1. I recognize how situations influence my emotions. & 0.771 \\
\hline Q20. I recognize how my emotions influence my actions. & \\
\hline Q39. I recognize how my emotions affect me. & \\
\hline
\end{tabular}

Table Continues 


\begin{tabular}{|l|l|}
\hline Capacity 8: Authenticity & Factor 8 \\
\hline Q3. I am honest about my intentions. & 0.746 \\
\hline Q22. I present my motives in an honest manner. & 0.752 \\
\hline Q41. I act genuinely. & 0.508 \\
\hline Capacity 9: Achievement & Factor 9 \\
\hline Q8. I establish personal standards for myself. & 0.659 \\
\hline Q27. I strive to improve based on my personal standard. & 0.629 \\
\hline Q46. I establish high personal standards for myself. & 0.747 \\
\hline Capacity 10: Standards of Oneself & Factor $\mathbf{1 0}$ \\
\hline Q26. I take advantage of opportunities that come my way. & 0.707 \\
\hline Q36. I seek to improve upon the status quo when future gains can be made. & 0.357 \\
\hline Q45. I take advantage of new opportunities. & 0.79 \\
\hline Capacity 11: Adaptable to Situations & 0.660 \\
\hline Q19. I intentionally alter my approach to leadership to meet the needs of the $\mathbf{1 1}$ \\
\hline situation. & 0.602 \\
\hline Q24. I adapt my behavior to changing situations. & \\
\hline
\end{tabular}




\begin{tabular}{|l|l|}
\hline Capacity 11: Adaptable to Situations & Factor $\mathbf{1 1}$ \\
\hline Q38. I adapt my approach to leadership based on the situation. & 0.603 \\
\hline Capacity 12: Commitment to Others & Factor $\mathbf{1 2}$ \\
\hline Q14. I fulfill my responsibilities to others. & 0.677 \\
\hline Q34. I follow through on my commitments to the group. & 0.797 \\
\hline
\end{tabular}

Note: A table that shows the strength of correlation with the 45 remaining questions, categorized into the 12 capacities. The term “factor" is used to categorize which factor (capacity) the questions most correlated with based on the factor analysis.

\section{Summary of Reliability Analysis}

The next analysis that was conducted is reliability analysis. A reliability analysis is utilized in this study to evaluate if the questions were appropriately loaded to each previously determined capacity (factor) and consciousness. This is done by analyzing Cronbach’s alpha among each of the capacities.

Cronbach’s alpha measures the internal consistency reliability coefficients for a given data set in comparison to a group. In this study, Cronbach’s alpha measures the questions that were correlated utilizing factor analysis within each of the 12 capacities. See the previous section, Summary of Results from Factor Analyses, and Table 4 to understand which questions were aligned with which capacities. The reliability analysis to determine Cronbach’s alpha is also utilized for measuring the 12 capacities among the 3 consciousnesses. The closer to 1.0 the Cronbach’s alpha is, the stronger the correlation. A Cronbach's alpha score of higher than .7 is considered strong, while a .5 to .7 is considered moderately strong. 
Therefore, the procedure measured the reliability of the aggregation of questions determined during the factor analysis completed for all variables. Once the correlation coefficient was determined for a factor subscale, it was compared against the Cronbach's alpha reliability coefficient for each item. This was done by placing each question into one of the 12 capacities with which the questions aligned. See Table 4 to note the factor analysis for each question in relation to its correlation within each capacity. The 12 capacities were then run through a reliability analysis where Cronbach's alpha reliability was established. This produced scores between .635 and .884 , which means that the questions that were loaded into each capacity had a moderately strong to strong correlation to each other and were loaded into the appropriate capacity. Table 5 shows what each capacity Cronbach's alpha was when correlation between questions was evaluated for strength in the capacities.

To determine the Cronbach’s alpha for the consciousnesses, the same procedure was utilized with grouping capacities and running a reliability analysis. The reliability analysis produced Cronbach’s alpha scores of .789 in Consciousness of Self, .635 in Consciousness of Others, and .792 in Consciousness of Context. This makes all the capacity alignments for each of the consciousnesses have a moderately high Cronbach's alpha, and therefore, appropriately aligns the capacities within the consciousnesses. It is important to note that based on the factor analysis data reported in the previous section, only one capacity fit within the Consciousness of Context. Due to a moderately high Cronbach’s alpha score of .792, it is determined that the capacity, Adaptable to Situations, is strong enough to be calculated on its own for the purpose of understanding student affairs professionals' scores within Consciousness of Context. A summary of the Cronbach's alpha reliability coefficients for capacities and consciousnesses can 
be found in Table 5 . Table 5 also includes the alignment between questions and capacities based on the previously reported factor analysis.

Table 5

Summary of Cronbach's Alpha Reliability Coefficient ( $N=863)$.

\begin{tabular}{|l|l|l|l|l|}
\hline $\begin{array}{l}\text { Capacity } \\
\text { Number }\end{array}$ & $\begin{array}{l}\text { Capacity New } \\
\text { Name }\end{array}$ & Consciousness & Related Questions & $\begin{array}{l}\text { Cronbach's } \\
\text { Alpha }\end{array}$ \\
\hline 1 & $\begin{array}{l}\text { Development of } \\
\text { Others }\end{array}$ & Other & $\begin{array}{l}\text { Q11, Q12, Q15, Q17, } \\
\text { Q29, Q30, Q33, Q48, } \\
\text { Q49, Q57 }\end{array}$ & 0.884 \\
\hline 2 & Self-Oriented & Self & $\begin{array}{l}\text { Q4, Q16, Q23, Q35, } \\
\text { Q42, Q54 }\end{array}$ & 0.848 \\
\hline 3 & $\begin{array}{l}\text { Developing } \\
\text { Relationships }\end{array}$ & Other & Q13, Q32, Q51 & 0.862 \\
\hline 4 & $\begin{array}{l}\text { Optimism } \\
\text { Initiative }\end{array}$ & Self & Q6, Q25, Q44 & 0.827 \\
\hline 6 & $\begin{array}{l}\text { Displaying } \\
\text { Empathy }\end{array}$ & Self & Q2, Q21, Q40 & 0.809 \\
\hline 7 & Authenticity & Self & Q3, Q22, Q41 & 0.793 \\
\hline 8 & $\begin{array}{l}\text { Emotional Self- } \\
\text { Perception }\end{array}$ & Self & Q1, Q20, Q39 & 0.798 \\
\hline 9 & Achievement & Self & Q8, Q27, Q46 & 0.818 \\
\hline 10 & Oneself & Self & Q26, Q36, Q45 & 0.762 \\
\hline
\end{tabular}

Table Continues 


\begin{tabular}{|c|c|c|c|c|}
\hline $\begin{array}{l}\text { Capacity } \\
\text { Number }\end{array}$ & $\begin{array}{l}\text { Capacity New } \\
\text { Name }\end{array}$ & Consciousness & Related Questions & $\begin{array}{l}\text { Cronbach's } \\
\text { Alpha }\end{array}$ \\
\hline 11 & $\begin{array}{l}\text { Adaptable to } \\
\text { Situations }\end{array}$ & Context & Q19, Q24, Q38 & 0.792 \\
\hline 12 & $\begin{array}{l}\text { Commitment to } \\
\text { Others }\end{array}$ & Other & Q14, Q34 & 0.796 \\
\hline $\begin{array}{l}\text { Consciousness } \\
\text { Number }\end{array}$ & Consciousness & & Related Capacities & $\begin{array}{l}\text { Cronbach } \\
\text { Alpha }\end{array}$ \\
\hline 1 & $\begin{array}{l}\text { Consciousness of } \\
\text { Self }\end{array}$ & & $2,4,5,6,7,8,9,10$ & 0.789 \\
\hline 2 & $\begin{array}{l}\text { Consciousness of } \\
\text { Others }\end{array}$ & & $1,3,12$ & 0.635 \\
\hline 3 & $\begin{array}{l}\text { Consciousness of } \\
\text { Context }\end{array}$ & & 11 & 0.792 \\
\hline
\end{tabular}

Note: A table that shows the reliability analysis through Cronbach's alpha scores of utilizing an organization of questions, based on a factor analysis, into 12 capacities and three consciousnesses.

\section{Results of the Analysis for Research Questions}

There were four primary research questions addressed in this study. The first question looked at how student affairs professionals scored on the EILE-I inventory in terms of emotionally intelligent leadership. The other three questions addressed student affairs professionals' scores on the EILE-I inventory based on demographics. These demographics included gender, racial identity categories, years in the profession, and student affairs 
educational background. The following section presents the results from the analysis completed on each research question.

\section{Research Question 1}

How do student affairs professionals score on the EILE-I inventory in terms of emotionally intelligent leadership?

To answer this question, descriptive statistics were utilized. Descriptive statistics—in this case, the minimum, maximum, and mean — help to understand the overall scores of student affairs professionals. To answer Research Question 1, the 863 participants were evaluated based on the three consciousnesses. Table 6 shows the outcome of the analysis of the overall scores within each of the three consciousnesses. The table includes the minimum and maximum scores of a participant in each consciousness, as well as the mean or average score of all 863 participants by consciousness. It is important to note that each question used a 7-point response scale, where the responses and corresponding scores were Never (1), Almost Never (2), Rarely (3), Sometimes (4), Usually (5), Almost Always (6), and Always (7).

Score thresholds were also used to determine the prevalence of emotionally intelligent leadership among student affairs professionals. The possible scores of EIL were broken down into the categories of Low, Somewhat Low, Medium, Somewhat High, and High. Because many questions were different for each consciousness, score thresholds for the various consciousnesses also varied. These thresholds, based on the number of questions, were as follows for each consciousness: Consciousness of Self scores were labeled as Low (0-37), Somewhat Low (38-75), Medium (76-113), Somewhat High (114-151), and High (152-189). The score threshold for Consciousness of Others was Low (0-19), Somewhat Low (20-39), Medium (40-59), Somewhat High (60-79), and High (80-98). Consciousness of Context 
threshold scores were Low (0-4), Somewhat Low (5-8), Medium (9-12), Somewhat High (1317), and High (18-21). See Table 7 for the scoring chart of the thresholds by consciousness.

\section{Table 6}

Descriptive Statistics for Total Consciousness Score

\begin{tabular}{|l|l|l|l|l|}
\hline \multicolumn{2}{|l|}{ Descriptive Statistics for Total Consciousness Score } & Minimum & Maximum & Mean \\
\hline & N & & & \\
\hline Consciousness of Self & 863 & 115 & 189 & 154.51 \\
\hline Consciousness of Others & 863 & 56 & 98 & 86.34 \\
\hline Consciousness of Context & 863 & 7 & 21 & 17.15 \\
\hline
\end{tabular}

Note: A table that shows the minimum, maximum, and mean of participants based on scores within the three consciousnesses.

\section{Table 7}

\section{Consciousness Score Chart}

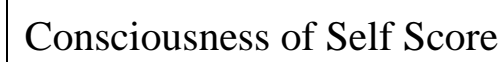

\begin{tabular}{|l|l|}
\hline & \\
\hline Low & $0-37$ \\
\hline $\begin{array}{l}\text { Somewhat } \\
\text { Low }\end{array}$ & $38-75$ \\
\hline Medium & $76-113$ \\
\hline $\begin{array}{l}\text { Somewhat } \\
\text { High }\end{array}$ & $114-151$ \\
\hline
\end{tabular}

Table Continues 


\begin{tabular}{|c|c|c|}
\hline Consciousness of Self Score & High & 152-189 \\
\hline \multicolumn{3}{|l|}{ Consciousness of Others Score } \\
\hline & Low & 0-19 \\
\hline & $\begin{array}{l}\text { Somewhat } \\
\text { Low }\end{array}$ & $20-39$ \\
\hline & Medium & $40-59$ \\
\hline & $\begin{array}{l}\text { Somewhat } \\
\text { High }\end{array}$ & $60-79$ \\
\hline & High & $80-98$ \\
\hline \multicolumn{3}{|l|}{ Consciousness of Context Score } \\
\hline & Low & $0-4$ \\
\hline & $\begin{array}{l}\text { Somewhat } \\
\text { Low }\end{array}$ & $5-8$ \\
\hline & Medium & $9-12$ \\
\hline & $\begin{array}{l}\text { Somewhat } \\
\text { High }\end{array}$ & $13-17$ \\
\hline & High & $18-21$ \\
\hline
\end{tabular}

Note: A table showing the score thresholds based on individual scores on the EILE-I.

To answer Research Question 1, data were utilized from both Table 6 and Table 7. Within Consciousness of Self, the minimum score was 115 and the mean score of the 863 participants was 154.51. This means that all participants scored at least "Somewhat High" and 
averaged a score of "High" within Consciousness of Self. Within Consciousness of Others, the minimum score was 56 and the mean score of the 863 participants was 86.34 . This means that all participants scored at least "Medium" and averaged a score of "High" within Consciousness of Others. Within Consciousness of Context, the minimum score was 7 and the mean score of the 863 participants was 17.15, which suggests that all participants scored at least "Somewhat Low" and averaged a score of "Somewhat High" within Consciousness of Context. All three consciousnesses showed a maximum score of "High.”

It can then be concluded that in regard to answering Research Question 1, student affairs professionals scored an average of "Somewhat High" or higher for emotionally intelligent leadership and among the three consciousnesses.

\section{Research Question 2}

Do emotionally intelligent leadership scores differ by student affairs professionals based on their student affairs graduate program?

To answer Research Question 2, an analysis of variance or one-way ANOVA was conducted within each of the consciousnesses to determine if statistically significant differences exist based on the type of graduate program a person attended. If a statistically significant difference was found, then a follow-up test could be done to evaluate where significant differences existed among the various degree programs, which are also known as professional preparation programs. To analyze the data, one-way ANOVA compared the means of participants within each category and evaluated if significant differences exist based on how individuals responded to the survey. To do this, each consciousness was evaluated separately. Responses were then analyzed based on the graduate program; here, the graduate program categories included in the survey were Administrative, Policy, Theory to Practice, Non-Student 
Affairs Master’s Program, and No Master’s Degree Obtained. If the p-value (level of significance) was greater than .05 , then it was considered not statistically significant and no further tests were necessary to analyze the data, because the probability of finding a difference by chance exceeded our threshold of $5 \%$.

A one-way analysis of variance was also conducted to evaluate the Consciousness of Self scores across student affairs program categories. The independent variable was the question "What graduate level student affairs program best describes your education?” and it included the following programs of emphasis: Administrative, Policy, Theory to Practice, Non-Student Affairs Master’s Program, and No Master's Degree Obtained. The dependent variable was Consciousness of Self, which was the category being analyzed to evaluate if scores significantly differed in this consciousness when evaluated by the independent variables. The analysis of variance (ANOVA) was not statistically significant: $\mathrm{F}(5,857)=.81, p=.545, \eta^{2}=.005$. This means that the student affairs graduate program that a professional attended did not affect or determine how a student affairs professional would score within Consciousness of Self in evaluating that person's EIL.

Next, a one-way analysis of variance was conducted to evaluate the Consciousness of Others scores across student affairs program categories. Once again, the independent variable was the question "What graduate level student affairs program best describes your education?" and it included the following groups: Administrative, Policy, Theory to Practice, Non-Student Affairs Master’s Program, and No Master’s Degree Obtained. The dependent variable was Consciousness of Others; in this analysis, it was the category being analyzed to evaluate if scores significantly differed in this consciousness when evaluated by the independent variables. The analysis of variance (ANOVA) was not statistically significant: $\mathrm{F}(5,857)=.17, p=.975, \eta^{2}$ 
$=.001$. This result means that the student affairs graduate program that a professional attended did not affect or determine how that person would score within Consciousness of Others in evaluating their EIL.

Finally, a one-way analysis of variance was conducted to evaluate the Consciousness of Context scores across student affairs program categories. Again, the independent variable was the question "What graduate level student affairs program best describes your education?” Available responses included the following groups: Administrative, Policy, Theory to Practice, Non-Student Affairs Master’s Program, and No Master’s Degree Obtained. The dependent variable was Consciousness of Context as the category being analyzed to determine if scores significantly differed in this consciousness when evaluated by the independent variables. As with the results in the previous two analyses, the analysis of variance (ANOVA) was not statistically significant: $\mathrm{F}(5,857)=.33, p=.896, \eta^{2}=.002$. This result means that the student affairs graduate program that a professional attended did not affect or determine how the person would score within Consciousness of Context in evaluating their own EIL.

Based on the outcomes of analysis of variances (ANOVA), no statistically significant differences were found within the three consciousnesses. This means that emotionally intelligent leadership scores among student affairs professionals do not differ based on a professional's educational program emphasis.

\section{Research Question 3}

Do the scores of emotionally intelligent leadership differ based on the number of years a student affairs professional has been in the field?

To answer Research Question 3, an analysis of variance or one-way ANOVA was conducted within each of the consciousnesses to determine if statistically significant differences 
existed based on the number of years an individual has been working in student affairs. If statistical significance was found, then a follow-up test could be done to evaluate where statistically significant differences existed among years of service in the field of student affairs. To analyze the data, analysis of variance (ANOVA) was used to compare the means of participants within each category and evaluate if significant differences existed based on how individuals responded to the survey. To do this, each consciousness was evaluated separately. Responses were then analyzed based on the years of service individuals had in the field, which were broken down into the following year ranges: 0-5 years, 6-10 years, $11-15$ years, adn 16 or more years. If the p-value (significance) was more than .05, then it was considered not statistically significant and no further tests would be necessary to analyze the data. The p-value of .05 means there is a 5\% chance that the differences in scores are due to chance and do not represent a true difference in scores in the population.

A one-way analysis of variance was conducted to evaluate the Consciousness of Self scores across the category of years within the field of student affairs. The independent variable was the question, "How many years have you been working in Student Affairs professionally?" and it included the following groups: 0-5 years, 6-10 years, $11-15$ years, and 16 or more years. The dependent variable was Consciousness of Self because this was the category being analyzed to evaluate if scores significantly differed in this consciousness when evaluated by the independent variables. The analysis of variance (ANOVA) was statistically significant, $\mathrm{F}(3$, 859) $=8.07, p<=.001, \eta^{2}=.027$, because the $\mathrm{p}$-value was less than .05 . The strength of the relationship between Consciousness of Self and years of service, as assessed by $\eta^{2}$, was weak, with years of service accounting for $2.7 \%$ of the variance of the dependent variable. This means that the independent variable, which was years of service in the field, only explains $2.7 \%$ of the 
variation in Consciousness of Self scores.

The follow-up tests were conducted to evaluate pairwise differences (significance) among the means to better understand the group differences in EIL scores. The study conducted post hoc comparisons with the use of a Tukey test to identify significant differences among the reported means, comparing " 16 or more years of service” to other categories of service. There were significant differences in the means between "16 or more years of service" and all other years of service. These significant differences show that $0-15$ years of service scores have no significant difference among professionals within these categories, but at 16 or more years of service, a student affairs professional's score will most likely increase. The sample sizes, means, and standard deviations for the years of groups are reported in Table 8.

\section{Table 8}

\section{Significance With Consciousness of Self and Years in the Profession}

Dependent Variable:

Consciousness of Self

DQ4. How many years have you been working in Student Affairs professionally? (Please do not count graduate assistantships.)

\begin{tabular}{|l|l|l|l|}
\hline & N & Mean & SD \\
\hline $0-5$ Years & 269 & 153.6389 & 12.40804 \\
\hline $6-10$ Years & 204 & 153.0306 & 12.68514 \\
\hline $11-15$ Years & 179 & 153.2157 & 13.4626 \\
\hline
\end{tabular}




\begin{tabular}{|l|l|l|l|}
\hline $16+$ Years & 211 & 158.1304 & 11.05517 \\
\hline Total & 863 & 154.5055 & 12.54084 \\
\hline
\end{tabular}

Note: A table that shows the mean and standard deviation, which reveals significance in 16 or more years of service compared to other years of service when evaluating Consciousness of Self.

A one-way analysis of variance (ANOVA) was conducted to evaluate the Consciousness of Others scores across the category of years within the field of student affairs. The independent variable was the question, "How many years have you been working in Student Affairs professionally?” and responses available included the following groups: $0-5$ years, $6-10$ years, 11-15 years, and 16 or more years. The dependent variable was Consciousness of Others; this was the category being analyzed to evaluate if scores significantly differed in this consciousness when evaluated by the independent variables. The analysis of variance (ANOVA) was statistically significant: $F(3,859)=6.60 . p<=.001, \eta^{2}=.023$. The analysis was significant because the p-value is less than .05 . The strength of the relationship between Consciousness of Others and years of service, as assessed by $\eta^{2}$, was weak, with years of service accounting for $2.3 \%$ of the variance of Consciousness of Others. This means that $2.3 \%$ of the variation in Consciousness of Others scores can be explained by years of service.

Follow-up tests were conducted to evaluate pairwise differences (significance) among the means to better understand group differences. This study conducted post hoc comparisons with the use of a Tukey test to identify statistically significant differences among the reported means, comparing " 16 or more years of service" to other categories of service. There were significant differences in the means between " 16 or more years of service" and all other years of 
service. These significant differences show that scores for 0-15 years of service show no significant difference among professionals within these categories, but at 16 or more years of service, a person's score will most likely increase. The sample sizes, means, and standard deviations for the years of groups are reported in Table 9.

\section{Table 9}

\section{Significance with Consciousness of Others and Years in the Profession}

Dependent Variable: Consciousness of Others

DQ4. How many years have you been working in student affairs professionally? (Please do not count graduate assistantships.)

\begin{tabular}{|l|l|l|l|}
\hline & N & Mean & SD \\
\hline $0-5$ Years & 269 & 85.735 & 8.53053 \\
\hline $6-10$ Years & 204 & 86.0097 & 7.71599 \\
\hline $11-15$ Years & 179 & 85.1376 & 8.93131 \\
\hline $16+$ Years & 211 & 88.4639 & 7.55854 \\
\hline Total & 863 & 86.3432 & 8.28131 \\
\hline
\end{tabular}

Note: A table that shows the mean and standard deviation, highlighting significance at the level of $16+$ years of service, when compared to less years of service within the Consciousness of Others. 
A one-way analysis of variance was conducted to evaluate the Consciousness of Context scores across the category of years working in the field of student affairs. The independent variable was the question, “How many years have you been working in Student Affairs professionally?” and response options included the following groups: 0-5 years, 6-10 years, 11-15 years, and 16 or more years. The dependent variable was Consciousness of Context because this was the category being analyzed to evaluate if scores significantly differed in this consciousness when evaluated by the independent variables. The analysis of variance (ANOVA) was not statistically significant: $\mathrm{F}(3,859)=.760, p=.517, \eta^{2}=.003$. This means that the number of years of service a professional has in student affairs did not affect or determine how that person would score within Consciousness of Context in evaluating their EIL.

The outcome of analysis of variances (ANOVA) revealed that significant differences existed within the consciousness of self and consciousness of others in relation to those student affairs professionals who have worked 16 or more years within the field. This means that when professionals reach 16 or more years of service within student affairs, their scores among EIL will slightly change. Additionally, no statistically significant differences were found within the consciousness of context in relation to years of service. This means that emotionally intelligent leadership scores among student affairs professionals, in regard to consciousness of context, do not appear to differ by years of service.

\section{Research Question 4}

Is there a relationship between Emotionally Intelligent Leadership and background characteristics, such as self-identified gender and race, among student affairs professionals?

For this analysis, the researcher removed the 18 participants who identified as nonbinary; the sample size that would be too small to accurately analyze with the comparable data 
of individuals with a binary gender identity. This gave the researcher a final sample size of 844 individuals for this analysis. A 2x4 factorial ANOVA was conducted to evaluate the differences in all three consciousnesses as a function of gender and racial identity. A factorial ANOVA is an analysis of variance used when analyzing more than one independent variable. Research Question 4 has two types of independent variables. The first is gender, which includes the categories of Men and Women. The second independent variable is racial identity, which is further divided into the following categories: White, Black or African American (AA), Latinx, and Another Racial Identity. The dependent variables are the three consciousnesses, which are Consciousness of Self, Consciousness of Others, and Consciousness of Context. Therefore, the analysis of variance utilizes the $2 \times 4$ factorial ANOVA to analyze the data for these research questions. The means and standard deviations are presented in Table 10, and the test statistics for the 2x4 factorial ANOVA are presented in Table 11.

Table 10 shows the outcome of the 2x4 factorial analysis of the overall scores within each of the three consciousnesses based on gender and racial identity variables. $\mathrm{N}$ stands for the number of participants that identified with that given category. The table also shows the mean or average score of self-identified participants by consciousness within each category of gender and racial identity. It is important to note that each question had a maximum of 7 possible answers, which included Never (1), Almost Never (2), Rarely (3), Sometimes (4), Usually (5), Almost Always (6), and Always (7). Score thresholds were also utilized to determine the prevalence of emotionally intelligent leadership among student affairs professionals. The possible scores for EIL are broken down by Low, Somewhat Low, Medium, Somewhat High, and High. Because the number of questions were different for each consciousness, score thresholds for the various consciousnesses would differ. These thresholds, based on the number 
of questions, were as follows for each consciousness: Consciousness of Self scores were labeled as Low (0-37), Somewhat Low (38-75), Medium (76-113), Somewhat High (114-151), and High (152-189). The score thresholds for Consciousness of Others were Low (0-19), Somewhat Low (20-39), Medium (40-59), Somewhat High (60-79), and High (80-98). Consciousness of Context thresholds scores were Low (0-4), Somewhat Low (5-8), Medium (9-12), Somewhat High (13-17), and High (18-21). Finally, Table 10 also contains standard deviation, which measures variance among participant scores. The higher the standard deviation, the less similar the answers are among participants. Conversely, the lower the standard deviation, the more similar the responses are among participants.

The 2x4 factorial ANOVA also revealed no statistically significant main effects for the three consciousnesses by gender. This included men and women reporting similar levels of EIL scores. See Table 11 for the outcomes of the $2 x 4$ factorial ANOVA in regard to main effects. The 2x4 factorial ANOVA not finding any main effects means that a binary gender identity as a whole does not significantly affect emotionally intelligent leadership scores among student affairs professionals. In this case, significance is defined as a p-value of less than .05.

In regard to differences by racial identity, there were statistically significant main effects for two of the three consciousnesses. For Consciousness of Self, Black or African American respondents scored higher than White respondents. For Consciousness of Others, Black or African American respondents scored higher than respondents in the categories of White and Another Racial Identity. For Consciousness of Context, there was no statistically significant difference between the racial categories. Chapter 5 will discuss why this might have occurred.

There was only one interaction effect between gender and race for Consciousness of Context. Figure 1 illustrates that the significant interaction effect of Consciousness of Context 
can be attributed to Latinx men scoring higher than Latinx women. This interaction effect between Latinx men and Latinx women will be analyzed further in Chapter 5 .

Table 10

2x4 Factorial ANOVA of Gender and Race

\begin{tabular}{|c|c|c|c|c|c|c|c|c|}
\hline \multirow[b]{2}{*}{ Gender } & \multirow[b]{2}{*}{ Race } & \multirow[b]{2}{*}{$\mathrm{N}$} & \multicolumn{2}{|c|}{$\begin{array}{l}\text { Consciousness of } \\
\text { Self }\end{array}$} & \multicolumn{2}{|c|}{$\begin{array}{l}\text { Consciousness of } \\
\text { Others }\end{array}$} & \multicolumn{2}{|c|}{$\begin{array}{l}\text { Consciousness of } \\
\text { Context }\end{array}$} \\
\hline & & & Mean & SD & Mean & SD & Mean & SD \\
\hline \multirow[t]{5}{*}{ Man } & White & 195 & 153.72 & 13.28 & 84.79 & 8.63 & 17.10 & 2.33 \\
\hline & $\begin{array}{l}\text { Black or } \\
\text { AA }\end{array}$ & 35 & 159.01 & 12.88 & 90.19 & 8.41 & 16.86 & 2.26 \\
\hline & Latinx & 14 & 160.00 & 12.75 & 93.00 & 7.92 & 18.43 & 1.34 \\
\hline & $\begin{array}{l}\text { Another } \\
\text { Racial } \\
\text { Identity }\end{array}$ & 15 & 153.92 & 14.36 & 86.04 & 9.71 & 17.07 & 2.74 \\
\hline & Total & 259 & 154.78 & 13.37 & 86.04 & 8.93 & 17.14 & 2.32 \\
\hline \multirow[t]{4}{*}{ Woman } & White & 435 & 154.13 & 12.02 & 86.14 & 7.69 & 17.09 & 2.18 \\
\hline & $\begin{array}{l}\text { Black or } \\
\text { AA }\end{array}$ & 55 & 158.66 & 13.08 & 90.44 & 8.34 & 17.76 & 2.42 \\
\hline & Latinx & 40 & 153.53 & 11.64 & 86.73 & 8.51 & 16.93 & 1.79 \\
\hline & $\begin{array}{l}\text { Another } \\
\text { Racial } \\
\text { Identity }\end{array}$ & 55 & 154.08 & 12.41 & 85.80 & 8.45 & 17.22 & 1.99 \\
\hline
\end{tabular}

Table Continues 


\begin{tabular}{|c|c|c|c|c|c|c|c|c|}
\hline & \multirow[b]{2}{*}{ Total } & \multirow[b]{2}{*}{585} & \multicolumn{2}{|c|}{$\begin{array}{l}\text { Consciousness of } \\
\text { Self }\end{array}$} & \multicolumn{2}{|c|}{$\begin{array}{l}\text { Consciousness of } \\
\text { Others }\end{array}$} & \multicolumn{2}{|c|}{$\begin{array}{l}\text { Consciousness of } \\
\text { Context }\end{array}$} \\
\hline & & & 154.51 & 12.18 & 86.56 & 7.96 & 17.16 & 2.17 \\
\hline Total & White & 630 & 154.00 & 12.41 & 85.73 & 8.01 & 17.10 & 2.23 \\
\hline \multirow[t]{5}{*}{ Gender } & Race & $\mathrm{N}$ & Mean & SD & Mean & SD & Mean & SD \\
\hline & $\begin{array}{l}\text { Black or } \\
\text { AA }\end{array}$ & 90 & 158.80 & 12.93 & 90.34 & 8.32 & 17.41 & 2.39 \\
\hline & Latinx & 54 & 155.20 & 12.16 & 88.35 & 8.74 & 17.31 & 1.80 \\
\hline & $\begin{array}{l}\text { Another } \\
\text { Racial } \\
\text { Identity }\end{array}$ & 70 & 154.05 & 12.74 & 85.85 & 8.66 & 17.19 & 2.15 \\
\hline & Total & 844 & 154.59 & 12.55 & 86.40 & 8.27 & 17.15 & 2.21 \\
\hline
\end{tabular}

Note: A table that shows the 2x4 factorial ANOVA of race and gender based on participants in the EILE-I. The table shows means and standard deviations.

Table 11

Factorial Analysis of Variance of Differences in Gender and Race

\begin{tabular}{|l|l|l|l|l|l|l|}
\hline & \multicolumn{2}{|l|}{ Gender } & \multicolumn{2}{l|}{ Race } & \multicolumn{2}{l|}{ Gender x Race } \\
\hline Measure & $\mathrm{F}\left(\mathrm{df}_{1}, \mathrm{df}_{2}\right)$ & Sig. & $\mathrm{F}\left(\mathrm{df}_{1}, \mathrm{df}_{2}\right)$ & Sig. & $\mathrm{F}\left(\mathrm{df}_{1}, \mathrm{df}_{2}\right)$ & Sig. \\
\hline $\begin{array}{l}\text { Consciousness of } \\
\text { Self }\end{array}$ & $\begin{array}{l}1.063(1, \\
836)\end{array}$ & 0.303 & $4.254(3,836)$ & 0.005 & $.981(3,836)$ & 0.401 \\
\hline $\begin{array}{l}\text { Consciousness of } \\
\text { Others }\end{array}$ & $1.555(1,836)$ & 0.213 & $\begin{array}{l}11.541(3, \\
836)\end{array}$ & 0.000 & $2.915(3,836)$ & 0.033 \\
\hline
\end{tabular}




\begin{tabular}{|l|l|l|l|l|l|l|}
\hline $\begin{array}{l}\text { Consciousness of } \\
\text { Context }\end{array}$ & $.180(1,836)$ & 0.672 & $\begin{array}{l}5.062(3, \\
836)\end{array}$ & 0.375 & $\begin{array}{l}2.813(3, \\
836)\end{array}$ & 0.038 \\
\hline
\end{tabular}

Note: A table that shows the factorial analysis of variance with gender and race. The table includes the data based on all three consciousnesses.

\section{Figure 1}

Graph of Estimated Marginal Means of Consciousnesses of Context

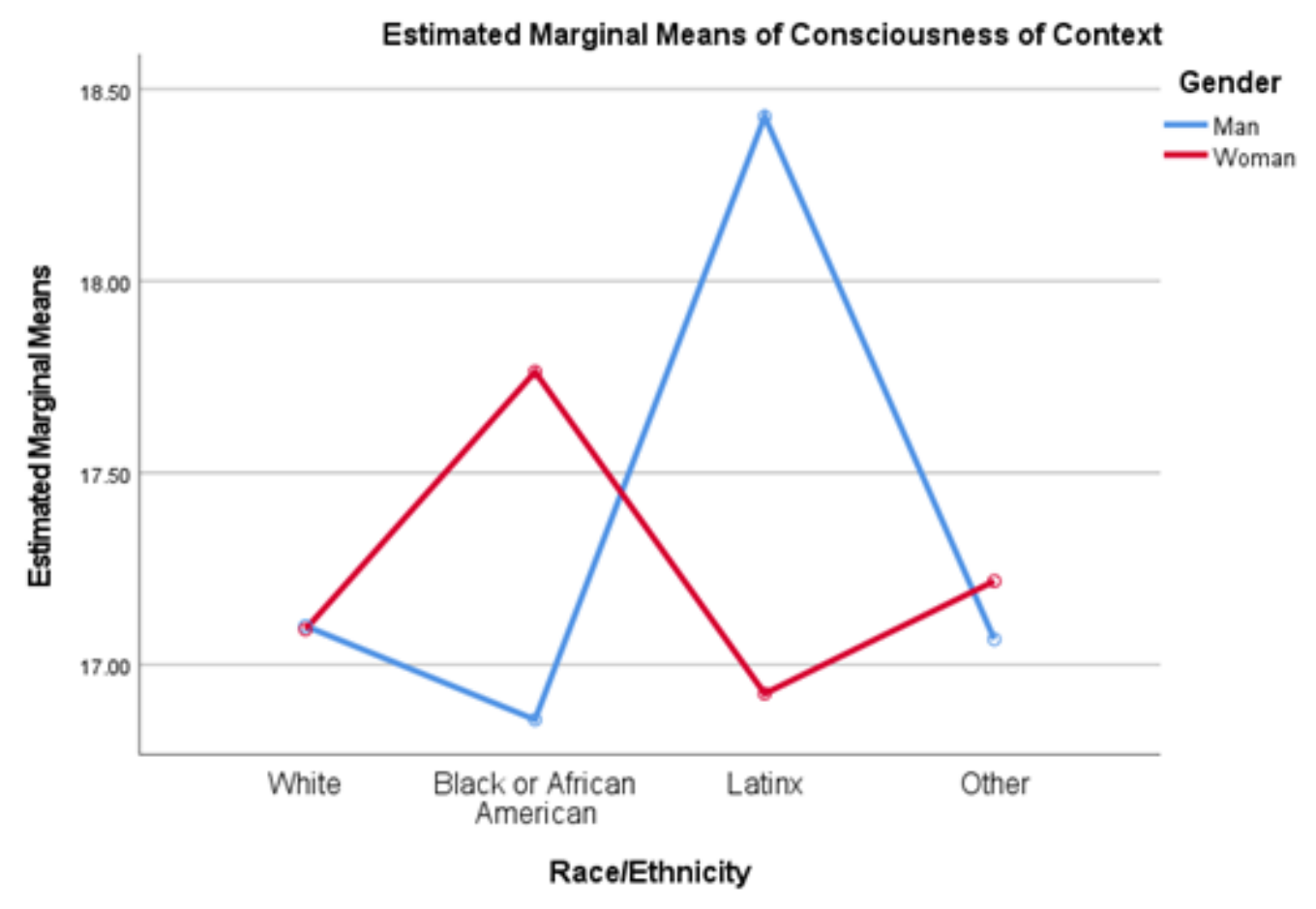

Note: A graph that shows the marginal means of gender based on racial categories.

\section{Chapter Summary}

A summary of the results of the data analyses conducted in this study has been presented in Chapter 4. This summary includes: participant demographics, descriptive statistics for the instrument results, summary of factor analysis, and summary of reliability analysis. In addition 
to the previous summaries, Chapter 4 also included a summary of results that are pertinent to the study's research questions. Within these tests a number of findings were revealed.

In regard to Research Question 1, student affairs professionals scored an average of “Somewhat High” or higher within emotionally intelligent leadership among the three consciousnesses. Research Question 2 revealed no statistical significance based on the education program of a student affairs professional in relation to how they scored on the EILE-I. Research Question 3 explored significant differences within the EIL concepts of consciousness of self and consciousness of others for student affairs professionals who have been in the field for 16 or more years in comparison to less seasoned professionals.

Research Question 4 exhibited a number of findings. The first was that there were no significant differences among student affairs professionals based solely on gender in relation to emotional intelligence. However, the statistical tests did reveal that Black or African Americans generally scored higher than people in all other racial categories. Additionally, the tests revealed an interaction effect where Latinx men scored higher on the EILE-I than Latinx women.

Chapter 5 will discuss what these findings could suggest for current recommendations as well as implications for further research. Additionally, Chapter 5 will discuss considerations for understanding emotionally intelligent leadership among student affairs professionals. 


\section{CHAPTER V: DISCUSSION}

\section{Introduction}

Chapter 5 provides findings and recommendations related to understanding the prevalence of the use of emotionally intelligent leadership skills among student affairs professionals. Previous studies into student affairs have utilized emotional intelligence and leadership separately to understand student affairs professionals and their work (McDade, 1987; Parrish, 2015; Kastberg, 2020; Mortiboys, 2012). Prior to this study being conducted, no others were found to have evaluated how understanding emotionally intelligent leadership among student affairs professionals could be beneficial. This makes this exploratory research unique and one of the pioneering studies into this topic within this profession. The study was developed to understand emotionally intelligent leadership among student affairs professionals because it is believed that EIL can be an area that can elevate the work done within the field .

Previous chapters within this dissertation explained that this study focuses on understanding the prevalence of emotionally intelligent leadership among student affairs professionals by evaluating overall scores and background characteristics through the utilization of the Emotionally Intelligent Leadership for Employees: Inventory (EILE-I). The adaptation of the EILE-I from the Emotionally Intelligent Leadership for Students: Inventory (EILS-I 2.0) is the first step in collecting data that measures student affairs professionals' use of emotionally intelligent leadership within their lives and work. The instrument, coupled with background questions such as a respondent's gender, racial identity, years of service, and higher education program of study, provided a holistic look at EIL within student affairs.

The EILE-I survey was completed by 863 student affairs professionals who worked at higher education institutions within the United States and were 18 years of age or older. Their 
responses were then analyzed utilizing statistical tests that included descriptive statistics, exploratory factor analysis, analysis of variance, and factorial ANOVA. Chapter 4 presented the results of the study in relation to the four research questions. These results yielded a number of significant findings, which were discussed in the preceding section.

Based on the findings of the study, Chapter 5 shares a summary of the results, discusses implications of the research, and offers recommendations for future studies. The first section is a summary of the overall study to share how these conclusions and recommendations were developed. The second section discusses the findings in relation to the research questions, with a brief overview of important conclusions. The third section discusses future recommendations and implications for practice.

\section{Summary of Findings}

This study's overall purpose was understanding the prevalence of emotionally intelligent leadership (EIL) among student affairs professionals. The study built upon research previously done on the topic, which had only focused on students, by evaluating responses from 863 participants through demographic variables such as years of service, education level, gender, and racial identity to determine if these variables had significance based on the EIL scores. Through the utilization of the EILE-I results and by employing a number of statistical tests (which included descriptive statistics, exploratory factor analysis, analysis of variance, and factorial ANOVA), a number of major findings were discovered.

Multiple results and conclusions were drawn from the outcomes of these statistical tests. The significant findings, which will be discussed in this chapter, are as follows:

1. Student affairs professionals scored an average of "Somewhat High" or higher within emotionally intelligent leadership among the three consciousnesses (consciousness of 
self, consciousness of others, and consciousness of context). This is based on a 5-point Likert scale, on which "Somewhat High" is a 4.

2. No statistical significance was found based on the education program of student affairs professionals in relation to how professionals scored on the EILE-I.

3. Studies found significant differences within consciousness of self and consciousness of others for student affairs professionals who have been in the field for 16 or more years in comparison to less seasoned professionals.

4. No statistical significance was found based on the number of years a student affairs professional was in the field in relation to consciousness of context.

5. No statistical significance was found when comparing binary genders in relation to student affairs professionals and emotionally intelligent leadership.

6. Statistical tests among student affairs professionals and emotionally intelligent leadership revealed that Black or African Americans scored higher on the EILE-I than people who identified with all other racial categories.

7. An interaction effect was revealed that shared Latinx men scored higher than Latinx women.

The following section examines the findings of the study and statistical tests to discuss the researcher's interpretation of the results, and draws a number of conclusions. The results will be examined based on the research questions that were introduced in Chapter 1 .

\section{Discussion of Findings in Relationship to Research Questions}

The study of emotionally intelligent leadership among student affairs professionals has significant findings based on the evaluation of the data, which were shared in the previous 
section. This section focuses on an in-depth discussion of the findings, based on the initial research questions.

To accomplish this detailed discussion, the section will be categorized based on each research question. Each category will follow the same format of sharing the research question and then sharing the results of the statistical tests related to the question. The category will then share the interpretation of the findings as it relates to the prevalence of EIL among student affairs professionals.

\section{Research Question 1}

How do student affairs professionals score on the EILE-I inventory in terms of emotionally intelligent leadership?

To answer Research Question 1, descriptive statistic tests were utilized to evaluate overall scores from student affairs professionals. These scores are based on each question within the EILE-I, which used a 7-point response scale. The available responses included Never (1), Almost Never (2), Rarely (3), Sometimes (4), Usually (5), Almost Always (6), and Always (7). This is then translated into overall scores on a 5-point scale for each consciousness, where the corresponding score was labeled Low (1), Somewhat Low (2), Medium (3), Somewhat High (4), and High (5). Data from the statistical tests showed that the 863 respondents scored a mean of High (5) in consciousness of self, High (5) in consciousness of others, and Somewhat High (4) in consciousness of context. It is also important to disclose that in consciousness of self and consciousness of others; the lowest scoring individuals were rated Medium (3). In consciousness of context, Somewhat Low (2) was the lowest score. In the end, student affairs professionals scored an average of "Somewhat High" or higher within emotionally intelligent leadership among the three consciousnesses. What this indicates is that student affairs 
professionals can be classified as having Somewhat High to High emotionally intelligent leadership.

These high scores demonstrate that emotionally intelligent leadership is apparent and relevant to student affairs professionals One thought is that professionals scored high in general because they do not understand emotional intelligence and therefore chose to score themselves high based on guessing. The researcher included the definition of emotional intelligence to help give contextual foundation to the EILE-I. The definition used within the study was "emotional intelligence is the subset of social intelligence that involves the ability to monitor one's own and others' feelings and emotions, to discriminate among them and to use the information to guide one’s thinking and actions” (Mayer and Salovey, 1990, p. 5). Based on this question, a significant number of participants (853) responded "Yes" to understanding emotional intelligence prior to completing the survey. This is important because one of the key tenets of EIL is emotional intelligence (EQ). The other 10 participants either skipped the question or responded "No" to understanding the definition of EQ before proceeding to complete the EILEI survey. Although 10 individuals did not acknowledge an understanding of EQ, that number of individuals is low enough that a conclusion can be drawn that student affairs professionals overwhelmingly understand EQ. If this is true, then it is concluded that student affairs professionals scored high because this field either attracts, trains, or develops individuals into having higher emotionally intelligent leadership.

A second finding that is revealed from this study is in the review of literature compared to the outcomes of the scores. As shared in Chapter 2, there is no agreed-upon conclusion that individuals must actively be interpreting their own emotional intelligence for EQ to be utilized. This same conclusion can be drawn with EIL, since a majority of concepts in its definition, as 
well as its interpretation, is rooted in EQ. Shankman, Allen, and Haber-Curran (2015) defined emotionally intelligent leadership as "promoting an intentional focus on three facets: consciousness of self, consciousness of others, and consciousness of context.” (p. 9). Since only one study has been done prior to this that utilized the same definition, it can be concluded that there is only one interpretation of emotionally intelligent leadership. Additionally, this definition can be used with this study because the EILE-I has very few differences from the original EILS-I 2.0. Using this definition is important because the study shows that EIL is prevalent within student affairs professionals. By having a standardized theory and method for study, the findings show that EIL can be evaluated and utilized among professionals, even if the theory is not commonly known among members of this workforce.

One finding that was not revealed within this study was how EIL is developed as a way to account for these high scores. As previously stated, the researcher believes EIL can be used consciously or unconsciously. The researcher also suggests that EIL can occur among student affairs professionals by attracting individuals with high EIL, providing professionals with training, or through learning experiences on the job, all of which could develop higher emotionally intelligent leadership. There may also be more conclusions that have not been revealed. Regardless of the reason why, EIL scores are high among student affairs professionals and therefore, there is a need to understand why high scores will be important as EIL use and its understanding become more common within student affairs.

Finally, the researcher draws the conclusion that if EIL is as prevalent as these scores suggest within student affairs, and this theory is not taught to student affairs professionals, then these professionals are subconsciously utilizing it in their work. This could be because, as previously suggested, student affairs may be attracting individuals with high emotional 
intelligence. It may also be because EIL is a significant part of how student affairs professionals approach their work in regards to decision-making, as well as how they respond to situations or approaches. Due to these high scores and the number of possibilities that could account for the fact that these scores are occurring with student affairs professionals in relation to EIL, more research is needed.

\section{Research Question 2}

Do emotionally intelligent leadership scores differ by student affairs professionals based on their student affairs graduate program?

This question dove deeper into the data from the results of the study to understand whether educational background plays a role in the use of EIL among student affairs professionals. Since a Master's degree is considered a standard of employment within this profession, but the type of Master's degree or focus of degree is not always specified, it was important to gather data about which of these programs influenced the use of EIL. The question in the EILE-I allowed participants to answer as: Administrative, Policy, Theory to Practice, Non-Student Affairs Master’s Program, and No Master’s Degree Obtained. The results of this demographic question were evaluated on the three consciousnesses utilizing a one-way analysis of variance. The results found no statistically significant differences in EIL scores based on the educational program background of professionals. This evaluation, as well as the possible answers specified on the instrument, focused on the graduate preparation programs that student affairs professionals attended in a general sense; it did not limit answers only to student affairsbased preparatory programs.

The conclusion drawn from this data, although not significant for the results, can be due to the nature of student affairs as a profession or since the field is made up of credentialed 
individuals. Student affairs was best defined by Love (2003) as "any advising, counseling, management, or administrative function at a college or university that exists outside the classroom" (para. 5). The nature of the work is helping students succeed, and a majority of this is done through interactions. Emotionally intelligent leadership focuses on understanding the interpretation of self, others, and context. It would make sense that due to this work, no significance would be found based on the program, but could possibly be found in the nature of the work and average interaction time with others.

It can also be concluded that the educational preparatory programs that student affairs professionals attended did not significantly impact their emotionally intelligent leadership scores because EIL is not typically taught as a part of the curriculum. If the topic is not taught, then in most cases, individuals may not know they are utilizing EIL in their work or everyday lives. This conclusion can be further supported by the programs that were listed in the demographic question as having different approaches to preparing graduates for the workforce. If these programs emphasize or teach different approaches to preparing professionals for student affairs work, then the development of EIL was most likely not occurring in the preparation of working in the field, and therefore was not a reason that student affairs professionals scored high in EIL. However, if an educational program introduced and taught aspiring student affairs professionals about EIL, then scores or approaches could change because they would be able to consciously utilize the theory. Additionally, since seasoned professionals with 16 or more years of service in the field scored higher than less seasoned professionals, it could be that teaching EIL in preparation programs that professionals may score higher in the use of EIL earlier in their careers. The researcher concludes that more information would be needed about what is 
taught within each of these student affairs programs in relation to EQ or EIL to evaluate if this has an impact on student affairs professionals.

\section{Research Question 3}

Do the scores of emotionally intelligent leadership differ based on the number of years a student affairs professional has been working in the field?

To analyze the results of this question, a one-way analysis of variance was conducted on the three consciousnesses. The demographic variables for the number of years of service utilized in measuring scores of EIL among student affairs professionals included: 0-5 years, 610 years, 11-15 years, and 16 or more years. The results showed that statistically significant differences existed within the consciousness of self and consciousness of others. No statistically significant differences were found in consciousness of context. Follow-up tests were conducted for both consciousness of self and consciousness of others to understand pairwise differences, utilizing the post hoc Tukey test. These results found that in both consciousnesses, professionals with 16 or more years of service had significantly higher EIL scores compared to professionals with all other levels of service.

In understanding that our experiences and interactions define us as individuals, it can also be concluded that we learn from our interactions and experiences. This means that those who have had more experiences within student affairs will more likely be able to respond, interact, or interpret experiences faster and more consistently. This yields less learning occurring over time in a given situation and more repetitive responses. The Unified Learning Model explains this phenomenon and, in turn, can give possible insight into why professionals with at least 16 years of service score higher within EIL than less seasoned professionals. The Unified Learning Model, developed by Shell et al. (2009), is based on the concept that we learn 
through three basic principles: “(1) learning is a product of working memory allocation; (2) working memory’s capacity for allocation is affected by prior knowledge; and (3) working memory allocation is directed by motivation” (Shell et al., 2009, p. 4). Based on this, it can be concluded that by having a significant amount of experience in the field, a person's EIL would be higher than a newer professional because of that person's working memory.

One possibility from the unified learning model is as EIL is developed, whether consciously or subconsciously, individuals would handle situations quicker and in a more consistent manner. This allows for a better understanding of one's own emotions, as well as how others would interact within given situations. However, the Unified Learning Model does not explain context, which was shown not to be significant. Since the model does not explain context, then how does context matter in regard to use of EIL when it comes to how we approach repetitive situations? Context may not be as important because of control factors such as policies, laws, and past experiences. Therefore, situations, interpretations, and responses are based on more knowledge and less on how the specific circumstances change how a person responds from an EIL perspective.

These results, however, do not reveal why this shift in scores occurs at 16 years or more of service rather than sooner in professional careers. To understand this, more research would be needed into these professionals around level of authority, career path within student affairs, or receiving terminal degrees. Additionally, it was recommended earlier that if EIL was added to graduate preparatory programs, then individuals may reach levels of statistical significance within EIL sooner. Student affairs is a broad field; therefore, a number of paths to upper-level administration, preparation through graduate programs, and types of roles can be traveled. 
These varying paths may explain why this phenomenon exists for professionals with 16 or more years of service.

\section{Research Question 4}

Is there a relationship between Emotionally Intelligent Leadership and background characteristics, such as self-identified gender and race, among student affairs professionals?

To analyze this question, a 2x4 factorial ANOVA was conducted. This factorial ANOVA utilized binary gender (Man or Woman) and the racial identities of White, Black or African American, Latinx, and Another Racial Identity. The results found that there were no statistically significant differences in EIL scores by gender within any of the three consciousnesses. Through further evaluation of the results, statistically significant differences were found among Black or African American respondents, as compared to White respondents, in the areas of consciousness of self and consciousness of others. No statistically significant differences were found in consciousness of context or in comparison to other identified races. Finally, the analysis found one interaction effect within consciousness of context. This interaction effect was Latinx men scoring higher than Latinx women within EIL.

To first understand the significance of Black or African American student affairs professionals scoring higher than their White counterparts, context must be given to emotions. Roxanna Harlow (2003) found that "black college and university professors engage in emotion management to contend with racialized classroom dynamics where their authority and intellectual capabilities are routinely challenged.” Harlow (2003) also found that black women professors in particular "contend with white students' perceptions that they are mean, cold, and intimidating” (p. 357). According to Allen et al. (2015), emotional management is a branch of Mayer and Salovey's model and is defined as "the regulation of negative emotions and the 
enhancement of positive ones'” (p. 196). It is important to note that Mayer and Salovey’s definition of emotional intelligence serves as a foundation of the EILE-I survey, as was explained in the findings of Research Question 1. This then leads EIL into higher education and student affairs professionals.

Although this study did not find a direct correlation to student affairs professionals, the results of Harlow's study did give some insight to higher education in relation to professionals who identified as Black or African American. The results revealed that professors must be aware of their emotions when dealing with individuals who identify as White because how a professor responds or does not respond will depend on how they are perceived. It can be also deduced that Black or African American individuals who work within student affairs, as a part of higher education, may utilize emotional management when working with their White counterparts for the same reasons as professors. Therefore, a stronger awareness of emotions and how they are interpreted out of belief that it is a necessity among this racial identity could explain why the scores of Black or African American professionals are higher than their White counterparts. One question still exists: Is this true for student affairs professionals as it is for Black or African American professors?

Adia Wingfield (2010) conducted research and concluded that there are two sets of emotional rules applied to Black or African American professionals: "Those that are generally applied to all workers ... and those that differ from the rules available to their white counterparts" (p. 265). Wingfield (2010) further concluded that "the feeling of rules in professional workplaces are not neutral, but are in fact racialized in ways that deny [Black or African Americans] areas of emotional expression accessible to their white colleagues" (p. 265). Based on these findings that a large majority of Black or African Americans in the workforce 
believe to be true, then it would also apply to Black or African American student affairs professionals. It is further deduced, based on this study, that Black or African Americans shared that they must be more cognizant of their emotions by understanding how they are projecting emotions, as well as how those emotions are being interpreted by others. This perception shows that individuals who have been more aware of their emotional intelligence—-in this case, Black or African Americans—-would score higher than their White counterparts in EIL because there is a belief that they are judged more harshly based on their emotions.

This would also explain why, in the results, consciousness of context would not be as relevant for Black of African Americans. If the belief exists that the context of the situation is not as important as how emotions are delivered or interpreted, then the context of that delivery would not be as crucial to Black or African Americans. Another conclusion that can be noted is that if Wingfield's and Harlow's findings are universal, then at least among Black or African Americans, emotionally intelligent leadership is developed over time. Through further study of emotionally intelligent leadership, growth over time could lead to a better understanding of how it is developed within various identities, which in turn can lead to new ways to teach and understand EIL. It is recommended that a future qualitative study be considered that examines why this phenomenon is occurring, and whether Wingfield and Harlow's findings about increased emotional management and differing societal rules are consistent among Black or African American professionals.

Another result of this study was that Latinx men scored higher than Latinx women within the consciousness of context. Although it cannot be definitely understood why this is, it may be because men of color "experience double jeopardy concerning emotions and behavior; not only are they socialized as all men are, but they are also socialized concerning their race or 
ethnicity and it is this socialization that shapes individual emotion, meaning, behavior, regarding social construct of race” (Smith, 2002, p. 104). This could make men more aware of their surroundings, and therefore, when deciding how to respond from an EIL perspective, focus on the context of a situation or response, as opposed to how they respond. The issue is that generally, men do not score differently than women, so the question is, why does this occur among Latinx people, and no other identified race?

The answer could be a mix of Smith's findings and those of Harlow and Wingfield. Harlow and Wingfield displayed a disproportionate view of how Black or African Americans must utilize emotional management in the workplace. This study could be applied to Latinx individuals to see if this view occurs among this racial identity as well. If so, it could show a different view of EIL among Latinx individuals, which would help explain why men and women that are Latinx do not have significant differences in scores within consciousness of self and consciousness of others. It would not explain consciousness of context differences within Latinx genders. Therefore, applying Smith’s findings would help to possibly explain why Latinx men score significantly differently than Latinx women. Research into this topic may also lead to an understanding of why Latinx women may not first use EIL to understand the context of their decision. Instead, Latinx women may focus first on how they internalize a situation and how their response will be interpreted. An answer may be impossible to deduce from this study, but the findings of this study may help to guide future research into answering why an interaction effect exists among Latinx people of both binary genders.

In all of these findings in relation to Research Question 4, further research would be needed to better understand the cause of the statistical significance of Black or African Americans scoring higher than Whites within consciousness of self and consciousness of others. 
Additionally, further research would be necessary to understand the interaction effect among Latinx men and Latinx women within consciousness of context. Further, by understanding why these differences occurred, approaches could be developed to enhance emotionally intelligent leadership within the context of an individual's multiple identities within the field of student affairs.

\section{Future Recommendations and Implications for Practice}

The overall goal of this research was to understand the prevalence of emotionally intelligent leadership among student affairs professionals, as well as to consider possible recommendations for its incorporation into the field through curriculum and/or training. Although the study was exploratory, as one of the first studies into EIL within student affairs, a series of recommendations for future research and implications are presented. These recommendations and implications are broken down into four categories: the development of student affairs core competencies, professional development within cultural education, mentorship, and further study of the instrument itself.

\section{Development of Student Affairs Core Competencies}

The first recommendation is the development of core competencies around emotionally intelligent leadership. A core competency is defined as a "level of competence in a particular job or academic program” (Dictionary.com, 2021). In 2010, ACPA and NASPA came together and developed a series of core competencies within the field of student affairs, which they reaffirmed in 2015 (NASPA, 2015). The committee that created these competencies stated that those competencies "lay out essential knowledge, skills, and dispositions expected of all student affairs educators” (ACPA \& NASPA, 2015, p. 7). Another way to view this was that the competencies were universally applied to most areas that make up student affairs. The ten 
competencies of student affairs include: personal and ethical foundations; values philosophy and history; assessment, evaluation, and research; law, policy, and governance; human and organizational resources; leadership; social justice and inclusion; student learning and development; technology; and advising and supporting (American College Personnel Association \& Student Affairs Administrators in Higher Education, 2015).

It is not being recommended that EIL replace a competency or be the $11^{\text {th }}$ competency. What is being recommended is that EIL become a subset of one of the core competencies that govern student affairs. Specifically, it is recommended that EIL be placed as one of the cornerstone elements of the personal and ethical foundation competency. Personal and ethical foundation is defined as "the knowledge, skills and attitudes needed to maintain emotional, physical, social, environmental, relational, spiritual, and intellectual wellness; be self-directed and self-reflective; maintain excellence and integrity in work; be comfortable with ambiguity; be aware of one’s own areas of strength and growth; have a passion for work; and remain curious” (American College Personnel Association \& Student Affairs Administrators in Higher Education, 2015, p. 2). Emotionally intelligent leadership focuses on understanding one's own emotions, interpretation of others' emotions, and the context in which emotions are interpreted. Because this competency is focused on an individual and student affairs professionals work with students and projects, and maintain an awareness of self, emotionally intelligent leadership would be a great addition to this competency. This understanding of EIL is woven throughout the personal foundation competency and therefore, by better understanding one’s EIL, an individual would grow and develop within this competency to become a better student affairs professional. 
The research also supports this recommendation because student affairs professionals are scoring Somewhat High or higher on average within emotionally intelligent leadership. Intentional development of a student affairs competency would help professionals better understand EIL and how it relates to the student affairs profession. This leads to the second portion of this recommendation, which is that EIL should be taught in student affairs professional preparation programs. The research showed that the professional preparation programs that student affairs professionals attended had no significant effect on EIL scores. However, the researcher believes that one possibility related to this outcome is that EIL is not taught within student affairs professional preparation programs. When a new professional enters a field, it can be assumed that the way they work is based on how they were educated. Most professionals who took the EILE-I revealed they had a Master's degree in the field of student affairs. Therefore, if EIL was taught within the coursework, then individuals would know about EIL and, in turn, would apply it to their work. This would include the development of professionals to help them understand the three consciousnesses and how they apply to student development. This addition of EIL into graduate preparatory course curricula would also show professionals reaching measurable levels of statistical significance on the EILE:I within EIL sooner than 16 years of service. In the end, this application would equip professionals to better serve students, institutions, and the profession as a whole because they are knowingly applying emotionally intelligent leadership to their work.

Lastly, this implementation of EIL education into student affairs programs and as a core competency would result in a wealth of data for future studies. The development and implementation of EIL is in its infancy as a concept. This is supported by the first research into the topic, written in 2015 by Shankman, Allen, and Haber-Curran. The notion is also supported 
by the fact that the EILE-I is the first instrument to measure and collect data on EIL scores among student affairs professionals. Through the implementation of EIL within the core competencies and within educational programs, more data could be collected to further examine its impact and implications on the profession. This in turn will show its importance to the field and the future development of EIL as a necessary competency within student affairs.

\section{Professional Development in Cultural Education}

The second recommendation for future research and implications is for professional development in cultural education. This is being recommended as a direct outcome of what was discovered in Research Question 4, which asked, "Is there a relationship between emotionally intelligent leadership and background characteristics, such as self-identified gender and race, among student affairs professionals?” As was previously shared, Black or African Americans scored higher on the EILE-I than people from all other racial categories; in addition, an interaction effect was revealed that Latinx men scored higher on the EILE-I than Latinx women.

Cultural competency is defined as "the process by which individuals and systems respond respectfully and effectively to people of all cultures, languages, classes, races, ethnic backgrounds, religions, and other diversity factors in a manner that recognizes, affirms, and values the worth of individuals, families, and communities" (NASW, 2001). Although it is not recommended to develop a core competency around culture, since social justice and inclusion are already a part of the ACPA/NASPA core competencies, it is important to understand the necessity of being culturally competent or culturally aware within the context of EIL. The dissertation study showed differences in scores within identified races —-therefore, understanding why this occurs, and how to educate members of the profession, will be vital to develop these cultural competencies around emotionally intelligent leadership and student 
affairs professionals.

Relating back to the study, the research revealed that Black or African Americans scoring higher in emotionally intelligent leadership could have occurred because of the belief that the workforce is inequitable towards individuals who identify as Black or African American. Additionally, Black or African Americans are believed to need to be more aware of their emotional management, based on the studies by Harlow and Wingfield. Wingfield (2010) shared that two sets of emotional rules applied to black professionals: "Those that are generally applied to all workers ... and those that differ from the rules available to their white counterparts” (p. 265). Additionally, Harlow (2003) noted that black college and university professors engage in "emotion management to contend with racialized classroom dynamics where their authority and intellectual capabilities are routinely challenged” (p. 357). These findings can be translated that Black or African Americans may believe they must be more cognizant of their emotions by understanding how they are projecting and how their emotions are being interpreted. To fully understand if this is true, further study in this phenomenon among student affairs professionals must occur. This research will lead to a few possible outcomes.

The first possible outcome from studying this phenomenon would be that if Harlow and Wingfield's findings are consistent with student affairs professionals, then it is imperative to evaluate why this is occurring within the population, and build training and development to address these inequities within the profession. This in turn can also lead to further research and an understanding of EIL as a subset of training and development among the profession. This justifies the need for training and development among student affairs professionals to acknowledge the existence of this phenomenon and how to develop professionals in the 
approach to these inequities. A future qualitative study is recommended to understand the phenomenon that is occurring and if Wingfield and Harlow's findings are consistent with Black or African American professionals. Further, this is important for understanding what colleagues may be going through and to begin to develop methods of equitable treatment for all student affairs professionals. It is vital that student affairs professionals look to break down barriers and build cohesion within the profession. Additionally, further research may highlight, and currently suggests, that this double standard of emotional management may not be found just in education, but in a number of professions. Training and development of professionals will not only help within student affairs, but in working with students as they transition from students to careers. This in turn can bring colleagues closer together, create better working relationships, and improve the field and the profession by offering overall better support students which is a core function of student affairs.

The research also found that Latinx men are often more aware of the context of a situation then Latinx women because of the fear of being treated inequitably as men of color by White counterparts. This is supported by Smith (2002), who revealed that men of color "experience double jeopardy concerning emotions and behavior; not only are they socialized as all men are, but they are also socialized concerning their race or ethnicity and it is this socialization that shape individual emotion, meaning, behavior, regarding social construct of race” (p. 104). Much like the recommendations for understanding individuals who identify as Black or African American, the same would apply for understanding why Latinx men scored higher than Latinx women. This means that further research is needed to understand why Latinx men score higher within the consciousness of context than Latinx women. It is recommended that a future study be done on the interrelationships between race, gender, and years of 
experience in the field of student affairs and the use of emotionally intelligent leadership. Since

only three identified races were evaluated within this study (due to low responses from individuals of other identified races) an expansion of other identified races within an interrelation study would determine whether this phenomenon is unique to Latinx men or if it affects other races.

If the field of student affairs is to address the inequities shown within this study, then the need to understand the reason it occurs is vital. Once understood, the field can develop professional development opportunities to address these differences and help build a more equitable profession. Through this understanding of EIL scores, the research could also lead to a whole new understanding of racial and gender identity that would be helpful because it will add another dimension to understanding this critical area of the profession. Ideally, future research, and the solutions that come from this additional research, could lead student affairs professionals past cultural competency and help them in become culturally proficient.

In both recommendations around racial identity, it is important to understand that EIL is most likely being subconsciously applied to student affairs work. This is because little research has been published on the topic. Experiences reported by individuals of color may be happening subconsciously, which means it is possible that individuals may not be aware of these emotional inequities around race and gender. Further study and application of education around gender and race in regard to emotionally intelligent leadership will help the profession work toward understanding, practice, and bringing equality to everyone in the profession and those individuals with whom they work. Therefore, the need for the profession to have cultural competency training within emotionally intelligent leadership is vital to creating an equitable workforce. This will help all individuals be able to work together, understand each other, and 
better serve the student affairs profession. The ultimate goal of training on cultural competency is to move student affairs professionals from competency to cultural proficiency, which can be considered one of the highest levels attainable within this area, and is a more aspirational goal for the field of student affairs.

\section{Mentorship}

The third recommendation for future research and implications is the development and study of mentorship among student affairs professionals—specifically, the mentorship of newer professionals by seasoned professionals with 16 or more years of experience in student affairs. Alexander et al. (2019) stated that "early exposure to mentorship opportunities leads to increased job satisfaction and possibly offers elevated professional acumen” (p. 122). Additionally, it is believed that "structured mentorship, both inside and/or outside of the institution, contributes to overall success secondary to elements of social support" (Alexander et al., 2019, p. 122). This means that by developing mentorship programs, both new and seasoned professionals will grow and will gain a stronger understanding within student affairs around diversity, inclusion, career growth, and overall support. Mentorship programs around topics such as EIL will specifically help professionals to apply this theory to their work, which in turn will have an overall impact within student affairs.

Mentorship is important because the data showed that student affairs professionals with 16 or more years of service scored higher in regards to emotionally intelligent leadership than those with less experience. It is important to acknowledge that a number of possibilities that would explain why this occurred have been shared within this dissertation. The most prevalent belief is based on the Unified Learning Model developed by Shell et al. (2009). Seasoned professionals have learned to apply skills and approaches to situations based on past 
experiences, which developed their working memories and in turn is why the researcher believes EIL scores for professionals in that group are higher than newer professionals. If working memory from past experiences is how seasoned professionals grew in EIL, then sharing these approaches and lessons with less seasoned professionals would develop stronger student affairs professionals. It would also develop seasoned professionals because these professionals would be consciously passing knowledge of EIL to others, which could reaffirm their understanding of the topic of EIL. Although this would lead to stronger student affairs professionals, it won’t necessarily create a better understanding of EIL.

Therefore, curricula should be developed around emotionally intelligent leadership through mentorship. This will develop intentional understanding of emotionally intelligent leadership and conscious application within the field. Student affairs professionals will then be able to utilize EIL more effectively, both consciously and subconsciously among the profession. Application of IEL will not only enhance the understanding of EIL among individuals, it will also increase the impact student affairs professionals have in their work by utilizing proven methods of approaches to various situations and interactions.

Although mentorship would potentially help with EIL scores, it does not share why, at 16 years of service, higher EIL scores do occur. Therefore, the final recommendation for further study is to better understand why it is that 16 or more years of service would cause individuals in student affairs to score higher in emotionally intelligent leadership. As was previously stated, the factors that caused this phenomenon could include, but are not limited to, level of authority, an individual's career path within student affairs, and having earned terminal degrees. By studying these and other variables, a clearer picture could be developed to explain why EIL scores are reported higher among these more experienced professionals. It also could lead to a 
better understanding of why it is that within various specialties of student affairs—such as orientation, fraternity and sorority affairs, or housing, among others—growth in EIL occurs differently. This in turn opens up research opportunities into emotionally intelligent leadership by explaining how EIL growth occurs, when it occurs, and how often.

Studying these variables will also lead to the redevelopment of specialized training depending on what area of student affairs a person works in, and how EIL affects growth within specific areas. This additional knowledge would in turn develop a better understanding of the theory and lead not only to more student affairs research into EIL, but to a better understanding of why 16 years of service or more increases scores.

\section{Development of the Instrument}

The final set of recommendations for future research and implications is around the EILE-I instrument itself. This includes replicating the study, evaluating the questions within the instrument, and administering the instrument among other professions or groups of individuals. Most notably, the recommendations are made due to a number of differences between the two studies that have been found to utilize EIL. These studies include the current researcher's study and the study that Shankman, Allen, and Miguel(2015) conducted on college leaders.

In comparing the data to the original study of the EILS-I 2.0, there were differences in the outcomes. This includes the EILE-I having 12 capacities, while the EILS-I 2.0 had 19 capacities. The study also revealed that in regard to factor loading, a number of questions were removed from the EILE-I, which brings the original 57 questions in the instrument to 44 usable questions. Furthermore, the original study by Shankman, Allen, and Miguel (2015) contained three questions to measure each of the 19 capacities. After finding 12 capacities within student affairs professionals, a number of capacities were measured by more than three questions, which 
gives different weight to the capacities. This means a capacity with three questions is only considered three times, while another may have more questions, making the weight toward that capacity stronger or weaker. Both instruments did measure EIL among the three consciousnesses, even though the results and process varied. Therefore, the study should be repeated within the student affairs profession to evaluate if the EILE-I is the appropriate method for measuring EIL, or if it needs to be adapted.

Additionally, a repeated study will help with solidifying whether the current questions are weighted appropriately or if different questions need to be developed, or different factor loading needs to occur. This will show if the EILE-I in its current form is the best measure of the three consciousnesses or if adjustments are necessary. This will also help show the strength of the instrument in relation to measuring EIL.

The third recommendation is to apply the EILE-I to other professions, such as those related to sociology and psychology. The researcher believes that jobs within these two professions, as well as others, have enough similarities to student affairs that the instrument could be used with them to measure EIL. This will lead to an evaluation of student affairs professionals' scores compared to scores and use of EIL in other helping professions. This is important because there is a need to understand if EIL findings are unique to student affairs or if it is the same in other professions. This would contribute to a stronger understanding of EIL and how it can affect student affairs, and will also help to develop research into EIL within other professions.

In review of the recommendations, stronger research is needed within student affairs in regard to emotional intelligence and emotionally intelligent leadership. The rapid growth of research into EIL and emotional intelligence in general, combined with the lack of research in 
student affairs specifically, shows that an opportunity is being missed. Student affairs’ partial roots in sociology and psychology leads to the conclusion that EQ and EIL could have promising outcomes within the field, such as new professional development, mentorship programs, more equitable treatment of colleagues, and ACPA/NASPA Professional Competencies. Although a number of recommendations have been made for EIL, there is more research needed as well. This includes research that would be needed to understand EIL in relation to racial identities, gender differences, years of service, and the instrument itself.

Emotionally intelligent leadership has been proven to exist within student affairs. Further study of EIL, implementation of these recommendations, and efforts to make it part of the student affairs profession will elevate the tools, impact, and application of the work to make colleges and universities better for students and colleagues alike.

\section{Chapter Summary}

Chapter 5 began with a summary of the significant findings within the dissertation research that examined emotionally intelligent leadership among student affairs professionals. The chapter then discussed possible reasons for these findings and outcomes.

The chapter concluded with a summary of recommendations and research in relation to emotionally intelligent leadership and the student affairs profession. These recommendations specified four key areas with subsequent proposals. These recommendations were:

1. Development of Student Affairs Core Competencies

a. Add emotionally intelligent leadership to the ACPA/NASPA core competency of Personal and Ethical Foundation.

b. Develop curriculum to teach emotionally intelligent leadership within graduate preparation programs. 


\section{Professional Development Within Cultural Education}

a. Develop and implement professional development around cultural education.

b. Complete a future study on the interrelationship between race, gender, and years of experience in the field of student affairs and use of emotionally intelligent leadership.

c. Consider a future qualitative study about why Black or African American's are scoring higher in emotionally intelligent leadership compared to professionals who identify as any other race.

\section{Mentorship}

a. Develop curricula for seasoned professionals with 16 or more years of experience to better mentor newer professionals in use of emotionally intelligent leadership.

b. Design a future study to understand why statistical significance was reached with professionals with 16 or more years of service and their use of emotionally intelligent leadership as opposed to earlier in their careers.

c. Complete a future study of professionals by specialized student affairs career area (ex. Resident life, enrollment management, fraternity and sorority life, etc.) into the use of emotionally intelligent leadership. 


\section{Development of the Instrument}

a. Replicate the study to evaluate and strengthen the use of this instrument to measure emotionally intelligent leadership among different types of professions and within the field of student.

b. Future researchers should continue research into emotionally intelligent leadership in order to enhance the literature and solidify EIL's use in the profession. 


\section{REFERENCES}

Alexander, D. and Sturges, D. (2019). Underrepresented minority physician assistant faculty mentorship: It takes a village. The Journal of Physician Assistant Education, 30, 122124. doi: 10.1097/JPA.0000000000000253

Allen, R. (2015). The Situational Test of Emotional Management - Brief (STEM-B):

Development and validation using item response theory and latent class analysis. Personality and Individual Differences, 81, 195-200. doi: 10.1016/j.paid.2015.01.053

American Council on Education. (1937). The student personnel point of view (Report of a conference of the American Council on Education student personnel work).

American College Personnel Association. (1996). The student learning imperative: Implications for student affairs [On-line]. http://www.acpa.nche.edu/ sli/sli.ht

American College Personnel Association \& Student Affairs Administrators in Higher Education. (2010). Envisioning the Future of Student Affairs (Report of a Task Force on the Future of Student Affairs).

https://naspa.org/files/dmfile/Task_Force_Student_Affairs_2010_Report.pdf

American College Personnel Association \& Student Affairs Administrators in Higher Education. (2015). Professional Competency Areas for Student Affairs Educators (Report of a Task Force on Professional Competencies). https://www.naspa.org/files/dmfile/ACPA_NASPA_Professional_Competencies_1.pdf American College Personnel Association \& Student Affairs Administrators in Higher Education (2016). ACPA/NASPA Professional Competencies Rubrics.

https://www.naspa.org/images/uploads/main/ACPA_NASPA_Professional_Competency _Rubrics_Full.pdf 
Avolio, B. J., \& Gardner, W. L. (2005). Authentic leadership development: Getting to the root of positive forms of leadership. Leadership Quarterly, 16, 315-338.

Bandura, A. (1993). Perceived self-efficacy in cognitive development and functioning. Educational Psychologist, 28(2), 117-148. doi: 10.1207/s15326985ep2802_3

Barr, M. J. (1993). Becoming a successful student affairs administrator. In M. J. Barr \& Associates (Eds.), The handbook of student affairs administration (pp. 522-529). Jossey-Bass.

Bar-on, R. (1997). Emotional quotient inventory: Technical manual. Multi-Health Systems.

Bass, B. (2008). The Bass handbook of leadership: Theory, research and managerial applications (3rd ed.). Free Press.

Beasley, K. (1987). The Emotional Quotient. Mensa, p. 25.

Boniwell, I. (2012). Positive psychology in a nutshell the science of happiness (3rd ed.). Open University Press.

Bradberry, T. (2015, January 21). Why you need emotional intelligence to succeed in business. Retrieved from https://www.entrepreneur.com/article/241998

Brown, R. D., \& Barr, M. J. (1990). Student development: Yesterday, today, and tomorrow. In L.V. Moore (Ed.), Evolving theoretical perspectives on students: new directions for student services (pp. 83-92). Jossey-Bass Publishers.

Buckingham, M., \& Clifton, D. O. (2001). Now discover your strengths. Free Press.

Caruso, D. R., Bhalerao, H., \& Karve, S. (2016). Special issue on emotional intelligence. Business Perspectives \& Research, 4(1), ix-xii. doi:10.1177/2278533715609205

Chapin, K. (2015). The effect of emotional intelligence on student success. Journal of Adult Education, 44(1), 25-31. doi: 10.1037/bul0000219 
Cherniss, C., Extein, M., Goleman, D., \& Weissberg, R. P. (2006). Emotional intelligence: What does the research really indicate? Educational Psychologist, 41(4), 239-245. doi:10.1207/s15326985ep4104_4

Ciarrochi, J., Forgas, J. P., \& Mayer, J. D. (2007). Emotional intelligence: A practitioner's guide. Psychology Press.

Claudet, J. (1999). Conceptualizing organizational dimensions of instructional supervisory practice: Implications for professional learning environments in schools. Learning Environments Research Journal, 1(3), 257-292. doi:10.1023/A:1009917722205

Conte, J. M. (2005). A review and critique of emotional intelligence measures. Journal of Organizational Behavior, 26(4), 433-440. doi:10.1002/job.319

Council for the Advancement of Standards in Higher Education. (2003). Standards. https://www.cas.edu/standards

Couto, D. \& Eken, S. (2002). To give their gifts. Nashville, TN: Vanderbilt University Press. Creamer, D. G., Winston, R. B., \& Miller, T. K. (2001). The professional student affairs administrator: Roles and functions. In R. B. Winston, D. G. Creamer, T. K. Miller \& Associates (Eds.), The professional student affairs administrator: Educator, leader, and manager (pp. 38). Brunner and Routledge.

Fiedler, F. (1972). The effects of leadership training and experience: A contingency model interpretation. Administrative Science Quarterly, 17(4), 453-470. doi: 10.2307/2393826

Fraenkel, J., Wallen, N., \& Hyun, H. (2011). How to design and evaluate research in education (8th ed.). McGraw-Hill. 
Greenbert, J., \& Murphy, M. (2015). Self-perception theory (SPT). In P. Moglia (Eds.), Salem health: Psychology \& behavioral health (pp. 1679-1682). Salem Press Encyclopedia of Health.

Goleman, D. (1995). Emotional intelligence. Bantam Books.

Goleman, D. (2001). Emotional intelligence: Issues in paradigm building. In C. Cherniss \& D. Goleman (Eds.). The emotionally intelligent workplace: How to select for, measure, and improve emotional intelligence in individuals, groups, and organizations (pp. 13-26). Jossey-Bass.

Hanson, M. (2004). Book review: Emotional intelligence: Science and myth. Psychiatric Services, 55(4), 458. doi: 10.1176/appi.ps.55.4.458

Hagger, M., Gucciardi, D., Turrell, A., \& Hamilton, K. (2019). Self-control and health-related behavior: The role of implicit self-control, trait self-control, and lay beliefs in selfcontrol. British Journal of Health Psychology, 24(4), 764-786. doi: 10.1111/bjhp.12378

Harter, S. (2002). Authenticity. In C.R. Snyder, S.J. Lopez (Eds.), Handbook of positive psychology (pp. 382-394). Oxford University Press.

Harlow, R. (2003). “Race doesn’t matter, but...”: The effect of race on professors’ experiences and emotion management in the undergraduate college Classroom. Social Psychology Quarterly, 66(4), 348-363. doi: 10.2307/1519834

Heifetz, R.A. (1994). Leadership without easy answers. Harvard University Press.

Hein, S. (2006). Critical review of Daniel Goleman. http://eqi.org/gole.htm.

Hill, P. C., \& O’Dell, C. (2015). Achievement motivation. In P. Moglia (Eds.), Salem health: Psychology \& behavioral health (pp. 19--21). Salem Press Encyclopedia of Health. 
Jaeger, A., \& Eagan, M. (2007). Exploring the value of emotional intelligence: A means to improve academic performance. NASPA Journal, 44(3), 512-537. doi: 10.2202/19496605.1834

Jones, S. R., \& McEwen, M. K. (2000). A conceptual model of multiple dimensions of identity. Journal of College Student Development, 41(4), 405-414.

Kastberg, B. (2020). Developing emotional intelligence: The role of higher education. Journal of Organizational Psychology, 20(3), 64-72. doi: 10.33423/jop.v20i3.2940

Keeling, R. P., Dungy, G. J., American College Personnel Association., \& National Association of Student Personnel Administrators (U.S.). (2004). Learning reconsidered: A campus-wide focus on the student experience. ACPA.

Kuk, L., \& Banning, J. (2016). Student affairs leadership: Defining the role through an ecological framework. Stylus Publishing.

Lawrence, E. J., Shaw, P., Baker, D., Baron-Cohen, S., \& David, A. S. (2004). Measuring empathy: Reliability and validity of the empathy quotient. Psychological Medicine, 34, 911-919. doi: 10.1017/s0033291703001624

Lencioni, P. (2002). The five dysfunctions of a team: A leadership fable. Jossey-Bass.

Long, D. (2012). The foundations of student affairs: A guide to the profession. In L. J. Hinchliffe \& M. A. Wong (Eds.), Environments for student growth and development: Librarians and Student Affairs in collaboration (pp. 1-39). Association of College \& Research Libraries.

Lord, R. G., \& Maher, K. (1991). Leadership and information processing: Linking perceptions and performances. Urwin Hyman. 
Love, P. (2003). Considering a career in student affairs. www.myacpa.org/considering-careerstudent-affairs.

Mathews, G., Zeidner, M., \& Roberts, R. D. (2002). Emotional intelligence: science and myth. MIT Press.

Mayer, J. D., Salovey, P. (1990). Emotional intelligence: Imagination, cognition, and personality. Laboratory Publication, 9, 185-211. doi: 10.2190/DUGG-P24E-52WK6CDG

Mayer, J. D., Salovey, P., \& Caruso, D. R. (1997). Multifactor Emotional Intelligence Scale (MEIS). Unpublished instrument-Item and answer booklet. University of New Hampshire.

Mayer, J. D., Salovey, P., \& Caruso, D. R. (2002). The Mayer-Salovey-Caruso Emotional Intelligence Test-User Manual. Multi-Health Systems.

McCauley, C. D., \& Van Velsor, E. (Eds.). (2003). The center for creative leadership handbook of leadership development. Jossey-Bass.

McDade, S. (1987). Higher education leadership: Enhancing skills through professional development programs. Association for the Study of Higher Education.

Miguel, R. F., and Allen, S. J.. (2016). Report on the validation of the emotionally intelligent leadership for students inventory. Journal of leadership education, 15, 15-32. doi: 10.12806/V15/I4/R2

Miller, T. K., \& Winston, R. B. (1991). Human development and higher education. In T. K. Miller, R. B. Winston \& Associates (Eds.), Administration and leadership in student affairs: Actualizing student development in higher education (pp. 3-36). Accelerated Development, Inc. 
Mitchell, T. R., Green, S. G., \& Wood, R. E. (1981). An attributional model of leadership and the poor performing subordinate: Development and validation. Research in Organizational Behavior, 3, 197-234.

Moore, L. V. \& Upcraft, M. L. (1990). Theory in student affairs: Evolving perspectives. In L.V. Moore (Ed.), Evolving theoretical perspectives on students (pp. 3-23). Jossey-Bass Publishers.

Newman, A. M. (2009). Student affairs professionals' efficacy beliefs related to college student character development. [Unpublished dissertation]. Illinois State University.

Mortiboys, A. (2012). Teaching with emotional intelligence: A step-by-step guide for higher and further education professionals (2nd ed.). Routledge.

NASPA. (n.d.). Retrieved January 10, 2021, from https://naspa.org/communities/knowledgecommunities

National Association of Social Workers. (2001). NASW standards for cultural competence in social work practice. Retrieved March 20, 2020 from http://www.socialworkers.org/sections/credentials/cultural_comp.asp.

Northhouse, P.G. (2012). Leadership: Theory and practice (6th ed). Sage.

Osborne, R. E. (2015). Self-esteem. In P. Moglia (Eds.), Salem health: Psychology \& behavioral health (pp. 1674-1676). Salem Press Encyclopedia of Health.

Parker, M., \& Stone, A. (2020). More than play: Benefits of play therapy training for undergraduates and implications for student affairs. Journal of College Student Development, 61(3), 385-390. doi: 10.1353/csd.2020.0041

Pendleton, D., \& Furnham, A. (2012). Leadership: All you need to know. Palgrave Macmillan. 
Parrish, D. (2015). The relevance of emotional intelligence for leadership in a higher education context. Studies in Higher Education (Dorchester-on-Thames), 40(5), 821-837. doi: 10.1080/03075079.2013.842225

Porterfield, K., \& Whitt, E. (2016). Past, present, and future: Contexts for current challenges and opportunities for student affairs leadership. New Directions for Student Services, 2016(153), 9-17. doi: 10.1002/ss.20165

Rentz, A. L., \& Zhang, N. (2011). Rentz's student affairs practice in higher education. C.C. Thomas.

Reynolds, A. L. (2010). Counseling and helping skills (5th ed). In Schuh, J. H., Jones, S. R., Harper, S. R., \& Harper (Eds.). (2010). Student services: A handbook for the profession (pp. 428-442). Jossey-Bass.

Rogers, R. F. (1990). Recent themes and research underlying student development. In D. Creamer \& Associates (Eds.), College student development: Theory and practice for the 1990s (pp. 27-29). American College Personnel Association.

Rosari, R. (2019). Leadership definitions applications for lecturers’ leadership development. Journal of Leadership in Organizations, 1(1). doi: 10.22146/jlo.42965

Rost, J. C. (1993). Leadership for the twenty-first century. Praeger.

Ruthkosky, P. (2013). A multiperspective analysis on developing and maintaining trust in senior student affairs leadership. Journal of Student Affairs Research and Practice, 50(2), 171188. doi: 10.1515/jsarp-2013-0013

Schuh, J. H., Jones, S. R., Harper, S. R., \& Komives, S. R. (2010). Student services: A handbook for the profession. Jossey-Bass.

Shuh, J. H. (2009). Assessment methods for student affairs. Wiley. 
Shankman, M. L., Allen, S. J., \& Haber-Curran, P. (2015). Emotionally intelligent leadership: A guide for students. Jossey-Bass.

Shankman, M. L., Allen, S. J., \& Miguel, R. (2015). Emotionally intelligent leadership for students. Jossey-Bass.

Shell, D. (2010). The unified learning model: How motivational, cognitive, and neurobiological sciences inform best teaching practices. Springer.

Shriberg, D., \& Shriberg, A. (2011). Practicing leadership: Principles and applications. Wiley. Smith, J. (2002). Race, emotions, and socialization. Race, Gender \& Class, 9(4), 94-110.

Terrell, R. G., \& Lindsey, R. B. (2009). Culturally proficient leadership: The personal journey begins within. Corwin Press.

Tuckman, B. (1965). Developmental sequence in small groups. Psychological Bulletin, 63(6), 384-399.

Waterhouse, L. (2006). Multiple intelligences, the Mozart effect, and emotional intelligence: A critical review. Educational Psychologist, 41(4), 207-225. doi:10.1207/s15326985ep4104_1

Webber, B., \& Forster J. (2017). Next generation leadership. New Directions for Adult and Continuing Education, (156), 43-52. doi: 10.1002/ace.20250

Wheatley, M. J. (2005). Finding our way: Leadership for an uncertain time. Berrett-Koehler. Wingfield, A. (2010). Are some emotions marked “whites only”? Racialized feeling rules in professional workplaces. Social Problems, 57(2), 251-268. doi:

10.1525/sp.2010.57.2.251 
Wofford, J. C. (1994). Getting inside the leader's head: A cognitive processes approach to leadership. SAM Advanced Management Journal, 59(3), 161-186. doi: 10.1016/10489843(94)90026-4

Wong, C. (2015). Emotional intelligence at work: 18-year journey of a researcher. Routledge.

Wu, M., \& Stemler, S. (2008). Resident advisor general intelligence, emotional intelligence, personality dimensions, and internal belief characteristics as predictors of rated performance. NASPA Journal, 45(4), 528-559. doi: 10.2202/1949-6605.2010 
APPENDIX A: EMOTIONALLY INTELLIGENT LEADERSHIP FOR EMPLOYEES:

INVENTORY

\begin{tabular}{|c|c|c|c|c|c|c|c|}
\hline \multicolumn{8}{|c|}{ Emotionally Intelligent Leadership Employee Inventory } \\
\hline \multicolumn{8}{|c|}{ Demographic Information } \\
\hline \multicolumn{8}{|c|}{ Please answer the following demographic information by clicking in the appropriate box. } \\
\hline Questions & Responses & & & & & & \\
\hline $\begin{array}{l}\text { Do you identify as a } \\
\text { student affairs } \\
\text { professional currently } \\
\text { working within a higher } \\
\text { education institution? }\end{array}$ & Yes & No & & & & & \\
\hline $\begin{array}{l}\text { What is your identified } \\
\text { gender? }\end{array}$ & Male & Female & Non-Binary & & & & \\
\hline $\begin{array}{l}\text { How would you identify } \\
\text { your race? }\end{array}$ & White & Latinx & $\begin{array}{c}\text { African } \\
\text { American }\end{array}$ & Asian & $\begin{array}{c}\text { Native } \\
\text { American } \\
\end{array}$ & $\begin{array}{l}\text { Multi- } \\
\text { Race }\end{array}$ & $\begin{array}{c}\text { Race not } \\
\text { Listed }\end{array}$ \\
\hline $\begin{array}{l}\text { What graduate-level } \\
\text { student affairs program } \\
\text { best describes your } \\
\text { education? }\end{array}$ & Counseling & Administrative & Policy & Research & $\begin{array}{l}\text { Theory to } \\
\text { Practice }\end{array}$ & \begin{tabular}{|c} 
Non- \\
Student \\
Affairs \\
Master's \\
Program
\end{tabular} & $\begin{array}{l}\text { No } \\
\text { Master's } \\
\text { Degree } \\
\text { Obtained }\end{array}$ \\
\hline $\begin{array}{l}\text { How many years have } \\
\text { you been working in } \\
\text { student affairs, post- } \\
\text { Master's program? }\end{array}$ & $0-5$ Years & $6-10$ Years & $\begin{array}{l}11-15 \\
\text { years }\end{array}$ & $\begin{array}{c}16+ \\
\text { Years }\end{array}$ & & & \\
\hline $\begin{array}{l}\text { Please acknowledge if } \\
\text { you understand this } \\
\text { definition of emotional } \\
\text { intelligence as the subset } \\
\text { of social intelligence that } \\
\text { involves the ability to } \\
\text { monitor one's own and } \\
\text { others' feelings and } \\
\text { emotions, to } \\
\text { discriminate among } \\
\text { them and to use the } \\
\text { information to guide } \\
\text { one's thinking and } \\
\text { actions. (Mayer and }\end{array}$ & Yes & No & & & & & \\
\hline
\end{tabular}


Salovey, 1990)

Emotionally Intelligent Leadership for Employees: Inventory Questionnaire

Instructions: This self-assessment gives you an opportunity to learn more about yourself and better understand how you lead others.

Use the rating numbers shown. Indicate the extent to which you intentionally do the following:

\begin{tabular}{|c|c|c|c|c|c|c|c|}
\hline & \multicolumn{7}{|c|}{ Responses } \\
\hline & Never & Never & Rarely & Sometimes & Usually & Always & Always \\
& & & & & & & \\
\hline & 1 & 2 & 3 & 4 & 5 & 6 & 7 \\
\hline
\end{tabular}

When serving in a formal or informal leadership role, I...

\begin{tabular}{|l|c|c|c|c|c|c|c|}
\hline 1. Recognize how situations influence & & & & & & \\
my emotions & 1 & 2 & 3 & 4 & 5 & 6 & 7 \\
\hline 2. Stay calm in challenging situations & 1 & 2 & 3 & 4 & 5 & 6 & 7 \\
\hline 3. Am honest about my intentions & 1 & 2 & 3 & 4 & 5 & 6 & 7 \\
\hline 4. Believe in my skills & 1 & 2 & 3 & 4 & 5 & 6 & 7 \\
\hline 5. Am open to change & & 2 & 3 & 4 & 5 & 6 & 7 \\
\hline 6. Present a positive outlook & 1 & 2 & 3 & 4 & 5 & 6 & 7 \\
\hline 7. Act before someone tells me to & 1 & 2 & 3 & 4 & 5 & 6 & 7 \\
\hline
\end{tabular}




\begin{tabular}{|c|c|c|c|c|c|c|c|}
\hline $\begin{array}{l}\text { 8. Establish personal standards for } \\
\text { myself }\end{array}$ & 1 & 2 & 3 & 4 & 5 & 6 & 7 \\
\hline $\begin{array}{l}\text { 9. Place a high value on the feelings } \\
\text { of others }\end{array}$ & 1 & 2 & 3 & 4 & 5 & 6 & 7 \\
\hline 10. Communicate an exciting vision & 1 & 2 & 3 & 4 & 5 & 6 & 7 \\
\hline 11. Help others realize their potential & 1 & 2 & 3 & 4 & 5 & 6 & 7 \\
\hline $\begin{array}{l}\text { 12. Demonstrate an appreciation for } \\
\text { cultural diversity }\end{array}$ & 1 & 2 & 3 & 4 & 5 & 6 & 7 \\
\hline 13. Build relationships with ease & 1 & 2 & 3 & 4 & 5 & 6 & 7 \\
\hline 14. Emphasize team goals & 1 & 2 & 3 & 4 & 5 & 6 & 7 \\
\hline $\begin{array}{l}\text { 15. Fulfill my responsibilities to } \\
\text { others }\end{array}$ & 1 & 2 & 3 & 4 & 5 & 6 & 7 \\
\hline $\begin{array}{l}\text { 16. Address difficult situations } \\
\text { effectively }\end{array}$ & 1 & 2 & 3 & 4 & 5 & 6 & 7 \\
\hline 17. Promote innovative thinking & 1 & 2 & 3 & 4 & 5 & 6 & 7 \\
\hline 18. Respond effectively to the group & 1 & 2 & 3 & 4 & 5 & 6 & 7 \\
\hline $\begin{array}{l}\text { 19. Intentionally alter my approach } \\
\text { to leadership to meet the needs of } \\
\text { the situation }\end{array}$ & 1 & 2 & 3 & 4 & 5 & 6 & 7 \\
\hline $\begin{array}{l}\text { 20. Recognize how my emotions } \\
\text { influence my actions }\end{array}$ & 1 & 2 & 3 & 4 & 5 & 6 & 7 \\
\hline $\begin{array}{l}\text { 21. Remain calm in stressful } \\
\text { situations }\end{array}$ & 1 & 2 & 3 & 4 & 5 & 6 & 7 \\
\hline
\end{tabular}




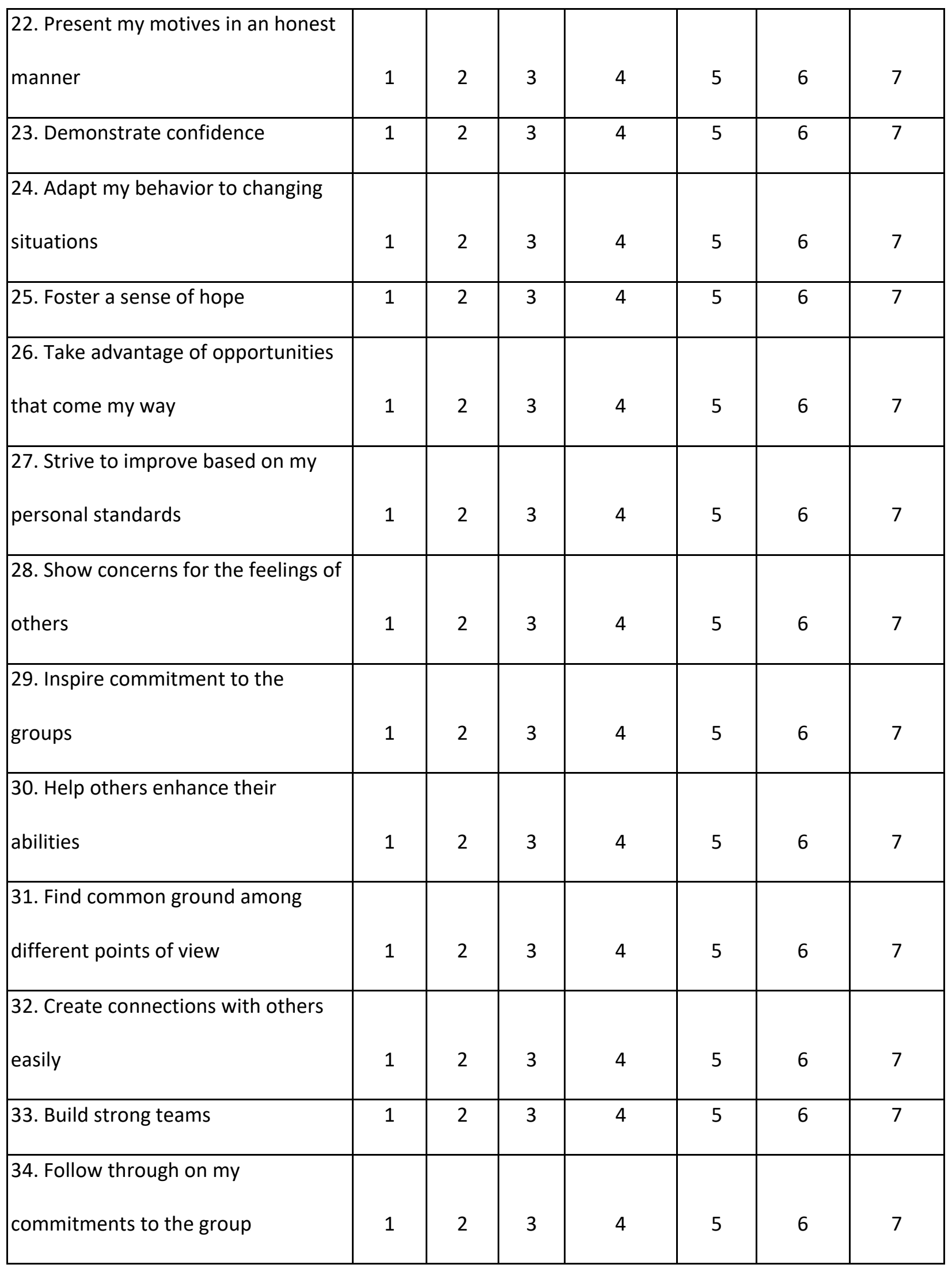




\begin{tabular}{|c|c|c|c|c|c|c|c|}
\hline $\begin{array}{l}\text { 35. Address conflict with individuals } \\
\text { effectively }\end{array}$ & 1 & 2 & 3 & 4 & 5 & 6 & 7 \\
\hline $\begin{array}{l}\text { 36. Seek to improve upon the status } \\
\text { quo when future gains can be made }\end{array}$ & 1 & 2 & 3 & 4 & 5 & 6 & 7 \\
\hline $\begin{array}{l}\text { 37. Follow the established rules of } \\
\text { the group }\end{array}$ & 1 & 2 & 3 & 4 & 5 & 6 & 7 \\
\hline $\begin{array}{l}\text { 38. Adapt my approach to leadership } \\
\text { based on the situation }\end{array}$ & 1 & 2 & 3 & 4 & 5 & 6 & 7 \\
\hline $\begin{array}{l}\text { 39. Recognize how my emotions } \\
\text { affect me }\end{array}$ & 1 & 2 & 3 & 4 & 5 & 6 & 7 \\
\hline 40. Maintain composure & 1 & 2 & 3 & 4 & 5 & 6 & 7 \\
\hline 41. Act genuinely & 1 & 2 & 3 & 4 & 5 & 6 & 7 \\
\hline $\begin{array}{l}\text { 42. Remain confident when facing } \\
\text { challenges }\end{array}$ & 1 & 2 & 3 & 4 & 5 & 6 & 7 \\
\hline 43. Am open to changing my opinion & 1 & 2 & 3 & 4 & 5 & 6 & 7 \\
\hline 44. Communicate a positive outlook & 1 & 2 & 3 & 4 & 5 & 6 & 7 \\
\hline $\begin{array}{l}\text { 45. Take advantage of new } \\
\text { opportunities }\end{array}$ & 1 & 2 & 3 & 4 & 5 & 6 & 7 \\
\hline $\begin{array}{l}\text { 46. Establish high personal standards } \\
\text { for myself }\end{array}$ & 1 & 2 & 3 & 4 & 5 & 6 & 7 \\
\hline $\begin{array}{l}\text { 47. Respond to the emotional needs } \\
\text { of others }\end{array}$ & 1 & 2 & 3 & 4 & 5 & 6 & 7 \\
\hline
\end{tabular}




\begin{tabular}{|c|c|c|c|c|c|c|c|}
\hline $\begin{array}{l}\text { 48. Inspire commitment to the } \\
\text { group's mission }\end{array}$ & 1 & 2 & 3 & 4 & 5 & 6 & 7 \\
\hline $\begin{array}{l}\text { 49. Create opportunities for others to } \\
\text { learn }\end{array}$ & 1 & 2 & 3 & 4 & 5 & 6 & 7 \\
\hline 50. Appreciate individual differences & 1 & 2 & 3 & 4 & 5 & 6 & 7 \\
\hline $\begin{array}{l}\text { 51. Build a strong network of } \\
\text { relationships }\end{array}$ & 1 & 2 & 3 & 4 & 5 & 6 & 7 \\
\hline $\begin{array}{l}\text { 52. Work well with others towards a } \\
\text { shared goal }\end{array}$ & 1 & 2 & 3 & 4 & 5 & 6 & 7 \\
\hline $\begin{array}{l}\text { 53. Recognize a need to give to the } \\
\text { group }\end{array}$ & 1 & 2 & 3 & 4 & 5 & 6 & 7 \\
\hline 54. Manage conflict effectively & 1 & 2 & 3 & 4 & 5 & 6 & 7 \\
\hline $\begin{array}{l}55 . \text { Consider ways to improve the } \\
\text { group's performance through } \\
\text { innovation }\end{array}$ & 1 & 2 & 3 & 4 & 5 & 6 & 7 \\
\hline $\begin{array}{l}\text { 56. Align my actions with the values } \\
\text { of the group }\end{array}$ & 1 & 2 & 3 & 4 & 5 & 6 & 7 \\
\hline $\begin{array}{l}\text { 57. Learn about what it takes to } \\
\text { succeed in different settings }\end{array}$ & 1 & 2 & 3 & 4 & 5 & 6 & 7 \\
\hline
\end{tabular}

\section{Request for Report}

Please answer the following questions if you wish to receive a report of your results:

\begin{tabular}{|c|c|c|}
\hline Questions & Answers & \\
\hline $\begin{array}{l}\text { Do you wish to receive a copy of your emotionally intelligent } \\
\text { leadership report? }\end{array}$ & Yes & No \\
\hline
\end{tabular}




\begin{tabular}{|l|l|l|}
\hline What is your name? & \multicolumn{2}{|l|}{} \\
\hline What is your email? & & \\
\hline \multicolumn{1}{|c|}{ Request to Share } & \\
\hline Please answer the following: & & \\
\hline $\begin{array}{l}\text { Are you willing to help the researcher by giving emails to } \\
\text { colleagues who may want to take this survey or by forwarding } \\
\text { this survey to them? }\end{array}$ & Yes & No \\
\hline $\begin{array}{l}\text { Will you be willing to give emails to individuals that the } \\
\text { researcher may forward this survey to? }\end{array}$ & Yes & No \\
\hline What is the email of potential individuals to take the survey? & & \\
\hline
\end{tabular}


APPENDIX B: EMOTIONALLY INTELLIGENT LEADERSHIP FOR EMPLOYEES:

INVENTORY NEW CAPACITY SCORING

\begin{tabular}{|c|c|c|c|c|c|c|}
\hline \multicolumn{7}{|c|}{ Emotionally Intelligent Leadership Employee Inventory Scoring } \\
\hline \multirow{2}{*}{$\begin{array}{l}\text { Capacity } \\
\text { Self-Oriented }\end{array}$} & \multicolumn{3}{|c|}{ Statement of Numbers } & \multirow[t]{2}{*}{ Total } & \multirow[t]{2}{*}{ Capacity Short form } & \multirow[t]{2}{*}{ EIL Face } \\
\hline & 4. & 16. & 23. & & & \\
\hline & 35. & 42. & 54. & & so & Self \\
\hline Optimism & 6. & 25. & 44. & & $\mathrm{OP}$ & Self \\
\hline Initiative & 2. & 21. & 40. & & IN & Self \\
\hline Achievement & 8. & 27. & 46. & & $A C$ & Self \\
\hline Displaying Empathy & 9. & 28. & 47. & & $\mathrm{DE}$ & Self \\
\hline Authenticity & 3. & 22. & 41. & & AU & Self \\
\hline $\begin{array}{l}\text { Emotional Self- } \\
\text { Perception }\end{array}$ & 1. & 20. & 39. & & ESP & Self \\
\hline Standards of One Self & 12. & 31. & 50. & & sos & Self \\
\hline \multirow[t]{3}{*}{ Developing Others } & 11. & 12. & 15. & & & \\
\hline & 17. & 29. & 30. & & & \\
\hline & 48. & 49. & 57. & & DO & Others \\
\hline Developing Relationships & 13. & 32. & 51. & & DR & Others \\
\hline Commitment to Others & 14. & 34. & & & $\mathrm{CO}$ & Others \\
\hline Analyzing the Group & 19. & 24. & 38. & & AG & Context \\
\hline
\end{tabular}




\begin{tabular}{|c|c|c|}
\hline \multicolumn{3}{|c|}{ Emotionally Intelligent Leadership Employee Inventory Scoring by Consciousness } \\
\hline & Capacity & Total Capacity Score \\
\hline & SO & \\
\hline & OP & \\
\hline & IN & \\
\hline & $A C$ & \\
\hline & DE & \\
\hline & $A U$ & \\
\hline & ESP & \\
\hline & sos & \\
\hline \multirow[t]{4}{*}{ Consciousness of Self Score } & & \\
\hline & DO & \\
\hline & DR & \\
\hline & $\mathrm{CO}$ & \\
\hline \multirow[t]{2}{*}{ Consciousness of Other Score } & & \\
\hline & AG & \\
\hline Consciousness of Context Score & & \\
\hline
\end{tabular}




\begin{tabular}{|c|c|c|}
\hline \multicolumn{3}{|c|}{ Consciousnesses Score Chart } \\
\hline Consciousness of Self Score & & \\
\hline & Low & $0-37$ \\
\hline & Somewhat Low & $38-75$ \\
\hline & Medium & $76-113$ \\
\hline & Somewhat High & 114-151 \\
\hline & High & 152-189 \\
\hline \multicolumn{3}{|l|}{ Consciousness of Others Score } \\
\hline & Low & 0-19 \\
\hline & Somewhat Low & $20-39$ \\
\hline & Medium & $40-59$ \\
\hline & Somewhat High & $60-79$ \\
\hline & High & 80-98 \\
\hline \multicolumn{3}{|l|}{ Consciousness of Context Score } \\
\hline & Low & $0-4$ \\
\hline & Somewhat Low & $5-8$ \\
\hline & Medium & $9-12$ \\
\hline & Somewhat High & $13-17$ \\
\hline & High & $18-21$ \\
\hline
\end{tabular}




\section{APPENDIX C: COVER LETTER FOR EMAIL}

Dear Colleague,

You are invited to participate in this research study. You are eligible to participate because you are a member of the National Association of Student Personnel Administrators (NASPA). The following information is provided in order to help you make an informed decision whether or not to participate. If you have any questions, please do not hesitate to ask. This research is being conducted by Alex Snowden, a doctoral candidate at Illinois State University.

The purpose of this study is to better understand the prevalence of emotionally intelligent leadership among Student Affairs professionals. Participation in this study will require no more than 15 minutes of your time by completing an online survey.

Participation in this project is voluntary and anonymous. You may refuse to participate or withdraw at any time without penalty. You have the right to skip or not answer any questions you prefer not to answer. No personally identifiable information will be collected as part of the survey. At the conclusion of the study, you will be given the option to receive a report with your scores.

If you have questions about this study, please contact:

Research Student:

Alex Snowden

Doctoral Candidate, College of Education

Illinois State University

Email: adsnowd@ilstu.edu

Faculty Sponsor:

Dr. Phyllis McClusky-Titus

Professor, College of Education

Illinois State University

Email: pamcclu2@ilstu.edu

Thank you,

Alex Snowden 


\section{Dear Colleague,}

You are invited to participate in this research study. You are eligible to participate because you are a member of the American College Personnel Association (ACPA). The following information is provided in order to help you make an informed decision whether or not to participate. If you have any questions, please do not hesitate to ask. This research is being conducted by Alex Snowden, a doctoral candidate at Illinois State University.

The purpose of this study is to better understand the prevalence of emotionally intelligent leadership among Student Affairs professionals. Participation in this study will require no more than 15 minutes of your time by completing an online survey.

Participation in this project is voluntary and anonymous. You may refuse to participate or withdraw at any time without penalty. You have the right to skip or not answer any questions you prefer not to answer. No personally identifiable information will be collected as part of the survey. At the conclusion of the study, you will be given the option to receive a report with your scores.

If you have questions about this study, please contact:

Research Student:

Alex Snowden

Doctoral Candidate, College of Education

Illinois State University

Email: adsnowd@ilstu.edu

Faculty Sponsor:

Dr. Phyllis McClusky-Titus

Professor, College of Education

Illinois State University

Email:pamcclu2@ilstu.edu

Thank you, Alex Snowden 


\section{Dear Colleague,}

You are invited to participate in this research study. You are eligible to participate because you have been identified as someone who is a Student Affairs professional working at a college or university. The following information is provided in order to help you make an informed decision whether or not to participate. If you have any questions, please do not hesitate to ask. This research is being conducted by Alex Snowden, a doctoral candidate at Illinois State University.

The purpose of this study is to better understand the prevalence of emotionally intelligent leadership among Student Affairs professionals. Participation in this study will require no more than 15 minutes of your time by completing an online survey.

Participation in this project is voluntary and anonymous. You may refuse to participate or withdraw at any time without penalty. You have the right to skip or not answer any questions you prefer not to answer. No personally identifiable information will be collected as part of the survey. At the conclusion of the study, you will be given the option to receive a report with your scores.

If you have questions about this study, please contact:

Research Student:

Alex Snowden

Doctoral Candidate, College of Education

Illinois State University

Email: adsnowd@ilstu.edu

Faculty Sponsor:

Dr. Phyllis McClusky-Titus

Professor, College of Education

Illinois State University

Email: pamcclu2@ilstu.edu

Thank you, Alex Snowden 


\section{Dear Colleague,}

You are invited to participate in this research study. You are eligible to participate because you have been recommended by a colleague to take the survey. The following information is provided in order to help you make an informed decision whether or not to participate. If you have any questions, please do not hesitate to ask. This research is being conducted by Alex Snowden, a doctoral candidate at Illinois State University.

The purpose of this study is to better understand the prevalence of emotionally intelligent leadership among Student Affairs professionals. Participation in this study will require no more than 15 minutes of your time by completing an online survey.

Participation in this project is voluntary and anonymous. You may refuse to participate or withdraw at any time without penalty. You have the right to skip or not answer any questions you prefer not to answer. No personally identifiable information will be collected as part of the survey. At the conclusion of the study, you will be given the option to receive a report with your scores.

If you have questions about this study, please contact:

Research Student:

Alex Snowden

Doctoral Candidate, College of Education

Illinois State University

Email: adsnowd@ilstu.edu

Faculty Sponsor:

Dr. Phyllis McClusky-Titus

Professor, College of Education

Illinois State University

Email: pamcclu2@ilstu.edu

Thank you,

Alex Snowden 


\section{APPENDIX D: COVER LETTER FOR SOCIAL MEDIA POST}

\section{Hello Colleagues!}

I am recruiting participants for my study about the prevalence of emotionally intelligent

leadership among Student Affairs professionals that work at a college or university. Participants

in this study will partake in the attached survey which should take approximately 15 minutes to complete. All participants will have the option to receive a report of your scores. Thank you for your help in my educational journey! 


\section{APPENDIX E: INFORMED CONSENT}

\section{Participation Consent Form:}

You are being asked to participate in a research study conducted by Alex Snowden, doctoral student. Under the direction of Dr. Phyllis McCluskey-Titus, Professor within The College of Education at Illinois State University. The purpose of this study is to investigate the prevalence of emotionally intelligent leadership among Student Affairs professionals.

\section{Why are you being asked?}

You have been asked to participate because you are 18 or older and a Student Affairs professional working at a college or university within the United States. Your participation in this study is voluntary. You will not be penalized if you choose to skip parts of the study, not participate, or withdraw from the study at any time.

\section{What would you do?}

If you choose to participate in this study, you will answer five background questions and 57 Likert scale type questions in an electronic survey. In total, your involvement in this study will last approximately 15 minutes.

\section{Are any risks expected?}

We do not anticipate any risks beyond those that would occur in everyday life. No information that you reveal regarding your perceptions on emotionally intelligent leadership will be shared.

\section{Will your information be protected?}

While it is possible that some of your responses could be sensitive in nature, we will use all reasonable efforts to keep any provided personal information that is sensitive confidential. At the end of the survey you will have the opportunity to receive your report if you so choose. It will ask for your name and email for the sole purpose of providing you the report. This report will be generated and sent to you prior to data analysis and then your email and name will be deleted to keep your responses and personal information confidential for the survey.

Information that may identify you or potentially lead to reidentification will not be released to individuals that are not on the research team. If you choose not to receive your report, then no identifiable information will be collected. However, when required by law or university policy, identifying information (including your approved consent form) may be seen or copied by authorized individuals.

\section{Could your responses be used for other research?}

We will not use any identifiable information from you in future research, but your de-identified information could be used for future research without additional consent from you.

\section{Will you receive anything for participating?}

By participating in this study you will be given the option to receive a report of your answers and scores around emotionally intelligent leadership. At the end of the survey you will be asked for your name and email to get an individualized report if you wish to receive one. Your name and email will not be included in the data analysis. This report will be generated and sent to you prior to data analysis and then your email and name will be deleted. 


\section{Who will benefit from this study?}

The possible benefit of your participation would be to reflect upon your own emotionally intelligent leadership and to assist in identifying how Student Affairs professionals score on the instrument for potential future research.

\section{Whom do you contact if you have any questions?}

If you have any questions about the research or wish to withdraw from the study, contact Alex Snowden at adsnowd@ilstu.edu or Phyllis McCluskey-Titus at pamcclu2@ilstu.edu.

If you have any questions about your rights as a participant, or if you feel you have been placed at risk, contact the Illinois State University Research Ethics \& Compliance Office at (309) 4385527 or IRB@ilstu.edu.

\section{Documentation of Consent}

You can print this form for your records or it will be sent to you automatically with your data report if you choose to receive it.

If you are willing to participate please begin the survey and respond to the first question stating "I have read the Participation Consent Form and respond yes I wish to continue with the study." 
APPENDIX F: EMOTIONAL INTELLIGENT LEADERSHIP SCORING FOR EILS:I 2.0

\begin{tabular}{|c|c|c|c|c|c|c|}
\hline \multicolumn{7}{|c|}{ Emotionally Intelligent Leadership for Students Inventory Scoring } \\
\hline Capacity & \multicolumn{3}{|c|}{ Statement of Numbers } & \multirow[t]{2}{*}{ Total } & \multirow{2}{*}{$\begin{array}{c}\text { Capacity } \\
\text { Short } \\
\text { form }\end{array}$} & \multirow{2}{*}{$\begin{array}{c}\text { EIL } \\
\text { Facet } \\
\text { Self }\end{array}$} \\
\hline Emotional Self-Perception & 1. & 20. & 39. & & & \\
\hline Emotional Self-Control & 2. & 21. & 40. & & ESC & Self \\
\hline Authenticity & 3. & 22. & 41. & & $\mathrm{AU}$ & Self \\
\hline Healthy Self-Esteem & 4. & 23. & 42. & & HSE & Self \\
\hline Flexibility & 5. & 24. & 43. & & $\mathrm{FL}$ & Self \\
\hline Optimism & 6. & 25. & 44. & & OP & Self \\
\hline Initiative & 7. & 26. & 45. & & IN & Self \\
\hline Achievement & 8. & 27. & 46. & & $A C$ & Self \\
\hline Displaying Empathy & 9. & 28. & 47. & & $\mathrm{DE}$ & Self \\
\hline Inspiring Others & 10 & 29. & 48. & & 10 & Others \\
\hline Coaching Others & 11. & 30. & 49. & & $\mathrm{CO}$ & Others \\
\hline Capitalizing on Difference & 12. & 31. & 50. & & $C D$ & Others \\
\hline Developing Relationships & 13. & 32. & 51. & & DR & Others \\
\hline Building Teams & 14. & 33. & 52. & & BT & Others \\
\hline Demonstrating Citizenship & 15. & 34. & 53. & & $\mathrm{DC}$ & Others \\
\hline Managing Conflict & 16. & 35. & 54. & & $\mathrm{MC}$ & Others \\
\hline Facilitating Change & 17. & 36. & 55. & & FC & Others \\
\hline Analyzing the Group & 18. & 37. & 56. & & $A G$ & Context \\
\hline Assessing the Environment & 19. & 38. & 57. & & $\mathrm{AE}$ & Context \\
\hline
\end{tabular}

